MÁRCIO DALLA VALLE MARTINO

ESTUDO DE TRANSISTORES DE TUNELAMENTO CONTROLADOS POR EFEITO DE CAMPO

São Paulo

2012 


\title{
ESTUDO DE TRANSISTORES DE TUNELAMENTO CONTROLADOS POR EFEITO DE CAMPO
}

\author{
Dissertação apresentada à Escola \\ Politécnica da Universidade de São Paulo \\ para obtenção do título de Mestre em \\ Engenharia Elétrica \\ Área de concentração: Microeletrônica \\ Orientador: Prof. Dr. Sebastião Gomes dos \\ Santos Filho
}

\section{São Paulo}


FICHA CATALOGRÁFICA

Martino, Márcio Dalla Valle

Estudo de transistores de tunelamento controlados por efei to de campo / M.D.V. Martino. -- São Paulo, 2012.

$91 \mathrm{p}$.

Dissertação (Mestrado) - Escola Politécnica da Universidade de São Paulo. Departamento de Engenharia de Sistemas Eletrônicos.

1. Microeletrônica 2. Transistores 3. Caracterização elétrica 4. Tunelamento 5. Dispositivos novos I. Universidade de São Paulo. Escola Politécnica. Departamento de Engenharia de Sistemas Eletrônicos II. t. 


\section{DEDICATÓRIA}

Dedico este trabalho

Aos meus pais,

João Antonio Martino

Marinês Dalla Valle Martino

À minha irmã,

Fernanda Dalla Valle Martino

Aos meus avós,

Nicola Martino (in memorian)

Ottilia Coti Martino

Ivo Rubens Dalla Valle (in memorian)

Maria de Lourdes Bonazza Dalla Valle 
"Quando eu tinha 17 anos, li uma frase que era algo assim: "Se você viver cada dia como se fosse o último, um dia ele realmente será o último". Aquilo me impressionou e desde então olho para mim mesmo no espelho todas as manhãs e pergunto: "Se hoje fosse o meu último dia, eu gostaria de fazer o que farei hoje?" Se a resposta é "não" por muitos dias seguidos, sei que preciso mudar alguma coisa."

Steve Jobs 


\section{AGRADECIMENTOS}

Ao professor e orientador Sebastião Gomes dos Santos Filho, pela dedicação, amizade e confiança depositada.

Aos meus pais e à minha irmã, pelo constante incentivo e pelos diários ensinamentos em mais esta etapa da minha vida.

À professora Paula Ghedini Der Agopian, pela imprescindível e incansável colaboração ao longo desses anos.

Aos colegas do grupo SOI, pelas enriquecedoras discussões e pelo compartilhamento da experiência de cada membro.

Ao professor Cor Claeys e ao IMEC pela disponibilidade da infraestrutura necessária para esta atividade de pesquisa.

Aos meus familiares e amigos, por todos os momentos especiais proporcionados e pelas alegrias compartilhadas.

A todos que de alguma forma colaboraram para a realização deste trabalho e que, de forma involuntária, foram aqui omitidos. 


\section{RESUMO}

Este trabalho apresenta o estudo de transistores de tunelamento controlados por efeito de campo, denominados TFETs. Foram realizadas análises com base em explicação teórica, simulação numérica e medidas experimentais para demonstrar a viabilidade do uso desta tecnologia como alternativa para permitir o contínuo escalamento de dispositivos.

A motivação para o uso de transistores com corrente principal resultante do tunelamento de banda para banda consiste na proposta de superar o limite físico de inclinação de sublimiar da tecnologia CMOS convencional de $60 \mathrm{mV} /$ década sob temperatura ambiente. Afinal, esta limitação impede a redução na tensão de alimentação de circuitos e, consequentemente, apresenta crescentes problemas quanto à dissipação de potência.

Com este objetivo, foram realizadas simulações numéricas de diversas geometrias alternativas visando atenuar as características indesejáveis dos TFETs, como a corrente ambipolar e a relativamente baixa relação $\mathrm{I}_{\mathrm{ON}} / \mathrm{l}_{\mathrm{OFF}}$. Inicialmente são definidos os modelos necessários para representar adequadamente os fenômenos relevantes sob variação de temperatura e é definida uma estrutura capaz de minimizar os efeitos da ambipolaridade.

Posteriormente, medidas experimentais foram utilizadas para calibrar as simulações e estudar o efeito da temperatura e do dimensionamento no funcionamento de dispositivos desta tecnologia.

Comparando resultados práticos e simulados, nota-se como uma redução no comprimento de porta, com a consequente inserção de uma subposição (underlap) em relação à junção canal/dreno, e uma diminuição na temperatura permitem a obtenção de valores promissores de inclinação de sublimiar e de relação loN/loFF, compatível com a proposta de futuras aplicações digitais e analógicas.

Palavras-chave: TFET, tunelamento de banda para banda, inclinação de sublimiar, ambipolaridade, impacto da temperatura, FinFET. 


\begin{abstract}
This works presents the study of tunneling field effect transistors, namely TFETs. Analyses were performed based on theoretical explanations, numerical simulations and experimental data in order to show this technology suitability as an alternative for the continuous devices scaling.

The basic idea of making use of band-to-band tunneling as the main current component comes from the possibility of reaching sub-60 $\mathrm{mV} /$ decade subthreshold slopes at room temperature, differently from conventional CMOS devices. After all, this physical limitation causes relevant power dissipation issues, since it requires relatively high power supply voltages.

Bearing this objective, numerical simulations of several alternative geometries were performed in order to tackle TFETs disadvantages, as the undesirable ambipolar currents and the low $\mathrm{l}_{\mathrm{ON}} / \mathrm{l}_{\mathrm{OFF}}$ ratio. At first, it was necessary to choose the most appropriate models to take into consideration the relevant phenomena under temperature variation and to define the physical structure in order to minimize ambipolar effects.

After these analyses, experimental data were used to calibrate simulation parameters and to study how temperature and physical dimensions affect the performance of devices based on this technology.

Comparing experimental and simulated results, it was possible to notice that when the structure is designed with gate underlap related to channel/drain junction and the temperature decreases, the obtained values for subthreshold slope and ION $/ l_{\text {OFF }}$ ratio may be used as an important reference of this technology as a promising alternative for both digital and analog applications.
\end{abstract}

Key-words: TFET, band-to-band tunneling, subthreshold slope, ambipolarity, temperature impact, FinFET. 


\section{LISTA DE FIGURAS}

Figura 1.1 Representação da integração de dispositivos e dos consequentes ganhos de performance na última década.

Figura 1.2 Esquema com as sucessivas propostas apresentadas para permitir contínuo

escalamento de dispositivos.

Figura 1.3 Evolução da tensão de alimentação e da tensão de limiar para tecnologias de

$1,4 \mu \mathrm{m}$ a $65 \mathrm{~nm}$ com dispositivos CMOS convencionais.

Figura 1.4 Corrente de dreno em função da tensão de porta para três diferentes dispositivos, evidenciando o impacto da variação de $V_{\text {th }}$ em $I_{\text {OFF. }}$.... .22

Figura 1.5 Estimativa da evolução da potência estática e dinâmica para tecnologia MOS convencional.

Figura 2.1 Comparação das inclinações de sublimiar previstas para uma chave ideal, um dispositivo MOS e um TFET.

Figura 2.2 Seção transversal de um nTFET de porta dupla. ........................................27

Figura 2.3 Diagrama de bandas de energia para um nTFET desligado. ...........................28

Figura 2.4 Diagrama de bandas de energia para um nTFET ligado................................28

Figura 2.5 Diagrama de bandas de energia representando predomínio de corrente SRH. ..30

Figura 2.6 Diagrama de bandas de energia representando predomínio de corrente TAT...31

Figura 2.7 Diagrama de bandas de energia representando predomínio de corrente BBT....31

Figura 2.8 Representação da variação do mecanismo de transporte predominante à medida que é alterada a tensão em uma determinada junção. 32

Figura 3.1 Representação dos blocos de entrada e saída do programa Atlas.

Figura 3.2 Seção transversal de transistores de porta dupla e estrutura nTFET (A) e pTFET (B).

Figura 3.3 Estrutura dos dispositivos simulados.

Figura 3.4 Diagrama de bandas de energia para diferentes valores de tensão de porta......44

Figura 3.5 Densidade de corrente na estrutura simulada para $\mathrm{V}_{\mathrm{DS}}=0,4 \mathrm{~V}$ e $\mathrm{V}_{\mathrm{GS}}=1 \mathrm{~V} \ldots \ldots \ldots .45$

Figura 3.6 Estrutura de dipositivos com (A) sobreposição, (B) auto-alinhamento e (C) subposição de porta em relação ao dreno

Figura 3.7 Corrente de dreno ( $\left.\mathrm{I}_{\mathrm{DS}}\right)$ em função da tensão de porta $\left(\mathrm{V}_{\mathrm{GS}}\right)$ para diferentes valores de $\Delta \mathrm{L}_{\mathrm{G}}$. 
Figura 3.8 Corrente de dreno ( $\left.\mathrm{I}_{\mathrm{DS}}\right)$ em função da tensão de porta $\left(\mathrm{V}_{\mathrm{GS}}\right)$ para temperatura na faixa de $150 \mathrm{~K}$ a $400 \mathrm{~K}$

Figura 3.9 Corrente de dreno ( $\left.\mathrm{I}_{\mathrm{DS}}\right)$ em função da tensão de porta $\left(\mathrm{V}_{\mathrm{GS}}\right)$ para temperatura na faixa de $200 \mathrm{~K}$ a $400 \mathrm{~K}$ e $\Delta \mathrm{L}_{G}=-20 \mathrm{~nm}$.

Figura 3.10 Corrente de dreno ( $\left.\mathrm{I}_{\mathrm{DS}}\right)$ em função da tensão de porta $\left(\mathrm{V}_{\mathrm{GS}}\right)$ para temperatura na faixa de $200 \mathrm{~K}$ a $400 \mathrm{~K}$ e $\Delta \mathrm{L}_{\mathrm{G}}=-10 \mathrm{~nm}$.

Figura 3.11 Corrente de dreno ( $\left.\mathrm{I}_{\mathrm{DS}}\right)$ em função da tensão de porta $\left(\mathrm{V}_{\mathrm{GS}}\right)$ para temperatura na faixa de $200 \mathrm{~K}$ a $400 \mathrm{~K} \mathrm{e} \Delta \mathrm{L}_{\mathrm{G}}=0 \mathrm{~nm}$.

Figura 3.12 Corrente de dreno ( $\left.\mathrm{I}_{\mathrm{DS}}\right)$ em função da tensão de porta $\left(\mathrm{V}_{\mathrm{GS}}\right)$ para temperatura na faixa de $200 \mathrm{~K}$ a $400 \mathrm{~K} \mathrm{e} \Delta \mathrm{L}_{\mathrm{G}}$ variando de $-20 \mathrm{~nm}$ a $0 \mathrm{~nm}$

Figura 4.1 Representação das duas etapas de dopagem aplicadas durante a fabricação. A figura $(A)$ refere-se á extensão de fonte e dreno e a figura $(B)$ refere-se à dopagem principal.

Figura 4.2 Representação da estrutura dos TFETs das lâminas D23 - padrão (A), D07 (B), D08 (C), D21(D) e D22 (E)

Figura 4.3 Corrente de dreno ( $\left.\mathrm{I}_{\mathrm{DS}}\right)$ de um pTFET em função da tensão de dreno ( $\left.\mathrm{V}_{\mathrm{DS}}\right)$ para $V_{G S}$ de $-1,7 \mathrm{~V},-1,3 \mathrm{~V}$ e $-0,9 \mathrm{~V}$.

Figura 4.4 Corrente de dreno $\left(\mathrm{l}_{\mathrm{DS}}\right)$ de um pTFET em função da tensão de porta $\left(\mathrm{V}_{\mathrm{GS}}\right)$ para $\mathrm{V}_{\mathrm{DS}}$ de $-0,9 \mathrm{~V}$ e $-0,5 \mathrm{~V}$.

Figura 4.5 Corrente de dreno ( $\left.\mathrm{I}_{\mathrm{DS}}\right)$ de pTFETs em função da tensão de porta $\left(\mathrm{V}_{\mathrm{GS}}\right)$ para $\mathrm{V}_{\mathrm{DS}}$ variando de $-0,9 \mathrm{~V}$ a $-0,5 \mathrm{~V}, \mathrm{~W}_{\text {fin }}$ variando de $20 \mathrm{~nm}$ a $250 \mathrm{~nm}$ e $\mathrm{N}_{\text {fin }}$ alternando em 15 e 30.61 Figura 4.6 Corrente de dreno ( $\left.\mathrm{I}_{\mathrm{DS}}\right)$ de um pTFET em função da tensão de porta $\left(\mathrm{V}_{\mathrm{GS}}\right)$ para $V_{D S}$ de $-0,9 V, W_{\text {fin }}$ de $250 \mathrm{~nm}$ e $N_{\text {fin }}$ de 15

Figura 4.7 Curvas simuladas e experimental da corrente de dreno (l $\mathrm{ISS})$ de pTFETs em função da tensão de porta $\left(\mathrm{V}_{\mathrm{GS}}\right)$ para $\mathrm{V}_{\mathrm{DS}}$ de $-0,9 \mathrm{~V}$.

Figura 4.8 Corrente de dreno ( $\left.\mathrm{I}_{\mathrm{DS}}\right)$ em função da tensão de porta $\left(\mathrm{V}_{\mathrm{GS}}\right)$ para $\mathrm{V}_{\mathrm{DS}}$ de $-0,9 \mathrm{~V}$, $\Delta \mathrm{L}_{\mathrm{G}}$ de $-20 \mathrm{~nm}$, temperatura de 240 a $420 \mathrm{~K}$ e três combinações de mecanismos de transporte.

Figura 4.9 Corrente de dreno ( $\left.\mathrm{I}_{\mathrm{DS}}\right)$ em função da tensão de porta $\left(\mathrm{V}_{\mathrm{GS}}\right)$ para $\mathrm{V}_{\mathrm{DS}}$ de $-0,9 \mathrm{~V}$, $\Delta \mathrm{L}_{\mathrm{G}}$ de $-10 \mathrm{~nm}$, temperatura de 240 a $420 \mathrm{~K}$ e três combinações de mecanismos de transporte.

Figura 4.10 Corrente de dreno ( $\left.I_{D S}\right)$ em função da tensão de porta $\left(V_{G S}\right)$ para $V_{D S}$ de $-0,9 \mathrm{~V}$, $\Delta \mathrm{L}_{\mathrm{G}}$ de $0 \mathrm{~nm}$, temperatura de 240 a $420 \mathrm{~K}$ e três combinações de mecanismos de transporte. 
Figura 4.11 Corrente de dreno $\left(\mathrm{I}_{\mathrm{DS}}\right)$ em função da tensão de porta $\left(\mathrm{V}_{\mathrm{GS}}\right)$ para $\mathrm{V}_{\mathrm{DS}}$ de $-0,9 \mathrm{~V}$, $\Delta \mathrm{L}_{\mathrm{G}}$ de $-20 \mathrm{~nm},-10 \mathrm{~nm}$ e $0 \mathrm{~nm}$ e temperatura de 240 a $420 \mathrm{~K}$. 69

Figura 4.12 Corrente de dreno ( $\left.\mathrm{I}_{\mathrm{DS}}\right)$ em função da tensão de porta $\left(\mathrm{V}_{\mathrm{GS}}\right)$ para $\mathrm{V}_{\mathrm{DS}}$ de $-0,9 \mathrm{~V}$, com $W_{\text {fin }}$ de $40 \mathrm{~nm}$ e $\mathrm{N}_{\text {fin }}$ de 5 e temperatura de 300 a $420 \mathrm{~K}$

Figura 4.13 Corrente de dreno ( $\left.I_{D S}\right)$ em função da tensão de dreno $\left(V_{D S}\right)$ para $V_{G S}$ de $-1,3 \bigvee$ e $-1,7 \mathrm{~V}$, com $\mathrm{W}_{\text {fin }}$ de $40 \mathrm{~nm}$ e $\mathrm{N}_{\text {fin }}$ de 5 .

Figura 4.14 Corrente de dreno ( $\left.\mathrm{I}_{\mathrm{DS}}\right)$ em função da tensão de dreno $\left(\mathrm{V}_{\mathrm{DS}}\right)$ para $\mathrm{V}_{\mathrm{GS}}$ de $-1,3 \mathrm{~V}$ e $-1,7 \mathrm{~V}$, com $\mathrm{W}_{\text {fin }}$ de $40 \mathrm{~nm}$ e $\mathrm{N}_{\text {fin }}$ de 5. 72

Figura 4.15 Corrente de dreno ( $\left.\mathrm{I}_{\mathrm{DS}}\right)$ em função da tensão de porta $\left(\mathrm{V}_{\mathrm{GS}}\right)$ para $\mathrm{V}_{\mathrm{DS}}$ de $-0,9 \mathrm{~V}$ e $-0,5 \mathrm{~V}$, com $\mathrm{W}_{\text {fin }}$ de $40 \mathrm{~nm}$ e $\mathrm{N}_{\text {fin }}$ de 5. 73

Figura 4.16 Corrente de dreno ( $\left.I_{D S}\right)$ em função da tensão de porta $\left(V_{G S}\right)$ para $V_{D S}$ de $-0,9 \mathrm{~V}$ em dispositivos de 5 lâminas diferentes. 


\section{LISTA DE TABELAS}

Tabela 3.1. Modelos adotados para simulações dos dispositivos TFETs..........................41

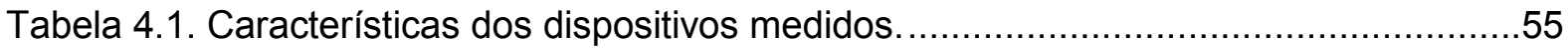

Tabela 4.2. Características das lâminas medidas..........................................................56

Tabela 4.3. Condições de sobreposição/subposição nas junções com os lados N e P.......58

Tabela 4.4. Condições de polarização dos dispositivos. ...................................................59 


\section{LISTA DE SÍMBOLOS}

BB.A

BB.B

BBT.GAMMA

BBT.A_KANE

BBT.B_KANE

BBT.GAMMA

$\mathrm{C}_{\text {total }}$

$\mathrm{E}_{\mathrm{C}}$

$\mathrm{E}_{\mathrm{F}}$

$E_{g}$

$\mathrm{E}_{\mathrm{i}}$

$E_{n}$

$\mathrm{E}_{\mathrm{p}}$

ETRAP

$E_{V}$

$\mathrm{F}$

f

$\mathrm{G}_{\mathrm{BBT}}$

h

$\hbar$

$\mathrm{H}_{\text {fin }}$

$I_{D S}$

$I_{G S}$

IOFF

ION

Itunelamento

k
Parâmetro de ajuste da taxa de geração de tunelamento

Parâmetro de ajuste da taxa de geração de tunelamento [V/cm]

Parâmetro de ajuste da taxa de geração de tunelamento

Parâmetro de ajuste da taxa de geração de tunelamento

$\left[\mathrm{eV}^{1 / 2} \cdot \mathrm{cm}^{-1} \cdot \mathrm{s}^{-1} \cdot \mathrm{V}^{-2}\right]$

Parâmetro de ajuste da taxa de geração de tunelamento $\left[\mathrm{V} \cdot \mathrm{cm}^{-1} \cdot \mathrm{eV}^{-3 / 2}\right]$

Parâmetro de ajuste da taxa de geração de tunelamento

Capacitância equivalente [F]

Nível energético de condução [V]

Nível de Fermi [V]

Largura de faixa proibida [V]

Nível energético intrínseco [V]

Nível energético dos elétrons [V]

Nível energético das lacunas [V]

Diferença entre o nível de energia da armadilha e o nível de Fermi intrínseco [V]

Nível energético de valência [V]

Campo elétrico aplicado na estrutura [V/cm]

Frequência de chaveamento [Hz]

Taxa de geração de tunelamento

Constante de Planck $\left(4,135667 \times 10^{-15}\right.$ eV.s)

Constante de Planck reduzida $\left(6,582119 \times 10^{-16} \mathrm{eV} . \mathrm{s}\right)$

Altura da aleta (fin) do transistor de múltiplas portas [nm]

Corrente entre dreno e fonte de dispositivos $[A]$

Corrente entre porta e fonte de dispositivos [A]

Corrente entre dreno e fonte de dispositivos desligados $[A]$

Corrente entre dreno e fonte de dispositivos acionados $[A]$

Corrente de tunelamento de dispositivos [A]

Constante de Boltzmann $\left[1,38066 \times 10^{-23} \mathrm{~J} / \mathrm{K}\right]$ 


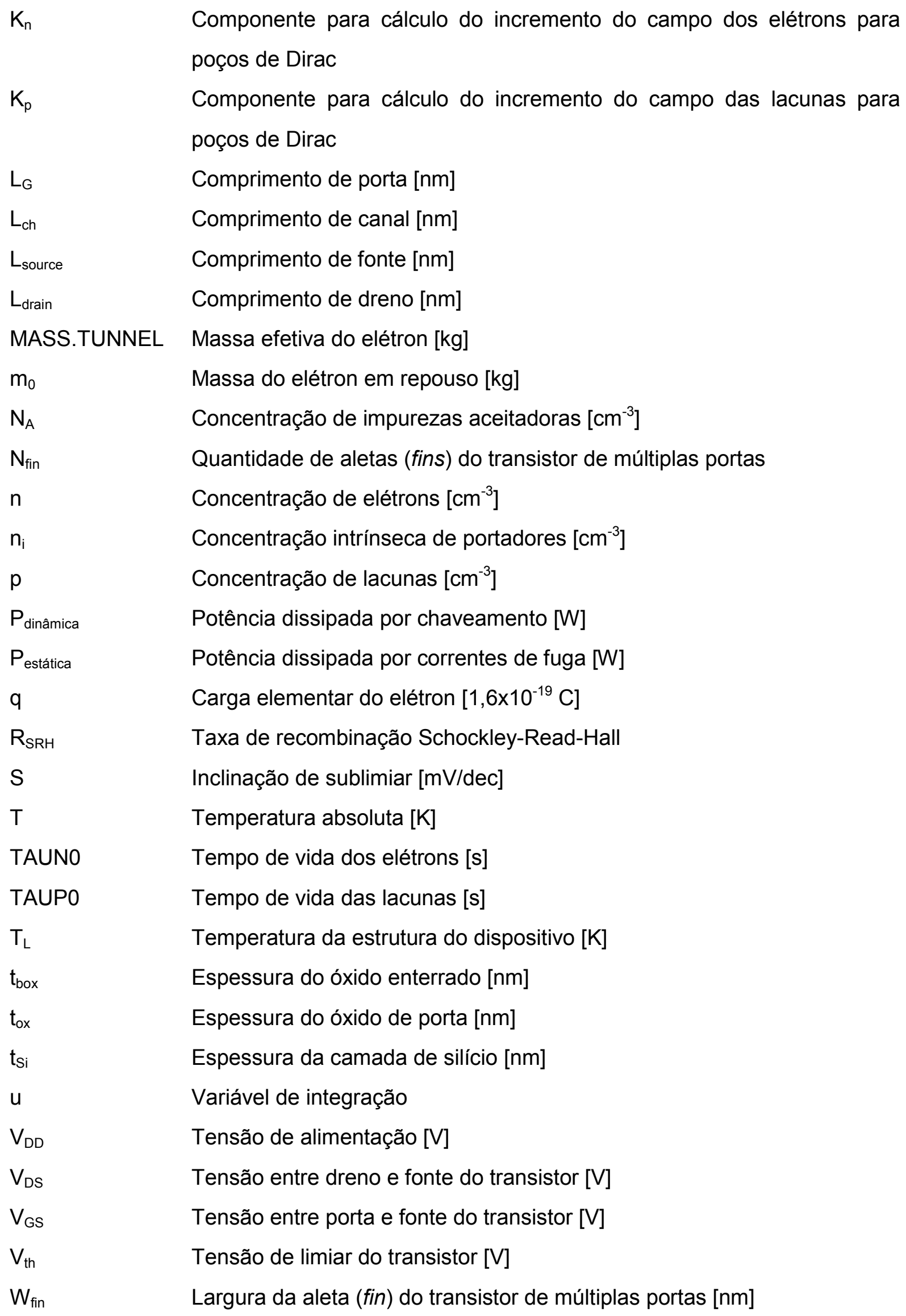


Permissividade do óxido de silício $\left[3,45 \times 10^{-13} \mathrm{~F} / \mathrm{cm}\right]$

Permissividade do silício $\left[1,06 \times 10^{-12} \mathrm{~F} / \mathrm{cm}\right]$ Incremento do campo dos elétrons para poços de Dirac Incremento do campo das lacunas para poços de Dirac 


\section{LISTA DE ABREVIATURAS E SIGLAS}

$\begin{array}{ll}\text { BBT } & \text { Tunelamento de banda para banda } \\ \text { EOT } & \text { Espessura equivalente de óxido } \\ \text { FinFET } & \text { Transistor de efeito de campo com estrutura em aletas (fins) } \\ \text { HfO }_{2} & \text { Óxido de háfnio } \\ \text { InAs } & \text { Arseneto de índio } \\ \text { IMEC } & \text { Interuniversity Microelectronic Center } \\ \text { LDD } & \text { Dreno levemente dopado } \\ \text { MOSFET } & \text { Transistor de efeito de campo com estrutura metal-óxido-semicondutor } \\ \text { MuGFET } & \text { Transistor de efeito de campo de múltiplas portas } \\ \text { Si } & \text { Silício } \\ \text { SiGe } & \text { Silício-germânio } \\ \text { SiO } & \\ \text { SRH } & \text { Óxido de silício } \\ \text { TAT } & \text { Schockley-Read-Hall } \\ \text { TFET } & \text { Tunelamento induzido por armadilhas } \\ \text { TiN } & \text { Transistor de tunelamento controlado por efeito de campo }\end{array}$




\section{SUMÁRIO}

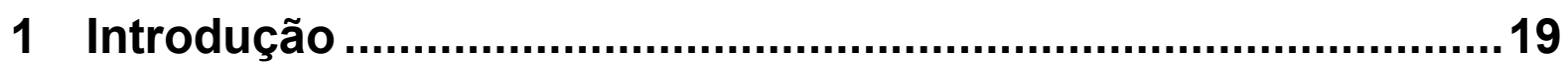

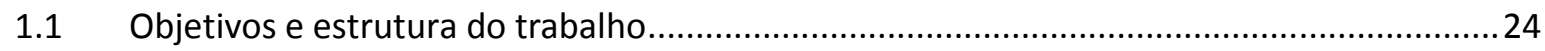

2 Conceitos teóricos................................................................26

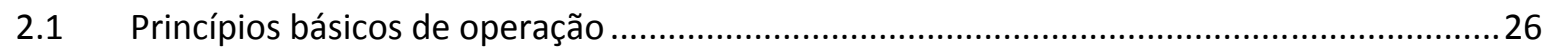

2.2 Comparação entre os tipos de tunelamento ………........................................................29

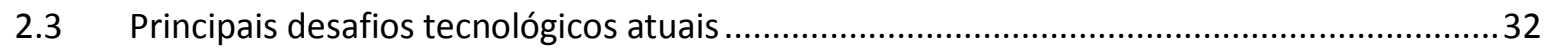

2.4 Breve histórico das propostas de transistores de tunelamento ..........................................33

3 Determinação de modelos de simulação e análise do comportamento de dispositivos nTFETs.........................................36

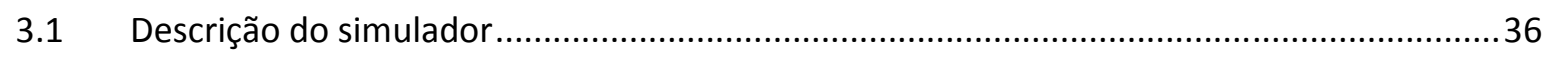

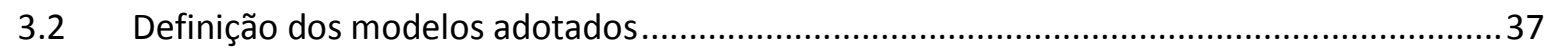

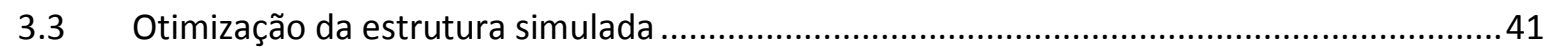

3.4 Impacto da temperatura e dos mecanismos de transporte de corrente ............................48

\section{Caracterização elétrica e comparação entre resultados experimentais e simulados de dispositivos pTFETs ......................54}

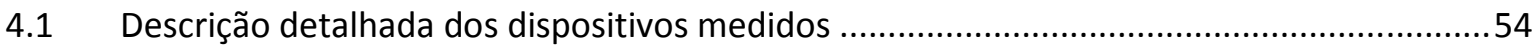

4.2 Metodologia da tomada de dados experimentais e de calibração das simulações ..............58

4.3 Identificação experimental do impacto das dimensões e das condições de polarização ....59

4.4 Identificação experimental do impacto da temperatura.....................................................62

4.5 Calibração das simulações com os dados experimentais para temperatura ambiente ........63

4.6 Simulações para análise do impacto dos mecanismos de transporte ....................................65

4.7 Análise experimental do impacto da temperatura e das condições de polarização nos

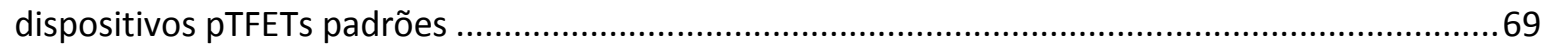

4.8 Comparação entre dispositivos de lâminas diferentes .......................................................74 


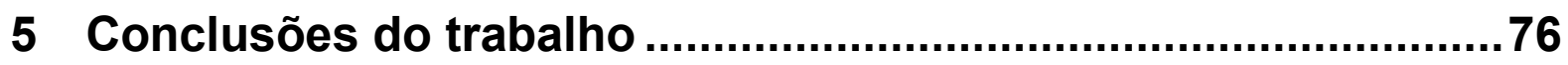

Publicações geradas .......................................................................79

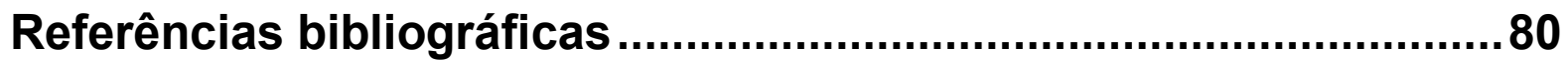

Anexo 1: Arquivo de simulação de um nTFET ...............................84

Anexo 2: Arquivo de simulação de um pTFET ...................................88 


\section{INTRODUÇÃO}

Nas últimas décadas, os dispositivos MOSFET têm sido continuamente reduzidos, atingindo dimensões nanométricas em suas gerações tecnológicas mais recentes. Paralelamente a este escalamento, limites físicos relacionados a efeitos de canal curto e a correntes de fuga tomam proporções cada vez mais significativas ${ }^{1}$, exigindo novas alternativas para que a exponencial Lei de Moore, segundo a qual o número de dispositivos no chip dobra aproximadamente a cada 18 meses $^{2}$, continue ditando o ritmo de integração de componentes.

Para ilustrar este o escalamento tecnológico, a Figura 1.1 indica a evolução de indicadores como quantidade de transistores, capacidade de memória e freqüência de operação na última década.
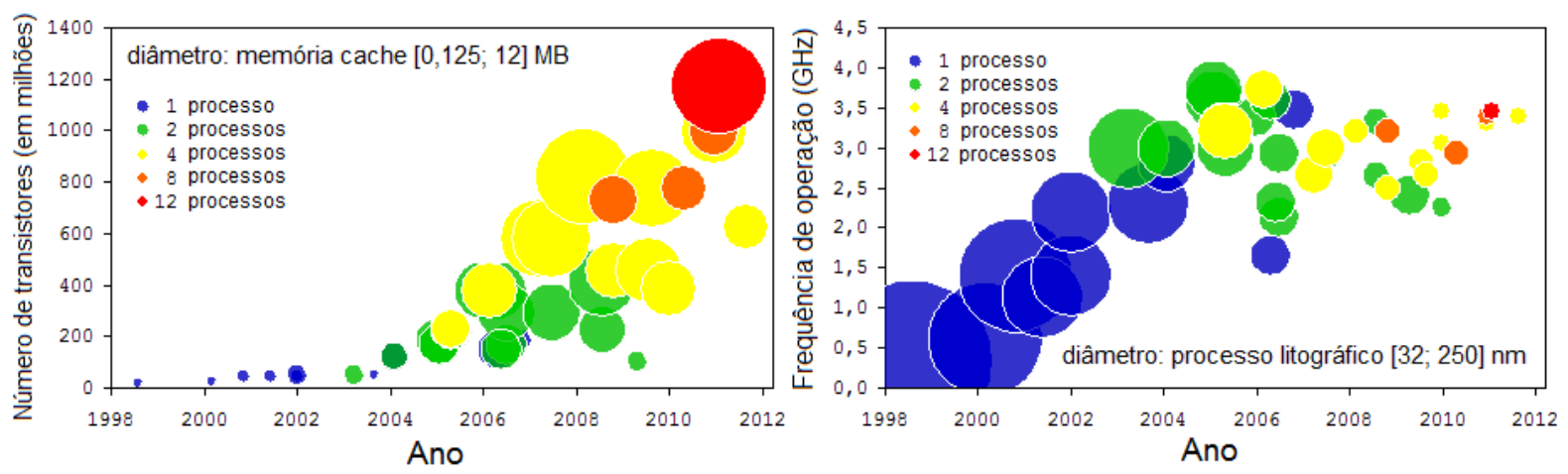

Figura 1.1 Representação da integração de dispositivos e dos consequentes ganhos de performance na última década ${ }^{3}$.

Diferentes propostas foram sucessivamente apresentadas pela comunidade científica, incluindo o uso de novos materiais e estruturas ${ }^{4}$. Afinal, enquanto materiais com alta constante dielétrica tenderiam a minimizar as correntes de fuga, estruturas com múltiplas portas resultariam num maior controle das cargas do canal pelas portas, atenuando efeitos de canal curto.

A complexidade de fabricação de dispositivos com porta superior e inferior adequadamente alinhadas foi suplantada com a proposta de transistores verticais com portas laterais, notadamente os FinFETs, que efetivamente apresentaram bom desempenho para dimensões abaixo de $100 \mathrm{~nm}^{5}$. Entretanto, nós tecnológicos mais recentes, abaixo de $22 \mathrm{~nm}$, requerem princípios funcionais diferentes, conforme esquematizado pela Figura 1.2. 
Fonte: C. Claeys, et. al; Fabrication and Characterization of $\mathrm{Si}$ and Hetero-junction Tunnel Field Effect Transistors, G-COE PICE Int. Symp., Tóquio, 2009.

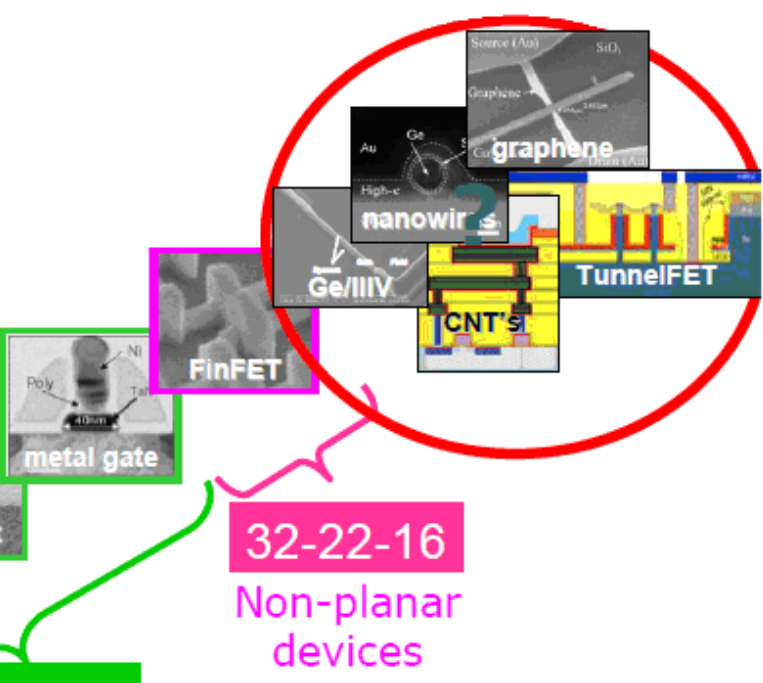

\section{5-32}

High-k, Metal Gate

90-65-45 propostas tecnológicas ao longo do tempo

$>=130$

Strain, USJ

Figura 1.2 Esquema com as sucessivas propostas apresentadas para permitir contínuo escalamento de dispositivos ${ }^{6}$.

Novas sugestões de dispositivos devem atentar à questão cada vez mais crítica da dissipação de potência, diretamente relacionada ao aumento da densidade de componentes nos circuitos integrados. Lembrando que tanto a componente dinâmica quanto a parcela estática da potência dissipada, equacionadas respectivamente em (1-1) e (1-2), são fortemente dependentes da tensão de alimentação, devem ser privilegiadas soluções que permitam funcionamento dos componentes sob tensões menores.

$$
\begin{aligned}
P_{\text {dinâmica }} & =C_{\text {total }} \cdot V_{D D}^{2} \cdot f \\
P_{\text {estatitica }} & =I_{O F F} \cdot V_{D D}
\end{aligned}
$$

onde $\mathrm{P}_{\text {dinâmica }}$ é a potência dissipada em virtude do chaveamento, $\mathrm{C}_{\text {total }}$ é a capacitância equivalente, $V_{D D}$ é a tensão de alimentação, $f$ é a frequência de chaveamento, $P_{\text {estática }}$ é a potência dissipada em virtude das correntes de fuga e lofF é a corrente quando o dispositivo está desligado ${ }^{7}$. 
Relembrando que outra especificação importante para aplicações digitais refere-se à maximização da razão ION/l OFF entre as correntes de dreno de um transistor acionado e de um desligado, deve-se atentar para que não seja muito reduzida a diferença entre a tensão de alimentação e a tensão de limiar do dispositivo $\left(V_{D D}-V_{\text {th }}\right)$. Consequentemente, na medida em que é almejada redução em $V_{D D}$, deve-se também privilegiar tecnologias com redução de $V_{\text {th. }}$.

A Figura 1.3 mostra a evolução desses dois parâmetros em função da dimensão da tecnologia MOS convencional, evidenciando a preocupante diminuição da diferença $V_{D D}-V_{\text {th }}$ da ordem de $4 \mathrm{~V}$ para pouco mais de $0,5 \mathrm{~V}$ entre as tecnologias de $1,4 \mu \mathrm{m}$ e $65 \mathrm{~nm}$.

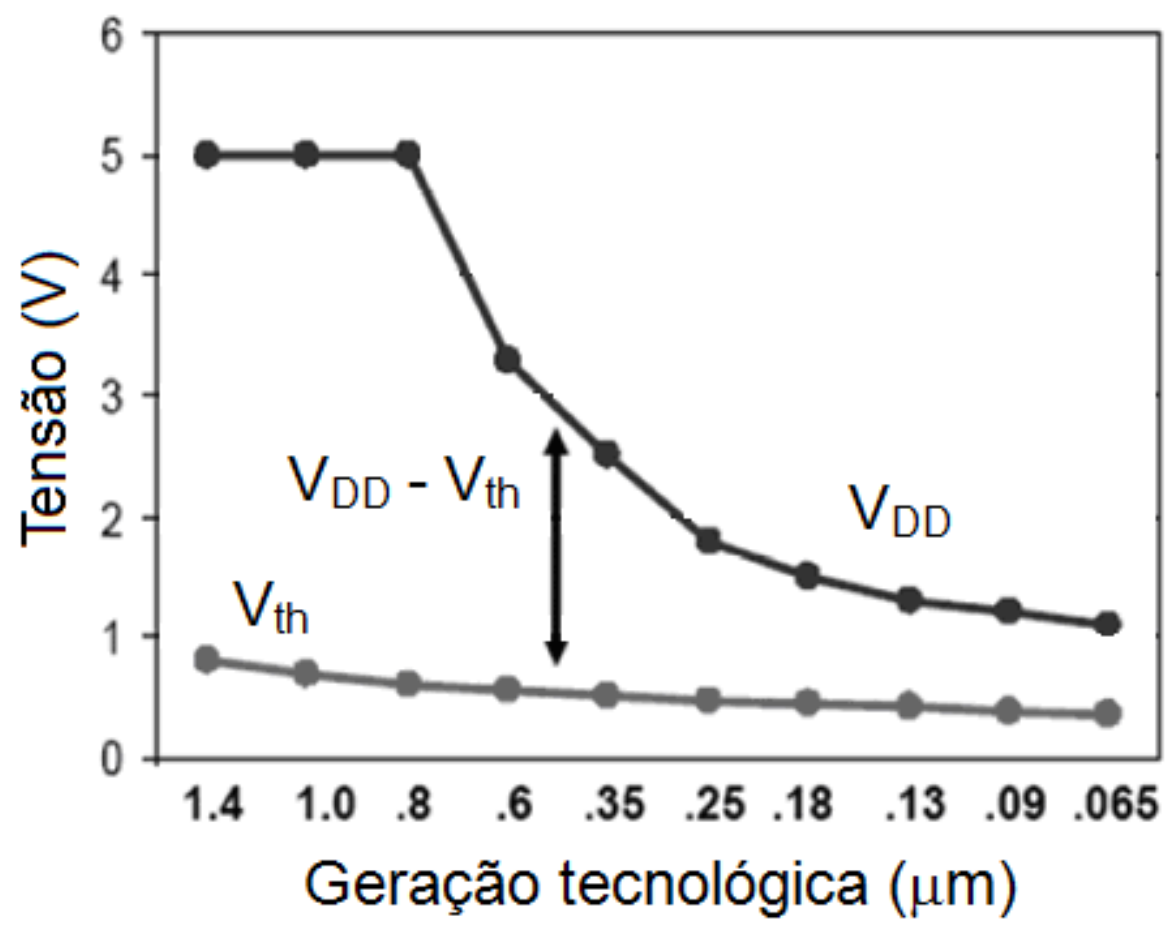

Figura 1.3 Evolução da tensão de alimentação e da tensão de limiar para tecnologias de 1,4 $\mu \mathrm{m}$ a $65 \mathrm{~nm}$ com dispositivos CMOS convencionais ${ }^{8}$.

Nesse ponto, é fundamental salientar o limite físico da variação da corrente por difusão térmica em função da variação de tensão, estimado em $\ln (10) . \mathrm{kT} / \mathrm{q}$, isto é, cerca de $60 \mathrm{mV} /$ década à temperatura ambiente. Esta limitação da inclinação de sublimiar impede que transistores MOS convencionais sejam utilizados com tensões de limiar diminutas, pelo motivo evidenciado pela Figura 1.4. 


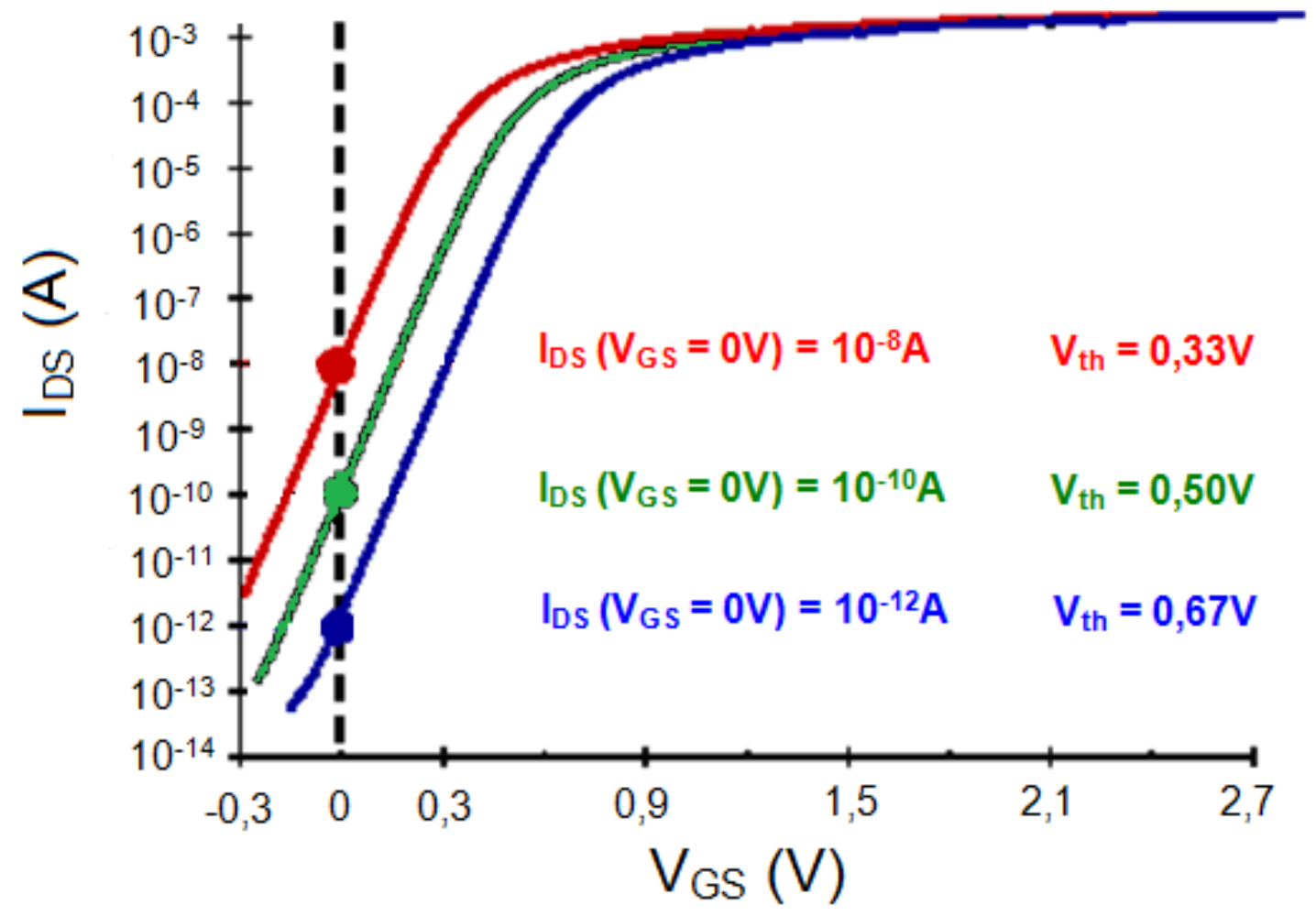

Figura 1.4 Corrente de dreno em função da tensão de porta para três diferentes dispositivos, evidenciando o impacto da variação de $V_{\text {th }}$ em $\mathrm{l}_{\mathrm{OFF}}$.

Nesta figura são exibidas as curvas da corrente de dreno em função da tensão de porta para três diferentes dispositivos à temperatura ambiente. Como resultado do limite da inclinação de sublimiar de $60 \mathrm{mV} /$ década, a diminuição de $V_{\text {th }}$ foi acompanhada de um vertiginoso aumento na corrente de fuga I IFF na condição de $V_{G S}=0 \mathrm{~V}$. Neste exemplo numérico, uma redução da tensão de limiar de $50 \%$ elevaria a corrente I IFF (e consequentemente a potência estática dissipada) da ordem de 10 mil vezes. Dessa forma, pode-se inferir a importância de propor alternativas de componentes que operem com novos mecanismos de condução de corrente $^{10}$.

Comparando-se ainda as Figuras 1.2, 1.3 e 1.4, pode-se ainda estabelecer um objetivo quantitativo em termos do já comentado desejo de maximizar a relação ION/l OFF dos dispositivos. Considerando a geração tecnológica na qual se destaca a tecnologia CMOS convencional e os valores adequados de tensão de alimentação e de tensão de limiar, uma razão de nove ordens de grandeza equivaleria à obtida na curva da Figura 1.4 para o caso de $V_{\text {th }}=0,67 \mathrm{~V}$. 
Em termos de tensão de alimentação, são desejados dispositivos que apresentem um comportamento vantajoso para tensões inferiores a $0,5 \mathrm{~V}^{11}$, o que daria continuidade à evolução tecnológica destacada na Figura 1.3.

Para finalizar a justificativa da necessidade de estudar novas tecnologias que permitam soluções com menor tensão de alimentação, menor tensão de limiar e menor dissipação de potência, é apresentada a Figura 1.5, com a previsão da evolução das componentes dinâmica e estática da potência estimadas para dispositivos CMOS convencionais.

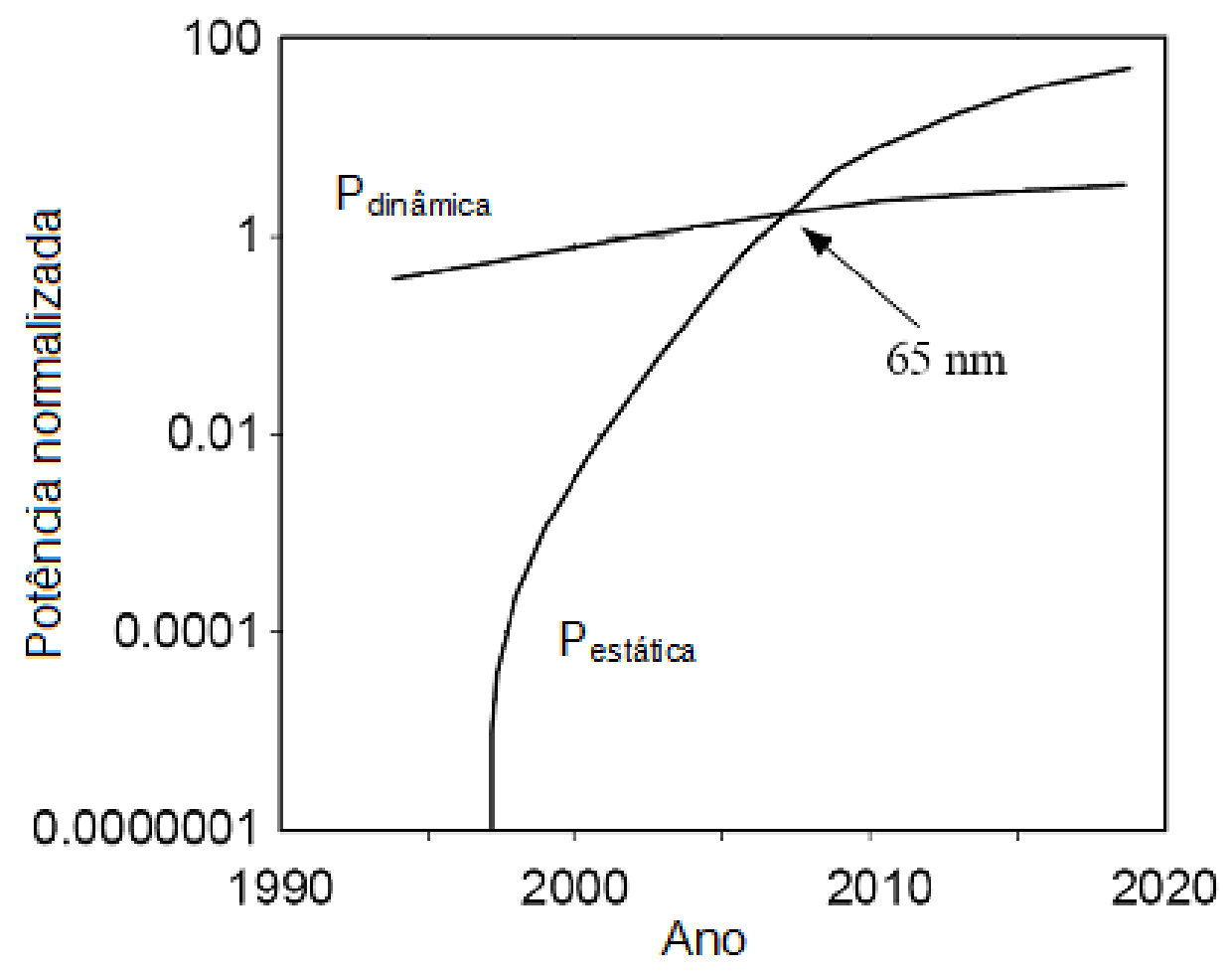

Figura 1.5 Estimativa da evolução da potência estática e dinâmica para tecnologia MOS convencional ${ }^{7}$.

É neste cenário que aparecem as propostas de utilização de transistores de tunelamento controlados por efeito de campo (TFETs), baseados numa estrutura similar à de um diodo PIN ( $p+$ - intrínseco - $n+$ ), porém com modulação do canal controlada por uma porta ${ }^{12}$. Uma vez que estes dispositivos têm corrente dependente principalmente de fenômenos de tunelamento quântico ao invés dos efeitos clássicos de difusão e deriva, é possível obter inclinação de sublimiar inferior a $60 \mathrm{mV} /$ década a temperatura ambiente e, consequentemente, obter dispositivos com bom desempenho mesmo nas dimensões previstas pelas gerações de dispositivos mais recentes ${ }^{13}$. 
Finalmente, vale salientar que a semelhança estrutural com a tecnologia MOSFET convencional permitiria a implementação através das técnicas de processamento já amplamente conhecidas. Em outras palavras, seriam aliadas a performance de transistores TFET com a confiabilidade do processo de fabricação dos transistores CMOS convencionais. Futuros dispositivos poderiam, por exemplo, apresentar estrutura tridimensional similar às propostas de nanofios verticais ${ }^{14}$.

\subsection{Objetivos e estrutura do trabalho}

O objetivo deste trabalho é estudar teórica e experimentalmente diversas estruturas de TFETs e indicar as mais promissoras alternativas de otimização de desempenho. Serão abordados resultados obtidos de simulações numéricas e de medidas experimentais inicialmente de modo individual e, posteriormente, de modo comparativo.

Será analisada a influência no desempenho dos dispositivos causada por suas dimensões e por fatores externos como a temperatura. Para análise mais ampla e detalhada do funcionamento dos TFETs, as simulações vão também abordar a influência de cada mecanismo de transporte separadamente, mostrando a parcela de contribuição de cada componente em função das diferentes condições de polarização.

A estrutura do trabalho está dividida da seguinte forma:

O capítulo 1 resume o contexto tecnológico em que o trabalho se encaixa e a motivação técnica que leva ao aprofundamento nos conhecimentos sobre os transistores TFETs.

O capítulo seguinte faz uma revisão teórica para justificar o funcionamento deste tipo de dispositivo e para apresentar as atuais dificuldades encontradas no seu desenvolvimento. Também é apresentado um breve histórico das propostas quanto à aplicação desta tecnologia.

O terceiro capítulo apresenta detalhes de estruturas nTFETs simuladas e os resultados mais importantes obtidos. Cada modelo selecionado é devidamente 
explicado e os resultados são analisados com base nas justificativas teóricas do capítulo anterior.

O capítulo 4 engloba os resultados experimentais, novamente acompanhados das devidas explicações sobre as escolhas de medição e das análises de desempenho. É descrita ainda a calibração das simulações com base nos dados experimentais de dispositivos pTFETs.

Finalmente, o quinto capítulo lista as conclusões deste trabalho e indica como futuros projetos poderiam se aproveitar das contribuições mais recentes desta tecnologia de transistores de tunelamento. 


\section{CONCEITOS TEÓRICOS}

Neste capítulo são explicados os conceitos teóricos mais relevantes para justificar o funcionamento dos TFETs e as dificuldades que ainda devem ser enfrentadas para que o desempenho seja otimizado. Neste capítulo serão abordados os conceitos teóricos dos temas envolvidos no trabalho.

\subsection{Princípios básicos de operação}

Os transistores de tunelamento controlados por efeito de campo, na medida em que substituem os mecanismos clássicos de condução por difusão e deriva ${ }^{15}$ pelos efeitos de tunelamento quântico ${ }^{16}$, permitem a obtenção de dispositivos com inclinação de sublimiar inferior a $60 \mathrm{mV} /$ década à temperatura ambiente.

Com estes valores menores do que o limite previsto para transistores MOSFET, obtém-se um comportamento mais próximo ao de uma chave ideal, permitindo a escolha de uma tensão de alimentação menor ${ }^{17}$. Esta comparação entre a inclinação de uma chave ideal, de um dispositivo MOS e de um TFET é ilustrada na Figura 2.1.

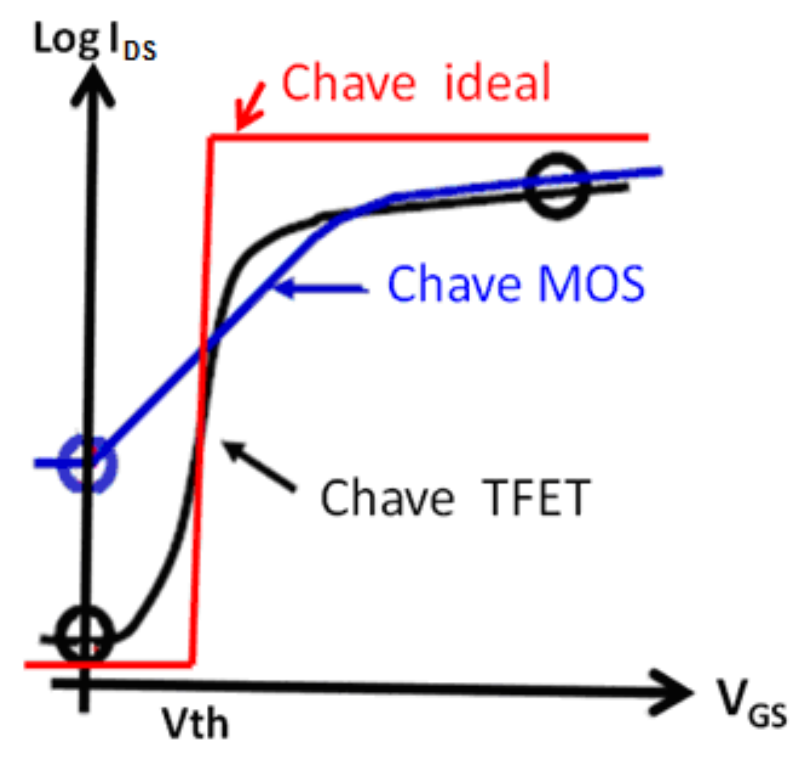

Figura 2.1 Comparação das inclinações de sublimiar previstas para uma chave ideal, um dispositivo MOS e um TFET. 
Para que este efeito seja observado, os TFETs são projetados com uma estrutura PIN ( $p+-$ intrínseco - $n+)$ com controle de porta. A título de exemplo, a Figura 2.2 esquematiza uma estrutura típica de um transistor de tunelamento controlado por efeito de campo com implementação planar e porta dupla.

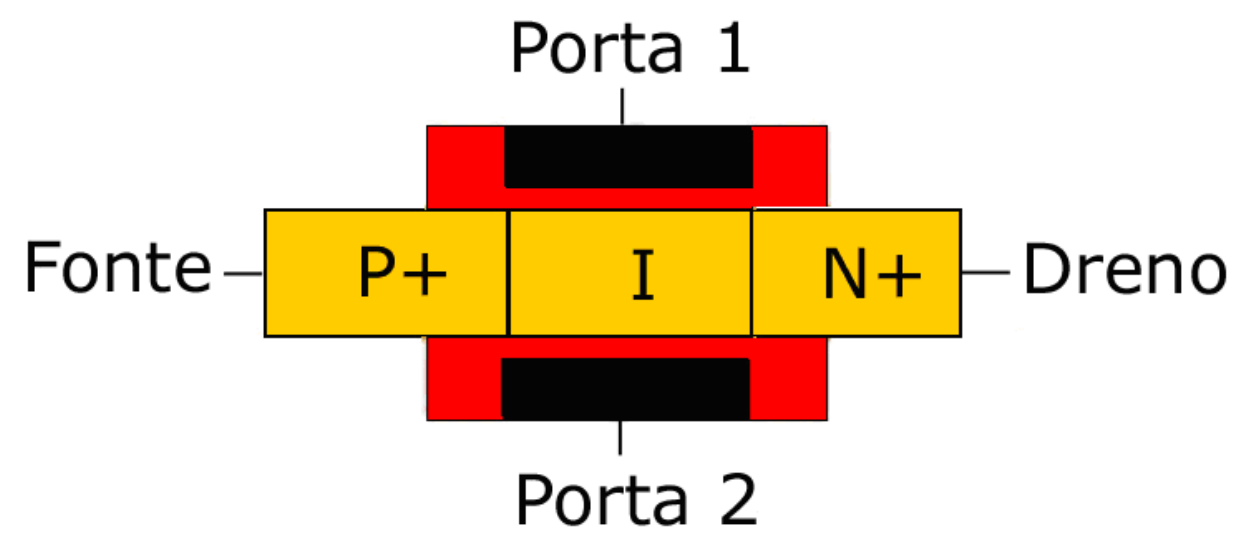

Figura 2.2 Seção transversal de um nTFET de porta dupla.

Vale lembrar que uma mesma estrutura pode funcionar como nTFET ou como pTFET dependendo da polarização. Este fenômeno indesejado, denominado efeito ambipolar, também faz com que uma determinada região possa atuar como fonte ou como dreno dependendo da aplicação. No caso da Figura 2.2, temos a representação de um nTFET, no qual a região n+ é o dreno e a p+ é a fonte.

O funcionamento deste dispositivo pode ser explicado pela comparação dos diagramas de faixas de energia em duas situações distintas, sendo uma na condição de transistor desligado e outra na polarização de dispositivo acionado. Em ambos os casos, temos a fonte aterrada e um potencial positivo aplicado no dreno.

A Figura 2.3 indica o diagrama representativo do caso em que a tensão de porta é nula, de modo que não haja passagem de nível significativo de corrente.

À medida que a tensão aplicada na porta é aumentada, nota-se gradativa redução nos níveis de energia das bandas de condução e valência da região do canal. A Figura 2.4 representa a situação em que o deslocamento nos níveis de energia leva a um forte tunelamento próximo à junção fonte-canal, de modo que os elétrons da banda de valência da fonte tunelem para a banda de condução da região do canal. 


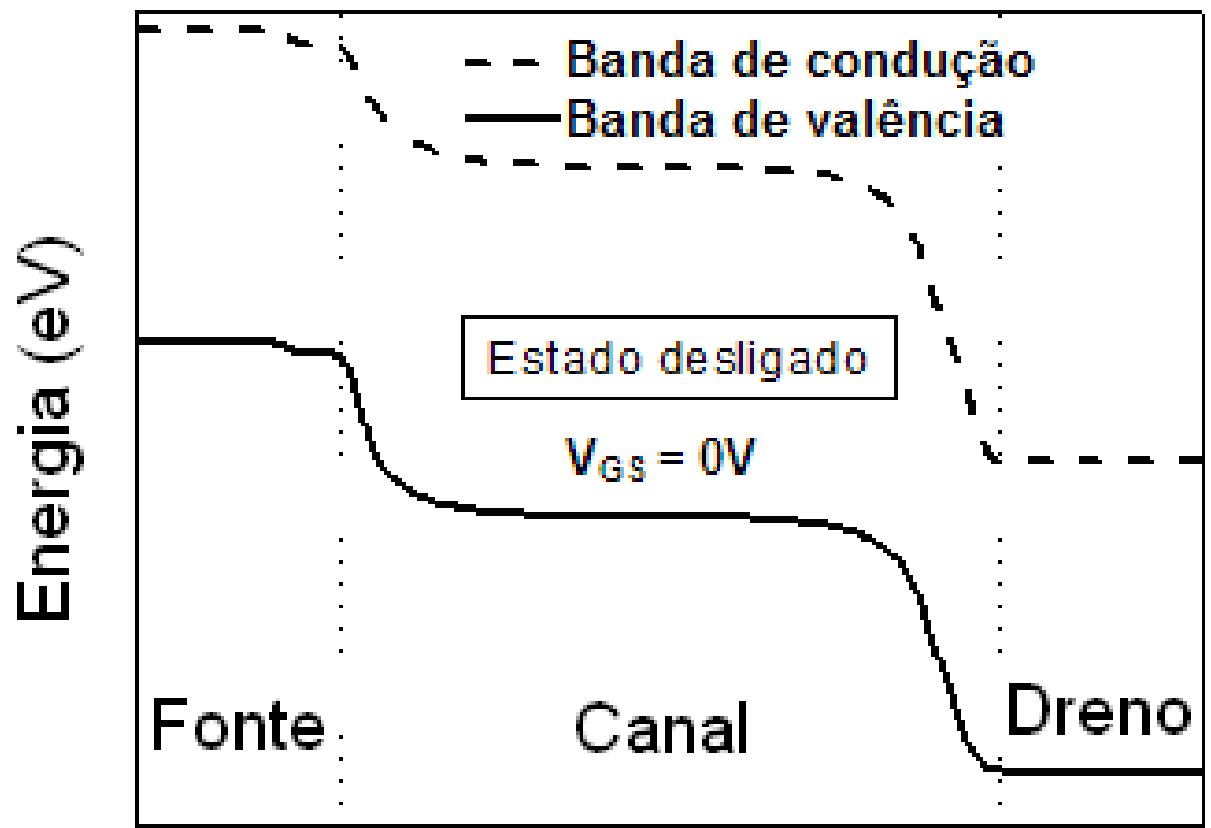

Posição ao longo do dispositivo (nm)

Figura 2.3 Diagrama de bandas de energia para um nTFET desligado.

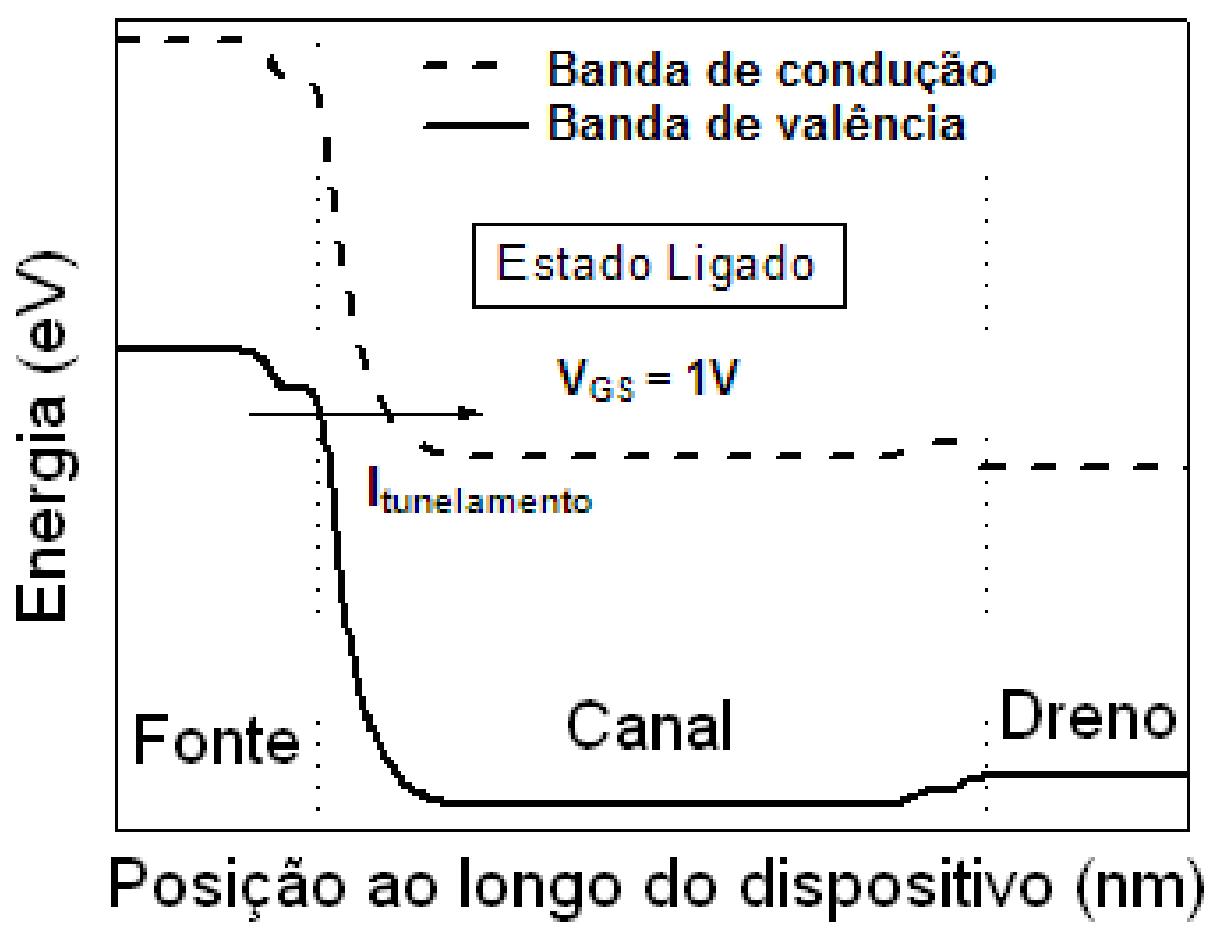

Figura 2.4 Diagrama de bandas de energia para um nTFET ligado. 
Esta análise também justifica a essência do efeito ambipolar. Caso fosse aplicado sobre a porta um potencial cada vez mais negativo, observaríamos o efeito de tunelamento na área próxima à junção dreno-canal e, consequentemente, um indesejável aumento na corrente. O item 2.3 resume este e outros desafios desses dispositivos, bem como suas mais aceitas propostas de soluções.

Analogamente à descrição do funcionamento do nTFET, poderíamos obter um pTFET simplesmente aterrando o lado $n+$ (que passaria a atuar como fonte) e aplicando um potencial negativo no lado p+ (dreno). Nessa condição, variando o potencial de porta negativamente, haveria crescente tunelamento entre a região $n+$ e o canal, ativando o dispositivo.

\subsection{Comparação entre os tipos de tunelamento}

Ao longo da análise das simulações e dos resultados experimentais, serão comentadas frequentemente as influências individuais das três principais componentes da corrente resultante: BBT (tunelamento de banda para banda), SRH (Schockley-Read-Hall) e TAT (tunelamento induzido por armadilhas).

Cada uma dessas componentes predomina sob uma determinada condição de polarização dos dispositivos e têm sua própria característica de dependência com temperatura, dimensões físicas, entre outros fatores.

Na condição de baixa tensão de porta, isto é, com o dispositivo desativado, temos apenas uma pequena corrente fluindo em virtude da geração de SchockleyRead-Hall. Afinal, há uma considerável barreira de energia dificultando o tunelamento, de modo a permitir apenas a passagem de uma componente dependente exponencialmente da largura da faixa proibida e da temperatura ${ }^{18}$. Esta condição é ilustrada pela Figura 2.5. 


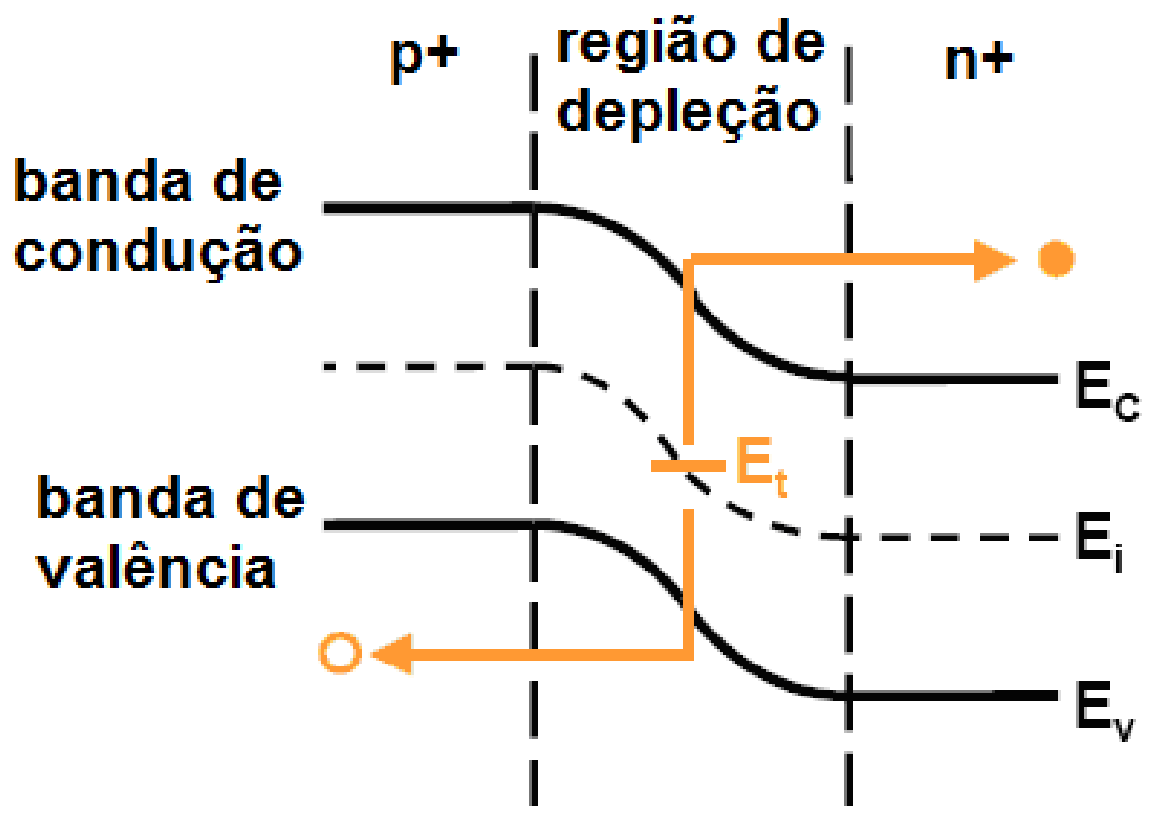

Figura 2.5 Diagrama de bandas de energia representando predomínio de corrente SRH.

À medida que se aumenta o potencial na porta, a barreira de energia vai sendo reduzida. Para estruturas com poucas armadilhas, essa condição ainda não seria suficiente para permitir o pleno tunelamento. Entretanto, a presença de quantidade significativa de armadilhas atua de modo a dividir a barreira de energia em múltiplas partes. Em outras palavras, é como se as cargas tivessem alternativas de caminhos para sucessivos tunelamentos, cada um dos quais com uma com uma barreira de potencial efetiva relativamente pequena.

Dessa forma, o aumento da corrente passa a ser potencializado com o aumento da tensão de porta, ou seja, há uma diminuição na inclinação de sublimiar, novamente com dependência exponencial da largura da faixa proibida e da temperatura. Um diagrama de bandas dessa corrente induzida por armadilhas (TAT) é representado na Figura 2.6.

Finalmente, com o contínuo incremento na tensão de porta, a barreira de potencial é dramaticamente reduzida, permitindo a passagem de corrente por tunelamento de banda para banda (BBT). Nessa região podem ser obtidos valores ainda menores de inclinação de sublimiar e, ao contrário das componentes mencionadas anteriormente, há uma influência muito reduzida da variação de temperatura ${ }^{19}$. Esta situação é indicada pela Figura 2.7. 


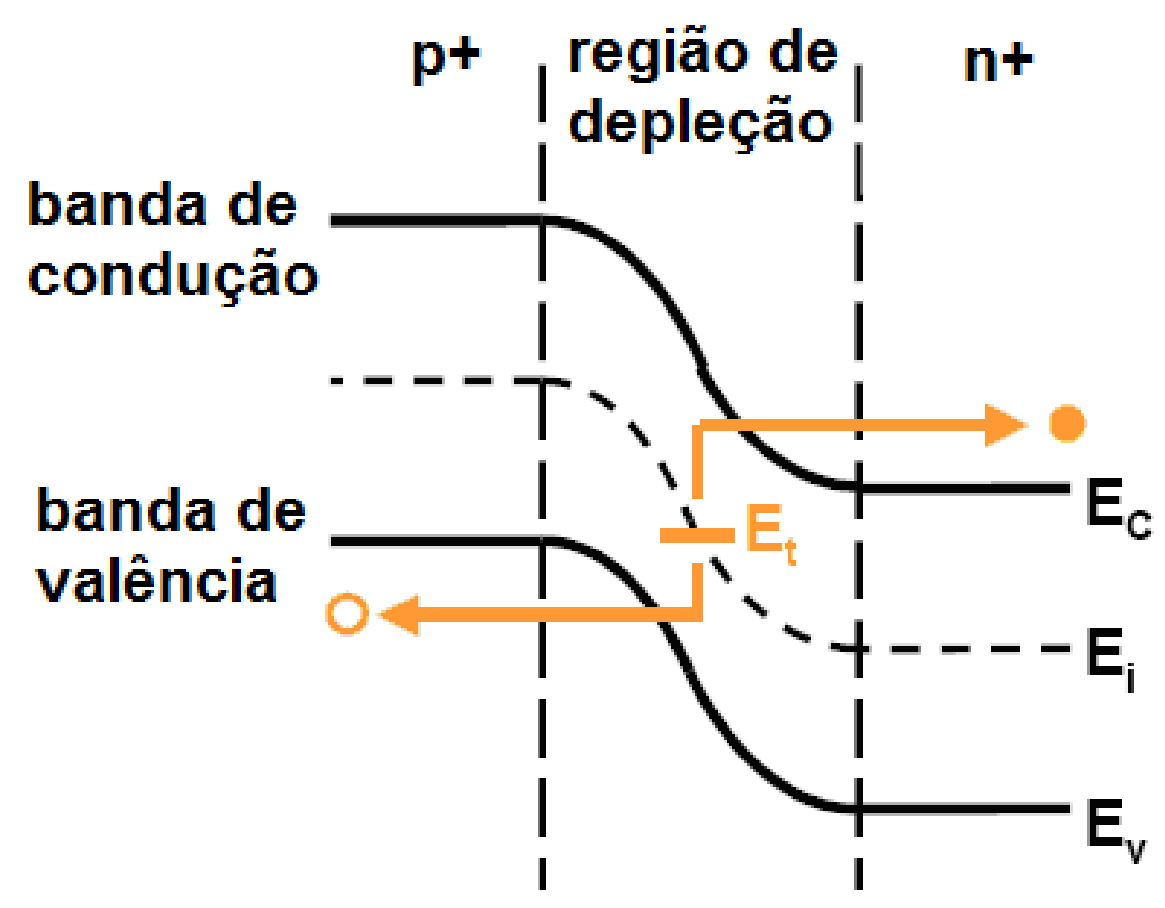

Figura 2.6 Diagrama de bandas de energia representando predomínio de corrente TAT.

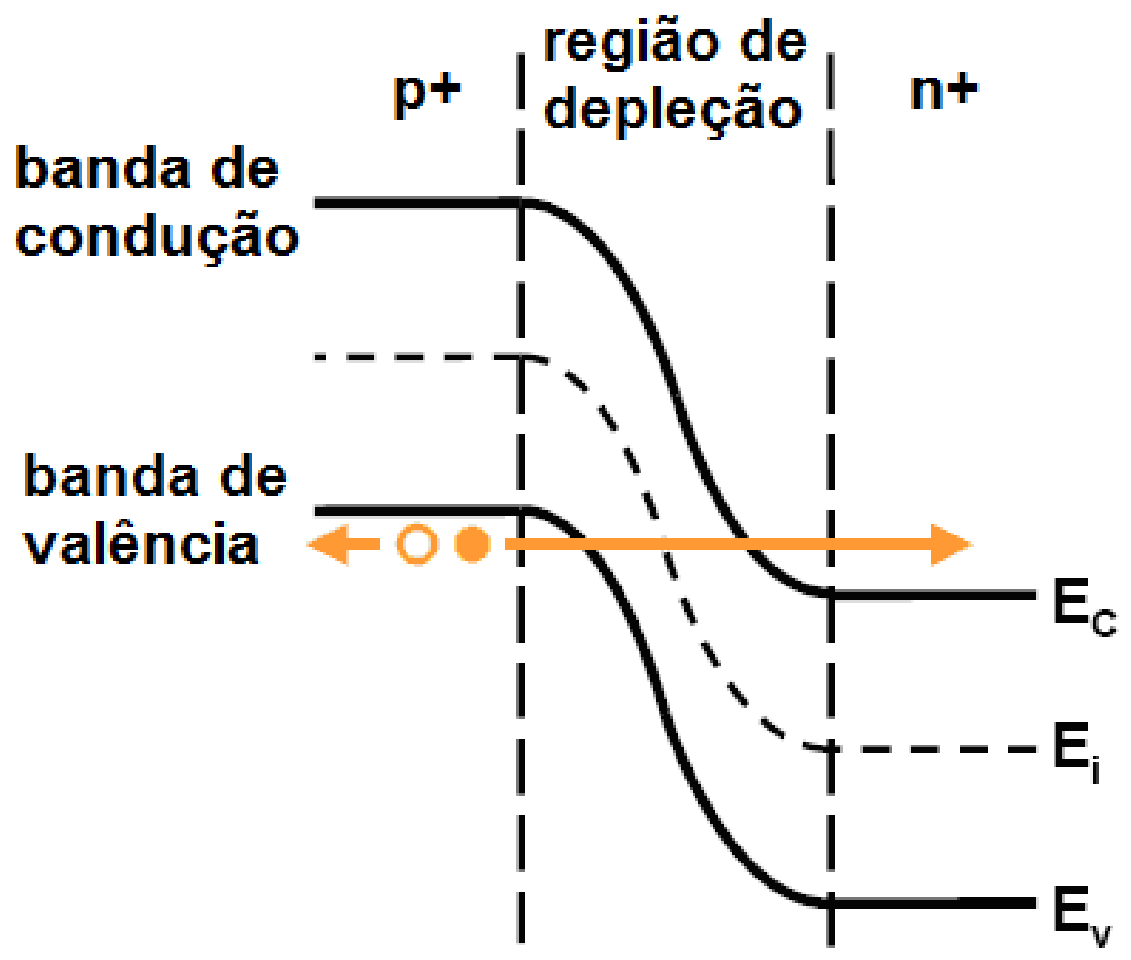

Figura 2.7 Diagrama de bandas de energia representando predomínio de corrente BBT.

Resumindo as situações de atuação de cada mecanismo de transporte, a Figura 2.8 esboça a variação de corrente numa junção à medida que é aumentada a tensão aplicada. 


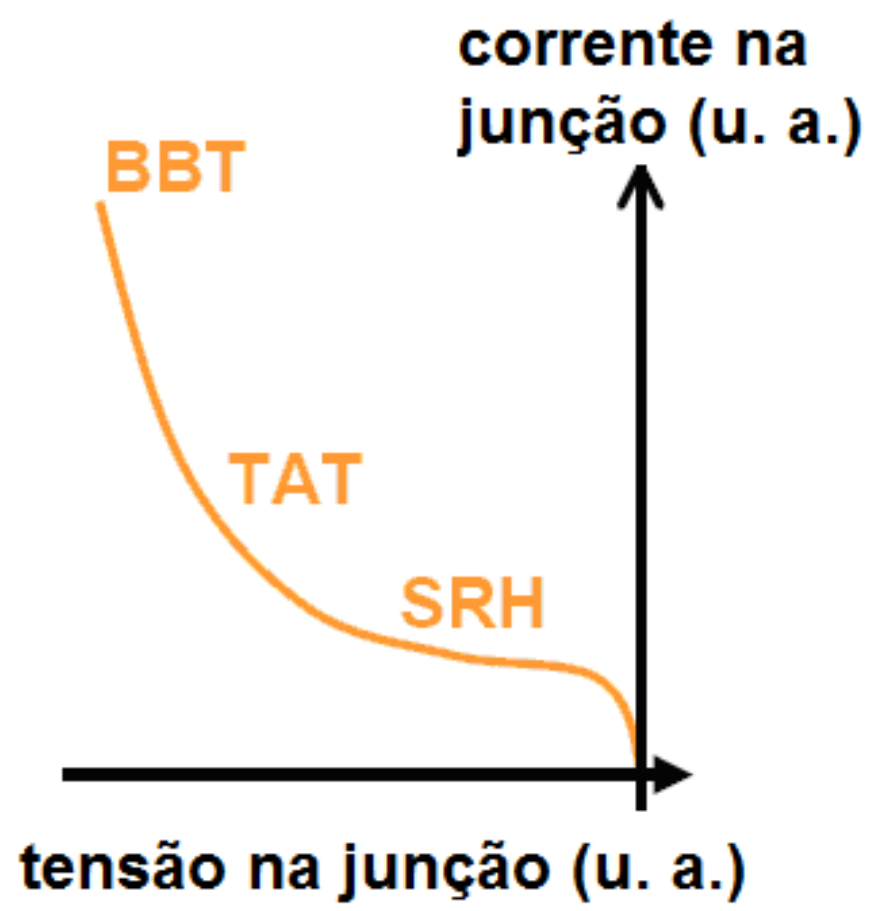

Figura 2.8 Representação da variação do mecanismo de transporte predominante à medida que é alterada a tensão em uma determinada junção.

O capítulo 3.2 detalha as equações implementadas pelos modelos selecionados para as simulações de cada uma destas componentes e justifica as escolhas com base nos parâmetros variáveis ao longo de todas as análises.

\subsection{Principais desafios tecnológicos atuais}

Apesar das diversas características promissoras da tecnologia dos TFETs, há importantes desafios enfrentados pela comunidade científica para maximizar o desempenho destes dispositivos, notadamente relacionados ao efeito ambipolar e à baixa corrente de acionamento $\left(\mathrm{I}_{\mathrm{ON}}\right)^{20}$.

O efeito ambipolar pode ser explicado pela simetria da estrutura básica dos TFETs apresentada na Figura 2.2, que permite que um mesmo dispositivo funcione como nTFET e como pTFET dependendo da condição de polarização. Esta característica é fortemente prejudicial para aplicações lógicas e têm recebido numerosas sugestões de abordagem prática ${ }^{21}$.

Neste trabalho serão enfocadas as propostas de implementação simples, mas com resultados bastante significativos. Para atenuar o tunelamento parasitário, 
são impostas assimetrias na estrutura física dos dispositivos, por exemplo com subposição (underlap) de porta na junção onde não deve ocorrer tunelamento ${ }^{22}$.

A questão da baixa corrente $\mathrm{I}_{\mathrm{ON}}$ também têm sido alvo de contínuas pesquisas para evitar impactos como a redução na velocidade de chaveamento ${ }^{23}$. Algumas soluções propõem processos que incluem strain local, epitaxia seletiva, materiais com elevadas constantes dielétricas, entre outras ${ }^{24}$. Por outro lado, óxidos com constantes dielétricas superiores a 100 ainda não são bem integrados na tecnologia CMOS e o alinhamento de porta com precisão nanométrica em relação à fonte com strain ou à heterojunção fonte/canal está acima do previsto por técnicas litográficas ${ }^{25}$.

Novamente, este trabalho vai destacar soluções estruturais, como o projeto de componentes com porta dupla para maximizar a corrente, e comentar aplicações similares a FinFETs.

Finalmente, outro ponto importante observado a partir das tomadas de dados experimentais de dispositivos TFETs refere-se à necessidade de utilizar um material na fonte com menor largura de faixa proibida para obter na prática valores de inclinação de sublimiar inferior a $60 \mathrm{mV} /$. década $^{26}$.

Dessa forma, os resultados medidos para estruturas com fonte de silício ao invés de SiGe ou InAs, apesar de não constituírem a solução final para transistores com inclinação de sublimiar inferior ao limite teórico da tecnologia CMOS convencional, são apresentados a título comparativo. Em outras palavras, mesmo ainda com valores acima de $60 \mathrm{mV} /$ década sob temperatura ambiente, é possível comparar os benefícios e prejuízos de diferenças estruturais, as quais também podem ser aplicadas a processos de fabricação que envolvam heteroestruturas ${ }^{27}$.

\subsection{Breve histórico das propostas de transistores de tunelamento}

A proposta de um dispositivo com estrutura PIN com controle de porta apareceu pela primeira vez ainda em 1978, porém sem qualquer relação com as motivações mais recente de minimizar a inclinação de sublimiar e a dissipação de potência ${ }^{22}$. O artigo de Quinn et al. pela Universidade de Brown ${ }^{28}$ era focado em aplicações de espectroscopia. 
Novas propostas com esta tendência, apesar de claras variações de estrutura e de condições de polarização, apareceram em trabalhos de Koga e Toriumi pela Toshiba em $1997^{29}$ e de Aydin e Zaslavsky em $2004^{30}$. No primeiro caso, a sugestão de um dispositivo similar a um TFET usa resultados experimentais de junções diretamente polarizadas. No segundo, é apresentada uma estrutura com tunelamento lateral fabricada sobre SOI. Entretanto, a porta é posicionada diretamente sobre a junção p-n, sem região intrínseca, sob a justificativa de reduzir a capacitância de porta e, consequentemente, aumentar a velocidade de chaveamento.

Também aparecem trabalhos sobre transistores de tunelamento de banda para banda adotando diferentes nomenclaturas. Por exemplo, enquanto Takeda et al. pela Hitachi ${ }^{31}$ usaram a denominação $B^{2} T-M O S F E T$, Baba pela NEC ${ }^{32}$ chamou os TFETs de Surface Tunnel Transistors (Transistores de Tunelamento Superficial).

Já em 2004, tunelamento banda para banda foi demonstrados em transistores com estrutura de nanotubos de carbono por Appenzeller et al. ${ }^{33}$ É notável neste trabalho o primeiro relato de obtenção de inclinação de sublimiar inferior a $60 \mathrm{mV} /$ década sob temperatura ambiente., ainda que tal medida tenha ocorrido para uma faixa mínima de tensão e para uma condição de baixa corrente de dreno.

Ainda em 2004, Bhuwalka et al. pela Universidade das Forças Armadas da Alemanha $^{34}$ propuseram estrutura com SiGe, com a justificativa de que a menor largura da faixa proibida diminuiria a largura da barreira de tunelamento e, desta forma, contribuiria para aumentar a corrente $\mathrm{I}_{\mathrm{ON}}$ e para reduzir a inclinação de sublimiar. Em 2006, o mesmo grupo propôs com base em resultados de simulação que o aumento da porcentagem de germânio no SiGe incrementaria o módulo da corrente enquanto o dispositivo estivesse acionado ${ }^{35}$.

Posteriormente, Verhulst et al. pelo $\mathrm{IMEC}^{36}$ sugeriram a redução do comprimento do canal de modo a evitar sobreposição com a junção canal/dreno como uma alternativa para a diminuição do efeito ambipolar, tema que será bastante comentado ao longo deste trabalho. 
Para fechar este resumo da evolução das propostas tecnológicas relacionadas aos TFETs, podem ser mencionados dois artigos como exemplos de aplicações destes dispositivos em circuitos eletrônicos. Fulde et al. da Universidade Técnica de Munique $^{37}$ relacionaram as características analógicas e digitais de um transistor pTFET de múltiplas portas a circuitos controladores de tensão em 2008.

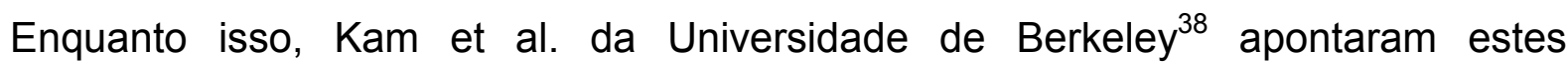
dispositivos de tunelamento como mais adequados para minimização de consumo de energia em circuitos operando a menos de $500 \mathrm{MHz}$. 


\section{DETERMINAÇÃO DE MODELOS DE SIMULAÇÃO E ANÁLISE DO COMPORTAMENTO DE DISPOSITIVOS NTFETS}

A etapa de simulação de dispositivos neste trabalho foi baseada no programa Atlas da Silvaco, um simulador numérico 2D e 3D baseado em equacionamentos físicos do comportamento de semicondutores. As principais vantagens desse tipo de simulador físico consistem na possibilidade de previsibilidade do desempenho de dispositivos sem a necessidade da inclusão de dados experimentais e na alternativa de avaliar impacto de fenômenos individualmente, inseparáveis na prática.

A título de comparação com a literatura, ajustes iniciais foram realizados com base em parâmetros já aprovados pela comunidade científica para dispositivos do tipo $\mathrm{N}$, com refinamento de grade de simulação elaborado com o intuito de garantir convergência e acurácia dos resultados.

Posteriormente, alguns parâmetros físicos foram ajustados de modo a compatibilizar as simulações com a tomada de dados experimentais. Vale salientar ainda que os resultados apresentados correspondem a simulações bidimensionais, uma vez que os modelos de tunelamento implementados pelo Atlas podem ser habilitados apenas para esta condição.

Neste capítulo serão apresentados os modelos físicos adotados, serão descritas as estruturas e condições de simulação e, finalmente, serão analisados os resultados obtidos.

\subsection{Descrição do simulador}

O programa Atlas pode ser usado em conjunto com outras aplicações focadas em simulação de processos e estruturas, conforme ilustrado na Figura 3.1. Este trabalho focou os esforços na preparação dos arquivos de comandos de entrada e na análise dos resultados gerados ${ }^{39}$. 


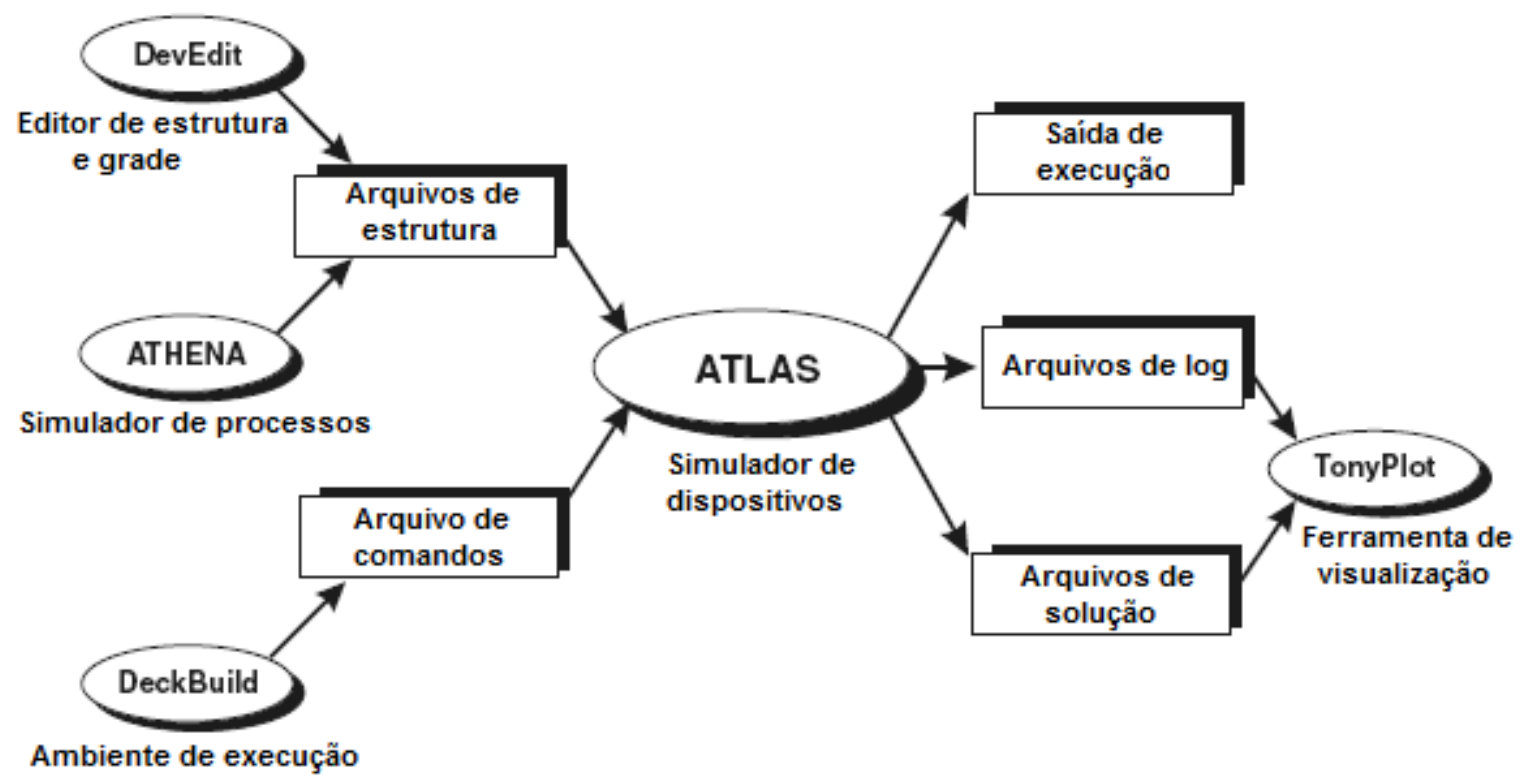

Figura 3.1 Representação dos blocos de entrada e saída do programa Atlas.

\subsection{Definição dos modelos adotados}

Este item detalhará a escolha dos modelos dos mecanismos de transporte escolhidos para execução das simulações dos TFETs considerados. Para cada modelo analisado é apresentado o respectivo equacionamento, no qual as variáveis de entrada do programa aparecem codificadas por letras maiúsculas seguidas.

Inicialmente são comparados os diferentes modelos físicos disponíveis para o fenômeno da corrente de tunelamento de banda para banda (BBT). De modo geral, o mecanismo de geração de portadores na banda de condução por tunelamento é dado pela equação $(3-1)^{40}$.

$$
G_{B B T}=(\text { BB.A }) F^{\text {BB.GAMMA }} \exp \left(-\frac{\text { BB.B }}{F}\right)
$$

onde $F$ é a magnitude do campo elétrico e BB.A, BB.B e BB.GAMMA são parâmetros definidos pelo usuário. $O$ programa prevê dois conjuntos distintos de parâmetros com base em diferentes aplicações.

O modelo padrão (BBT.STD) é adequado para semicondutores com transição direta como GaAs, e admite como padrão os valores indicados por (3-2 $)^{41}$. 
BB. $A=9,6615 \times 10^{18} \quad$ BB.B $=3,0 \times 10^{7}$ V $/ \mathrm{cm} \quad$ BB.GAMMA $=2,0$

Para semicondutores com transição indireta, como Si e $\mathrm{Ge}$, o modelo de Klaassen (BBT.KL) adota os valores iniciais de (3-3) ${ }^{42}$.

$$
\text { BB.A }=4,00 \times 10^{14} \quad \text { BB.B }=1,9 \times 10^{7} \mathrm{~V} / \mathrm{cm} \quad \text { BB.GAMMA }=2,5
$$

Vale salientar que estas equações simplificam o modelo geral de Kane, omitindo a influência da temperatura.

Como uma das análises previstas para este trabalho inclui a questão do impacto desta variável, foi adotado um modelo de Kane mais completo $(B B T . K A N E)^{43}$. Ao invés de considerar uma constante na componente exponencial como nos modelos anteriores, a equação de Kane inclui a largura da faixa proibida $E_{g}$, que apresenta ligeira flutuação com a temperatura. A equação completa é indicada por (3-4).

$$
G_{B B T}=\frac{(\text { BBT.A_KANE) }}{\sqrt{E_{g}}} F^{\text {BBT.GAMmA }} \exp \left[-(\text { BBT.B_KANE }) \frac{E_{g}^{\frac{3}{2}}}{F}\right]
$$

onde $E_{g}$ é a largura da faixa proibida dependente da temperatura, $F$ é a magnitude do campo elétrico e BBT.A_KANE, BBT.B_KANE e BBT.GAMMA são parâmetros definidos pelo usuário.

Os valores numéricos padrão destes parâmetros são apresentados em (3-5).

$$
\text { BBT.A_KANE }=3,5 \times 10^{21} \quad \text { BBT.B_KANE }=2,25 \times 10^{7} \quad \text { BBT.GAMMA=2,5 (3-5) }
$$

Enquanto isso, a corrente de recombinação prevista por Schockley-ReadHall, também explicada teoricamente em 2.2, é modelada conforme (3-6).

$$
R_{S R H}=\frac{p n-n_{i}^{2}}{\operatorname{TAUP} 0\left[n+n_{i} \exp \left(\frac{\mathrm{ETRAP}}{k T_{L}}\right)\right]+\mathrm{TAUN} 0\left[p+n_{i} \exp \left(\frac{-\mathrm{ETRAP}}{k T_{L}}\right)\right]}
$$

onde ETRAP é a diferença entre o nível de energia da armadilha e o nível de Fermi intrínseco, $T_{L}$ é a temperatura da estrutura em Kelvin e TAUNO e TAUPO são os tempos de vida dos elétrons e das lacunas, respectivamente. Implementando o modelo SRH, TAUNO e TAUPO são definidos pelo usuário e tratados como 
constantes. Para estruturas de silício, são adotados como padrão os valores exibidos em (3-7).

$$
\text { ETRAP }=0 \mathrm{eV} \quad \text { TAUN0 }=1 \times 10^{-7} \mathrm{~s} \quad \text { TAUP0 }=1 \times 10^{-7} \mathrm{~s}
$$

Vale comparar a influência da temperatura na corrente BBT e na do SRH. Enquanto na primeira, a influência resume-se à variação na largura da faixa proibida, na segunda há menção explícita à temperatura no denominador do fator exponencial.

Finalmente, o modelamento da corrente de tunelamento induzido por armadilhas (TRAP.TUNNEL) é implementado matematicamente por uma correção do modelo $\mathrm{SRH}$, conforme a equação (3-8).

$$
R_{S R H}=\frac{p n-n_{i}^{2}}{\frac{\text { TAUP0 }}{1+\Gamma_{p}^{D I R A C}}\left[n+n_{i} \exp \left(\frac{\mathrm{ETRAP}}{k T_{L}}\right)\right]+\frac{\text { TAUN0 }}{1+\Gamma_{n}^{D I R A C}}\left[p+n_{i} \exp \left(\frac{-\mathrm{ETRAP}}{k T_{L}}\right)\right]}
$$

onde $\Gamma_{\mathrm{n}}{ }^{\text {DIRAC }}$ é o termo de incremento do campo dos elétrons para poços de Dirac e $\Gamma_{\mathrm{p}}^{\text {DIRAC }}$ é o de aumento do campo das lacunas para poços de Dirac, definidos conforme as equações (3-9) e (3-10) ${ }^{44}$.

$$
\begin{aligned}
& \Gamma_{n}^{\text {DIRAC }}=\frac{\Delta E_{n}}{k T_{L}} \int_{0}^{1} \exp \left(\frac{\Delta E_{n}}{k T_{L}} u-K_{n} u^{\frac{3}{2}}\right) d u \\
& \Gamma_{p}^{\text {DIRAC }}=\frac{\Delta E_{p}}{k T_{L}} \int_{0}^{1} \exp \left(\frac{\Delta E_{n}}{k T_{L}} u-K_{p} u^{\frac{3}{2}}\right) d u
\end{aligned}
$$

onde $\mathrm{u}$ é a variável de integração, $\Delta \mathrm{E}_{\mathrm{n}}$ é a faixa de energia para a qual há tunelamento de elétrons, $\Delta \mathrm{E}_{\mathrm{p}}$ é a faixa de energia para tunelamento de lacunas e $\mathrm{K}_{n}$ e $K_{p}$ são definidos por (3-11) e (3-12).

$$
K_{n}=\frac{4}{3} \frac{\sqrt{2 m_{0} \mathrm{MASS} . \mathrm{TUNNEL} \Delta E_{n}^{3}}}{3 q \hbar|E|}
$$




$$
K_{p}=\frac{4}{3} \frac{\sqrt{2 m_{0} \mathrm{MASS} . \mathrm{TUNNEL} \Delta E_{p}^{3}}}{3 q \hbar|E|}
$$

onde $\hbar$ é a constante de Planck reduzida $(h / 2 \pi), m_{0}$ é a massa do elétron em repouso e MASS.TUNNEL é a sua massa efetiva.

Comparando-se as equações (3-6) e (3-8), nota-se que o tunelamento induzido por armadilhas é implementado matematicamente através de uma correção na equação da corrente de recombinação prevista por Schockley-Read-Hall. Este ajuste leva em consideração os incrementos dos campos para elétrons e lacunas, baseado em faixas de energia onde ocorre tunelamento.

Em outras palavras, para que o efeito do tunelamento induzido por armadilhas tenha de fato efeito na simulação é necessário não apenas utilizar o modelo TRAP.TUNNEL, mas também garantir que a corrente de Schockley-ReadHall utilize o modelo denominado no Atlas por SRH. Modelos como o CONSRH ou o KLASRH, também disponíveis na mesma versão do simulador com equacionamento similar a (3-6), foram preteridos justamente porque não seriam devidamente alterados na implementação de (3-8).

Outro ponto relevante na análise do modelo TRAP.TUNNEL é que persiste a influência da temperatura diretamente na componente exponencial das equações de geração de cargas, o que poderá ser observado nos resultados obtidos nas simulações.

Ainda foi necessário definir outros modelos para compatibilizar as simulações deste trabalho com a literatura em quesitos relacionados à concentração de portadores, à ionização incompleta em baixas temperaturas, entre outros.

Os cálculos referentes às correntes de difusão e deriva foram baseados no modelo DRIFT.DIFF, derivado de desenvolvimento teórico de Boltzmann ${ }^{45}$. $\mathrm{Na}$ determinação destas correntes, a abordagem estatística da concentração de portadores utiliza o modelo FERMI, adequada para estruturas com regiões fortemente dopadas ${ }^{46}$. 
Além disso, foi levado em consideração o modelo de recombinação de Klaassen-Auger (KLAAUG), com coeficientes dependentes de variações na temperatura $^{47}$. Outro modelo implementado para compatibilizar resultados de simulações de dispositivos sob baixas temperaturas foi o que considera os efeitos da ionização incompleta nesta condição (INCOMPLETE) ${ }^{48}$.

A tabela 3.1 resume os modelos adotados para levar em consideração os fenômenos de tunelamento e o comportamento geral da estrutura quando submetida a ampla faixa de variação de temperatura.

Tabela 3.1. Modelos adotados para simulações dos dispositivos TFETs.

\begin{tabular}{|c|c|}
\hline Fenômeno físico & Modelo adotado \\
\hline Tunelamento de banda para banda & BBT.KANE \\
\hline Recombinação de Schockley-Read-Hall & SRH \\
\hline Tunelamento induzido por armadilhas & TRAP.TUNNEL \\
\hline Correntes de difusão e deriva & DRIFT.DIFF \\
\hline Estatística da concentração de portadores & FERMI \\
\hline Recombinação de Klaassen-Auger & KLAAUG \\
\hline lonização incompleta sob baixas temperaturas & INCOMPLETE \\
\hline
\end{tabular}

\subsection{Otimização da estrutura simulada}

Os dispositivos simulados neste trabalho consistem basicamente numa estrutura p-i-n com canal controlado por porta dupla. Seguindo a terminologia amplamente utilizada na literatura para dispositivos do tipo $\mathrm{n}$, o dreno corresponde à região com dopagem do tipo $\mathrm{n}$ de $10^{20} \mathrm{~cm}^{-3}$, o canal à região apenas com a dopagem natural da lâmina $\left(10^{15} \mathrm{~cm}^{-3}\right)$ e a fonte corresponde à dopagem do tipo $p$ 
de $10^{20} \mathrm{~cm}^{-3}$. Um pTFET poderia ser obtido apenas com a inversão da polarização de porta e das regiões $p+e n+$.

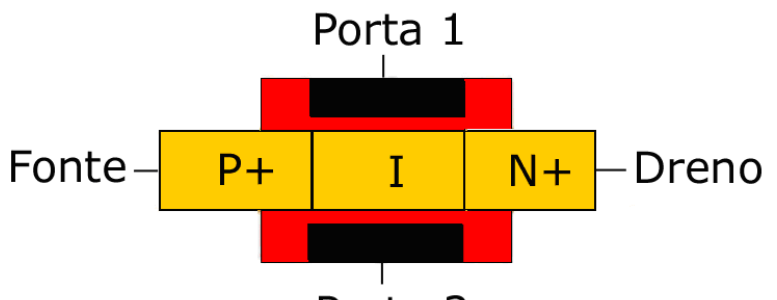

Porta 2

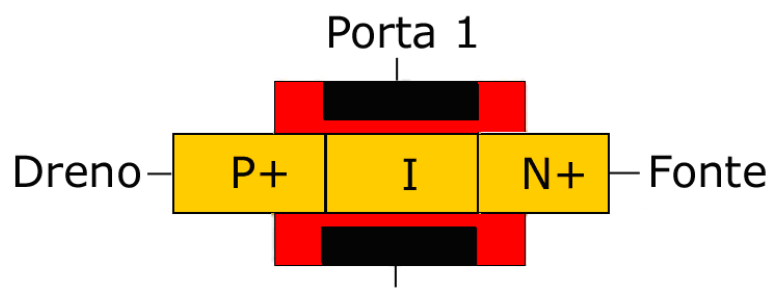

Porta 2

(A)

Figura 3.2 Seção transversal de transistores de porta dupla e estrutura nTFET (A) e pTFET (B).

A estrutura simulada apresenta espessura do óxido de porta $\left(\mathrm{t}_{\mathrm{ox}}\right)$ de $2 \mathrm{~nm}$, espessura da camada de silício $\left(t_{s i}\right)$ de $25 \mathrm{~nm}$ e comprimento de canal $\left(L_{c h}\right)$ de 165nm. O material adotado para a porta apresenta função trabalho de 4,7eV. Estes valores foram utilizados de modo a compatibilizar as simulações com outras da literatura, de modo a facilitar as validações e as análises dos resultados obtidos ${ }^{6}$.

A parte inicial do estudo das simulações consistiu na otimização da estrutura do TFET de maneira a minimizar o efeito ambipolar, já explicado em 2.3. Com este intuito, foram comparadas estruturas com sobreposição (overlap) e subposição (underlap) de.porta.

Conforme indicado na Figura 3.3, no lado da porta próximo à junção fonte/canal foi deixada uma sobreposição fixa de 10nm. Entretanto, do lado do dreno foi variado o parâmetro $\Delta \mathrm{L}_{G}$, onde $\Delta \mathrm{L}_{G}>0$ indicava sobreposiçãoda região de porta, $\Delta \mathrm{L}_{\mathrm{G}}<0$ indicava subposição e $\Delta \mathrm{L}_{\mathrm{G}}=0 \mathrm{~nm}$ referia-se à condição de autoalinhamento de porta. Neste trabalho, $\Delta \mathrm{L}_{\mathrm{G}}$ foi variado de $-80 \mathrm{~nm}$ a $+10 \mathrm{~nm}$.

Enquanto isso, a estrutura de porta dupla foi proposta para atenuar o já comentado efeito de baixo $\mathrm{I}_{\mathrm{ON}}$ e as longas regiões de fonte e dreno foram projetadas para oferecer a possibilidade de avaliação de influências de resistência série induzida pela dopagem. A estrutura final simulada é ilustrada, como já mencionado, na Figura 3.3. 


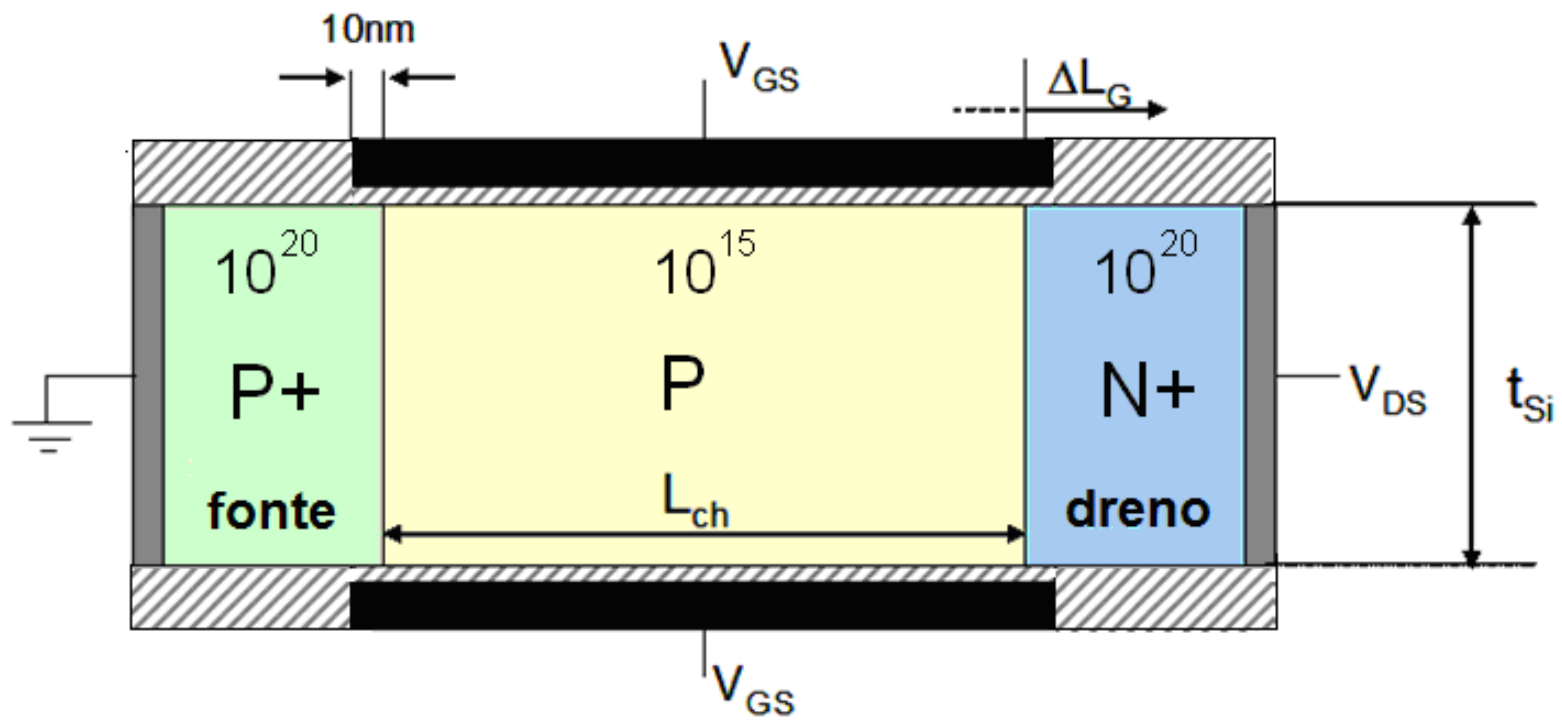

Figura 3.3 Estrutura dos dispositivos simulados.

Definida a estrutura estudada, foram escolhidos ainda os valores de tensão para polarização de dreno e porta. Para ocorrência do tunelamento, aplicou-se tensão de dreno de cerca de $0,4 \mathrm{~V}$ e tensão de porta variável de $-1 \mathrm{~V}$ a $+1 \mathrm{~V}$. Com valores positivos de $V_{G S}$, foram observadas as correntes $B B T$, conforme explicado em 2.2. Valores negativos de tensão de porta foram importantes para análise do impacto das dimensões da estrutura no efeito ambipolar.

Quanto à metodologia de simulações e análises, ainda é importante salientar que um parâmetro que será continuamente analisado como base de comparação de desempenho é a inclinação de sublimiar (S). Afinal, como já explicado na Figura 2.1, a redução neste parâmetro para valores menores do que o limite convencional de $60 \mathrm{mV} /$ década é representativa da motivação que levou aos primeiros estudos desta tecnologia e ainda norteia os projetos de novos dispositivos.

A Figura 3.4 apresenta o diagrama de bandas de energia para $V_{D S}=0,4 \mathrm{~V}$ e $\mathrm{V}_{\mathrm{GS}}$ variando de 0 a $1 \mathrm{~V}$. 


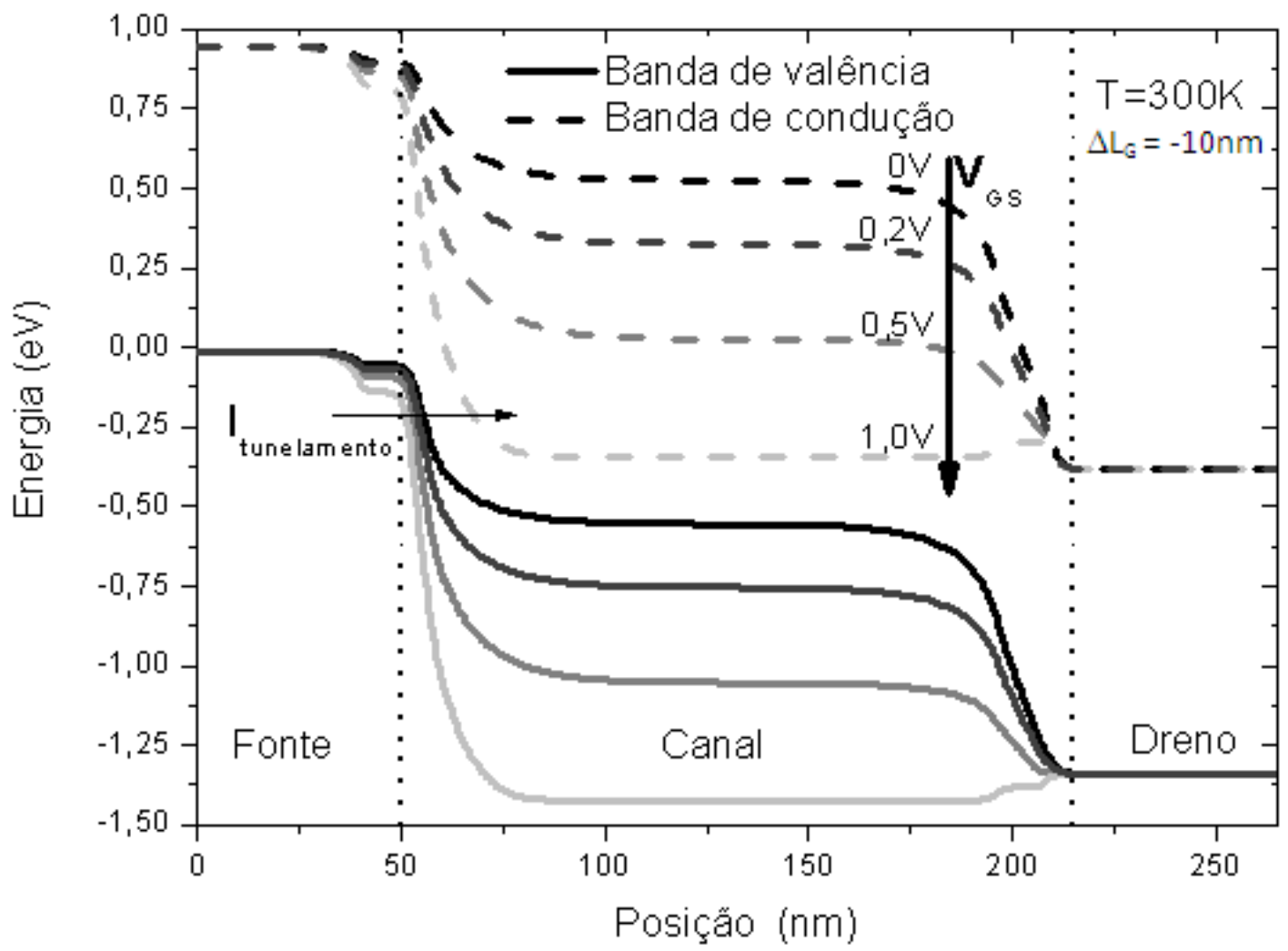

Figura 3.4 Diagrama de bandas de energia para diferentes valores de tensão de porta.

A variação dos níveis de energia em função da variação da tensão de porta deixa claro novamente como o fenômeno do tunelamento é facilitado pelo aumento da tensão de porta. Os diagramas também evidenciam a concentração do efeito na região próxima à junção entre fonte e canal.

Esse comportamento também pode ser ilustrado pela análise da densidade de corrente em cada ponto da estrutura, conforme indicado pela Figura 3.5. Nesse caso, é apresentada a condição de polarização para tunelamento maximizado, isto é, com $V_{D S}=0,4 \mathrm{~V}$ e $V_{G S}=1,0 \mathrm{~V}$.

Além de ser possível observar os picos de densidade de corrente próximos à fonte, nota-se ainda que não é muito grande o acoplamento entre as áreas sob influência de cada uma das portas. Isso justifica a proposta de que a corrente total deste dispositivo será aproximadamente o dobro da corrente que seria obtida em caso de simulação com porta simples. 


\section{$\mathrm{I}\left(\mathrm{A} / \mathrm{cm}^{2}\right)$}

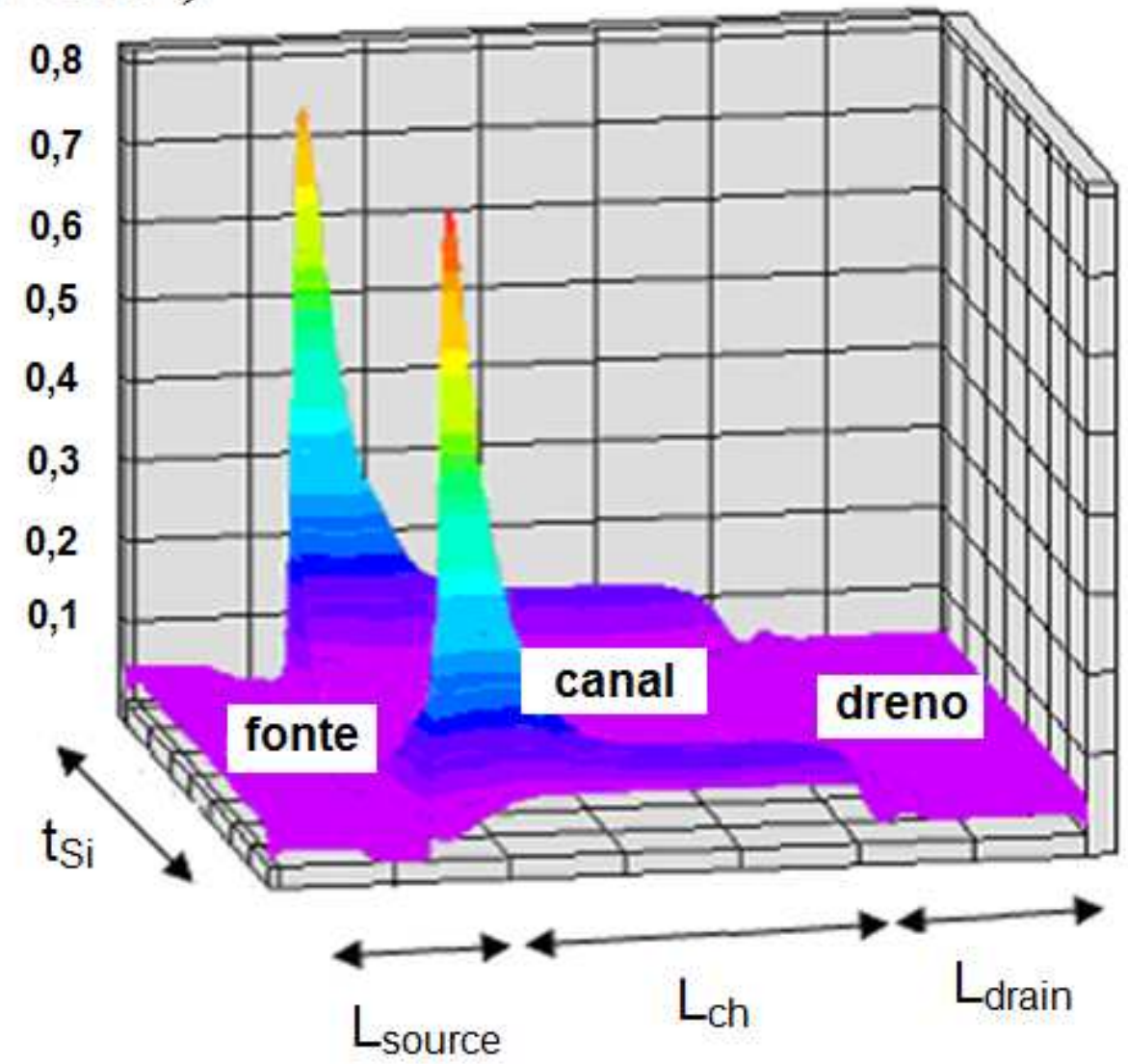

Figura 3.5 Densidade de corrente na estrutura simulada para $\mathrm{V}_{\mathrm{DS}}=0,4 \mathrm{~V}$ e $\mathrm{V}_{\mathrm{GS}}=1 \mathrm{~V}$.

Após esta comparação preliminar entre 0 desenvolvimento teórico apresentado e os resultados de simulação para uma condição de polarização determinada, o trabalho voltou-se à realização de múltiplas simulações para a otimização da estrutura.

O parâmetro físico enfocado nesta análise foi o comprimento da porta, mais especificamente quanto à sobreposição (overlap) ou subposição (underlap) em relação à junção canal/dreno. $\mathrm{O}$ valor de $\Delta \mathrm{L}_{\mathrm{G}}$ foi variado de $-80 \mathrm{~nm}$ (subposição) a +10nm (sobreposição). A Figura 3.6 representa as estruturas correspondentes a três diferentes valores de $\Delta \mathrm{L}_{\mathrm{G}}$. 


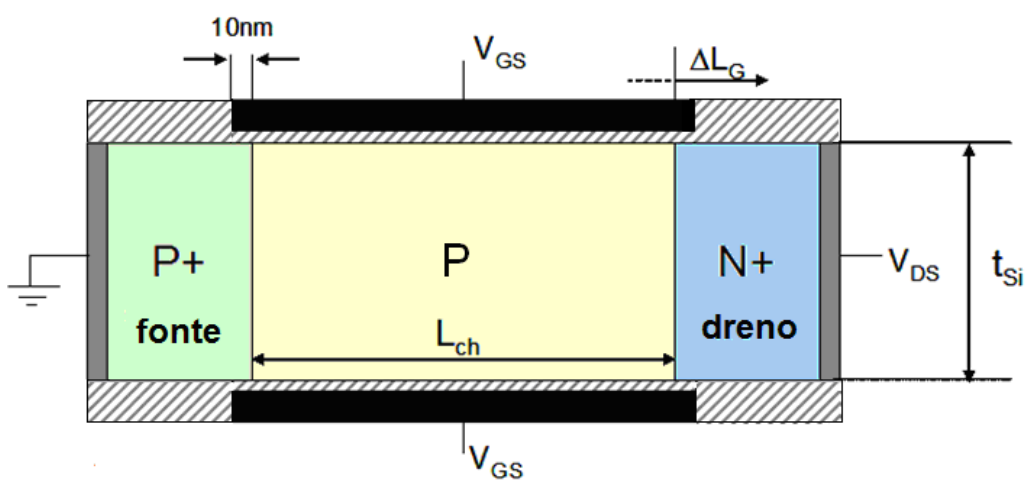

$$
\text { (A) } \Delta \mathrm{L}_{\mathrm{G}}=+10 \mathrm{~nm}
$$

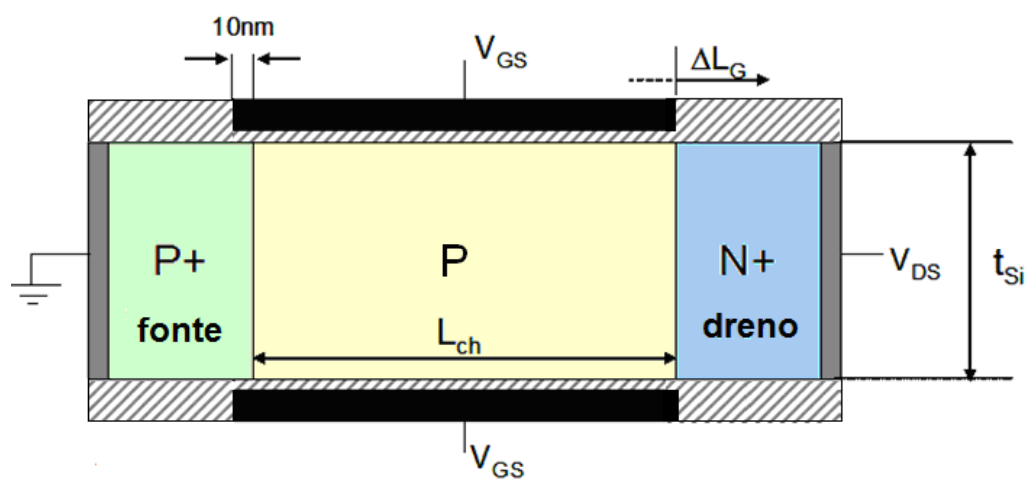

(B) $\Delta \mathrm{L}_{\mathrm{G}}=0 \mathrm{~nm}$

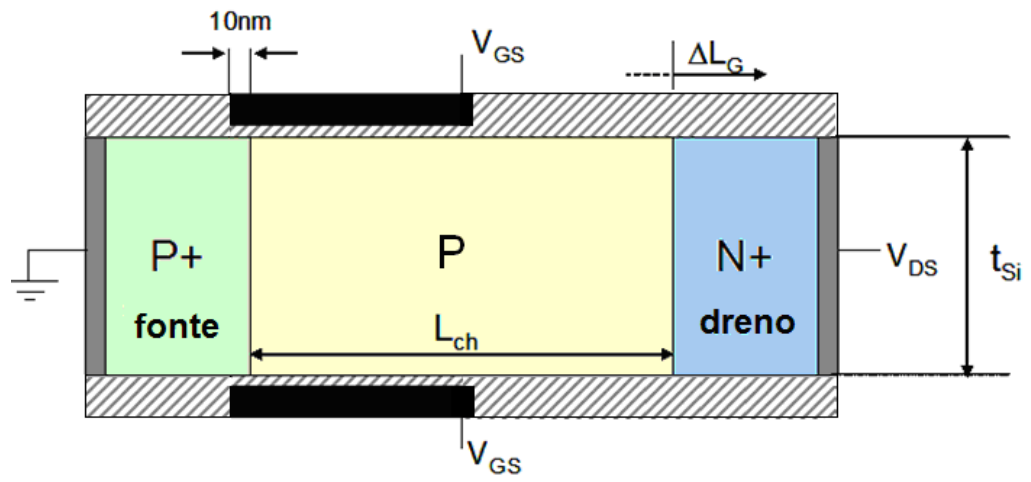

(C) $\Delta \mathrm{L}_{\mathrm{G}}=-80 \mathrm{~nm}$

Figura 3.6 Estrutura de dipositivos com (A) sobreposição, (B) auto-alinhamento e (C) subposição de porta em relação ao dreno

Vale lembrar que uma solução otimizada deve apresentar um bom compromisso entre os dois principais desafios da tecnologia do TFET, notadamente o efeito ambipolar e a baixa corrente $\mathrm{I}_{\mathrm{ON}}$, conforme 2.3. Desse modo, foram comparadas as curvas da corrente de dreno em função da tensão de porta para diferentes valores de $\Delta \mathrm{L}_{\mathrm{G}}$.

Observou-se que os resultados para $\Delta \mathrm{L}_{\mathrm{G}}=10 \mathrm{~nm}$ coincidiam com os obtidos no caso de $\Delta \mathrm{L}_{\mathrm{G}}=0 \mathrm{~nm}$. Já para $\Delta \mathrm{L}_{\mathrm{G}}<-30 \mathrm{~nm}$, a curva passava a ser pouco dependente de $\Delta \mathrm{L}_{\mathrm{G}}$. Considerando estas observações, a Figura 3.7 exibe os resultados obtidos para $\Delta \mathrm{L}_{\mathrm{G}}$ entre $-30 \mathrm{~nm}$ e $0 \mathrm{~nm}$. 


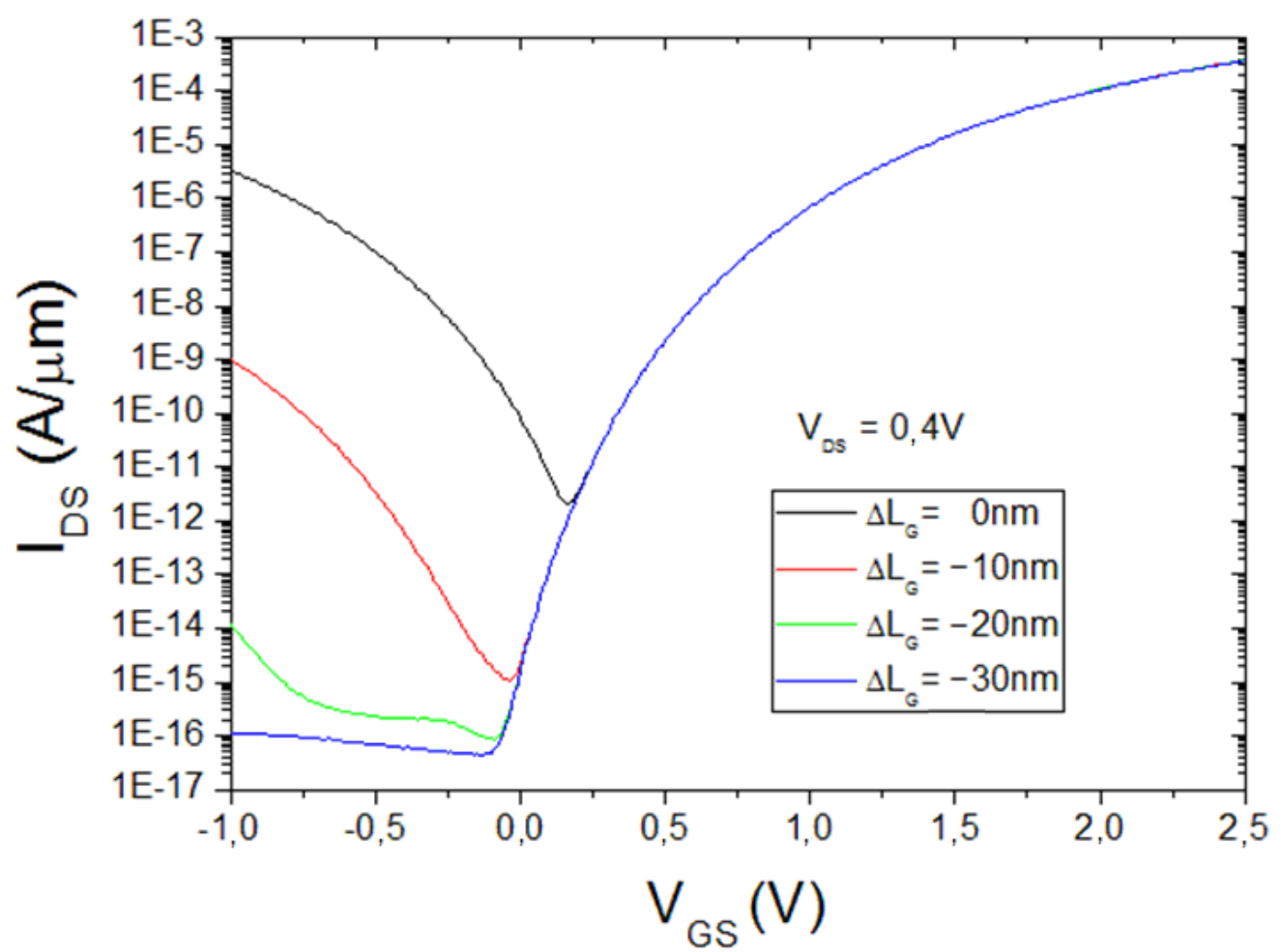

Figura 3.7 Corrente de dreno ( $\left.\mathrm{IDS}_{\mathrm{DS}}\right)$ em função da tensão de porta $\left(\mathrm{V}_{\mathrm{GS}}\right)$ para diferentes valores de $\Delta \mathrm{L}_{\mathrm{G}}$.

As curvas mostram que o valor de $\Delta \mathrm{L}_{\mathrm{G}}$ não interfere no tunelamento para elevada tensão de porta, uma vez que o fenômeno ocorre na região próxima à junção fonte/canal.

Por outro lado, há uma forte dependência da magnitude da corrente ambipolar em relação a $\Delta \mathrm{L}_{\mathrm{G}}$. Para $\mathrm{V}_{\mathrm{GS}}=-1,0 \mathrm{~V}$, por exemplo, há cerca de 10 ordens de grandeza de diferença entre a corrente de dreno dos dois casos extremos representados da figura. Além do claro prejuízo ao desempenho desse tipo de dispositivo em aplicações digitais, o efeito ambipolar muito elevado $\left(\Delta \mathrm{L}_{\mathrm{G}}=0 \mathrm{~nm}\right)$ ainda impede que o transistor opere na sua condição de mínima inclinação de sublimiar, que ocorre para $V_{\mathrm{GS}}$ entre $0,0 \mathrm{~V}$ e $0,1 \mathrm{~V}$ no caso analisado.

Em termos quantitativos, os dispositivos com $\Delta \mathrm{L}_{\mathrm{G}}$ de $-20 \mathrm{~nm}$ e $-30 \mathrm{~nm}$ apresentam valores de $S$ de 47 a $63 \mathrm{mV} /$ década para $V_{G S}$ entre 0 e $0,1 \mathrm{~V}$. No outro extremo, a curva para $\Delta \mathrm{L}_{\mathrm{G}}=0 \mathrm{~nm}$ tem mínima inclinação de sublimiar para $V_{G S}$ na faixa de 0,2 a 0,3V, para a qual $\mathrm{S}$ sobe para valores entre 78 e $97 \mathrm{mV} /$ década.

Levando em consideração que grandes valores de subposição poderiam levar a uma diminuição de lon para alta tensão de porta em virtude de aumento da 
taxa de recombinação ${ }^{49}$, um dispositivo de $20 \mathrm{~nm}$ de subposição foi considerado satisfatório para combinar mínima tensão de sublimiar e máximo loN.

\subsection{Impacto da temperatura e dos mecanismos de transporte de corrente}

Após a definição da estrutura simulada, serão avaliadas as influências da variação da temperatura e de cada uma das componentes individuais da corrente (BBT, SRH e TAT). Inicialmente, o dispositivo de $\Delta \mathrm{L}_{G}=-20 \mathrm{~nm}$ foi simulado para temperaturas de $150 \mathrm{~K}$ a $400 \mathrm{~K}$, considerando a corrente de tunelamento completa, conforme resultados ilustrados na Figura 3.8.

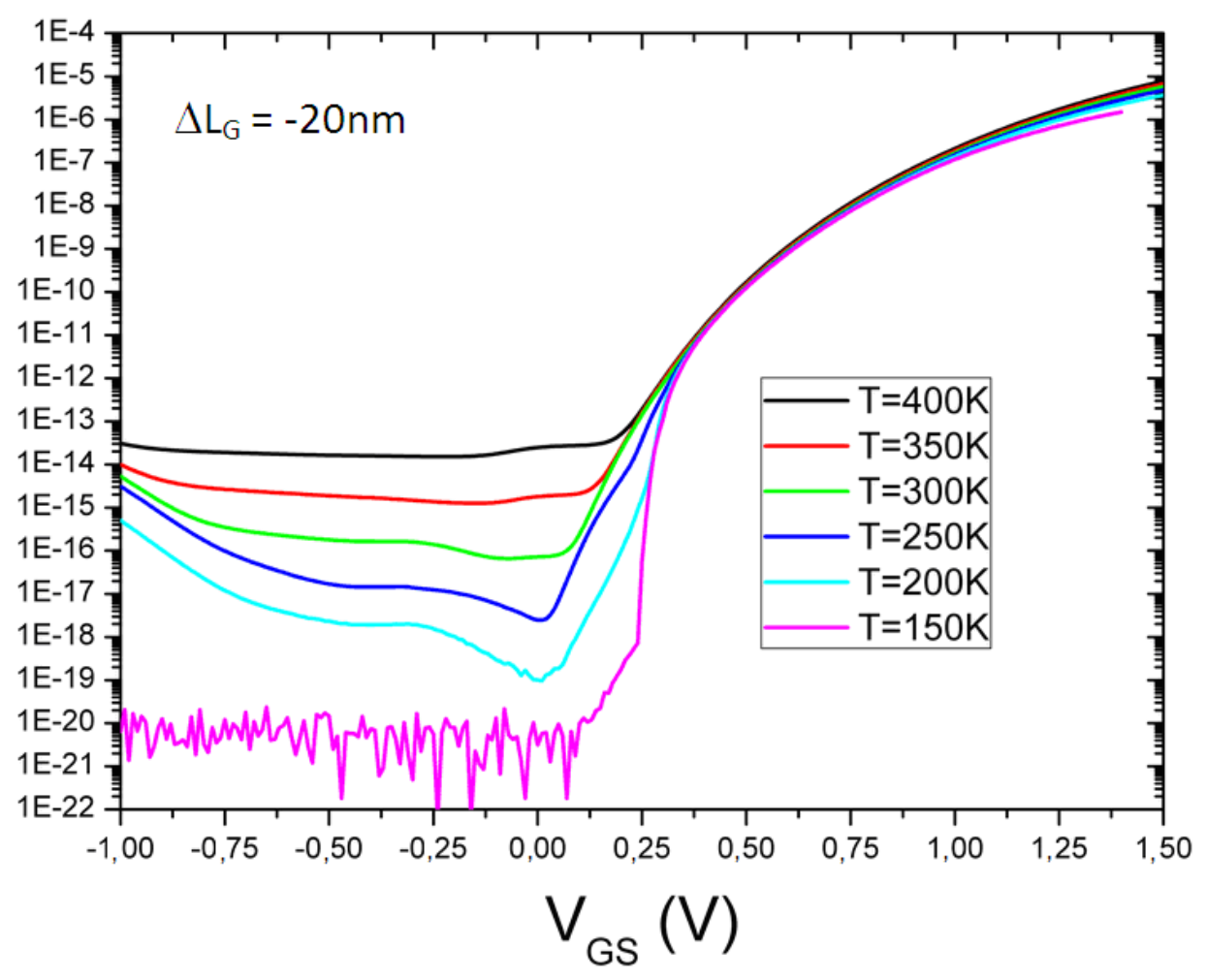

Figura 3.8 Corrente de dreno ( $\left.\mathrm{I}_{\mathrm{DS}}\right)$ em função da tensão de porta $\left(\mathrm{V}_{\mathrm{GS}}\right)$ para temperatura na faixa de $150 \mathrm{~K}$ a $400 \mathrm{~K}$.

Nota-se que à medida que a temperatura aumenta, a corrente de dreno também é incrementada. Entretanto, a maneira como cada trecho das curvas varia com a temperatura é bem distinta. Para valores de tensão de porta mais elevados, a diferença é bastante sutil, enquanto que para valores menores há um distanciamento mais claro entre as curvas. 
Esta observação pode ser explicada focando a análise em cada um dos três principais mecanismos de transporte de corrente. Para alto $\mathrm{V}_{\mathrm{GS}}$, predomina a corrente BBT, isto é, de tunelamento de banda para banda, a qual é influenciada pela temperatura apenas pelo estreitamente da largura da faixa proibida entre as bandas de condução e de valência. Para menor polarização na porta, passam a predominar os mecanismos de TAT e de SRH, dependentes exponencialmente da temperatura. Nesse caso, o aumento da temperatura é responsável por um considerável incremento na corrente $\mathrm{I}_{\mathrm{OFF}}$, o que é considerado uma desvantagem quanto à performance do dispositivo.

Além de prejudicar a relação $\mathrm{I}_{\mathrm{ON}} / \mathrm{I}_{\mathrm{OFF}}$, o aumento da temperatura exige que seja aplicada uma maior tensão na porta para que a corrente BBT passe a predominar. Isto também deve ser observado com preocupação, uma vez que é este mecanismo que seria responsável pela obtenção dos desejados diminutos valores de inclinação de sublimiar, devendo, portanto, ter sua ação ampliada tanto quanto possível.

Depois desta avaliação da temperatura, serão incluídas análises quanto à necessidade de definição dos modelos otimizados para cálculo das corrente de BBT, SRH e TAT.

Inicialmente, a estrutura com $\Delta \mathrm{L}_{\mathrm{G}}=-20 \mathrm{~nm}$ foi simulada para $200 \mathrm{~K}, 300 \mathrm{~K} \mathrm{e}$ $400 \mathrm{~K}$, de modo que, para cada temperatura, foram comparadas três diferentes combinações de modelos. Uma possibilidade incluía o modelo BBT escolhido como o ideal para este trabalho em 3.2, outra adicionava ao BBT o modelo otimizado do $\mathrm{SRH}$ e uma terceira também considerada o modelo da corrente por TAT. As nove curvas resultantes destas simulações estão representadas na Figura 3.9.

Comparando um trio de curvas sob uma mesma temperatura para avaliar o impacto dos modelos de mecanismos de transporte, notamos que menores valores

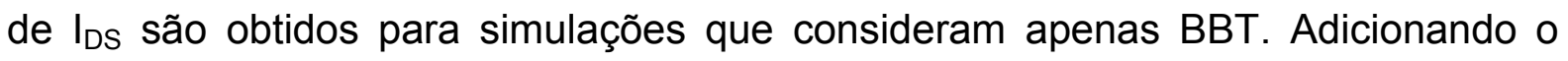
efeito do $\mathrm{SRH}$, os cálculos dos parâmetros de geração/recombinação levam a um incremento na corrente. Esse aumento é ainda maior com o efeito TAT, que adiciona um fator de correção ao tempo de vida das lacunas e dos elétrons, simulando o efeito das armadilhas da estrutura. 
Escolhendo-se a seguir um trio de curvas com os mesmos modelos para avaliação do efeito da temperatura, observa-se comportamento compatível com a análise da Figura 3.8, isto é, com aumento da corrente e piora no efeito ambipolar causados por uma temperatura mais elevada. Em termos de susceptibilidade à variação de temperatura, a corrente ambipolar apresentou-se muito mais dependente, visto que é composta, na faixa de tensão de porta analisada, majoritariamente por TAT e SRH, bem mais influenciados pela temperatura.

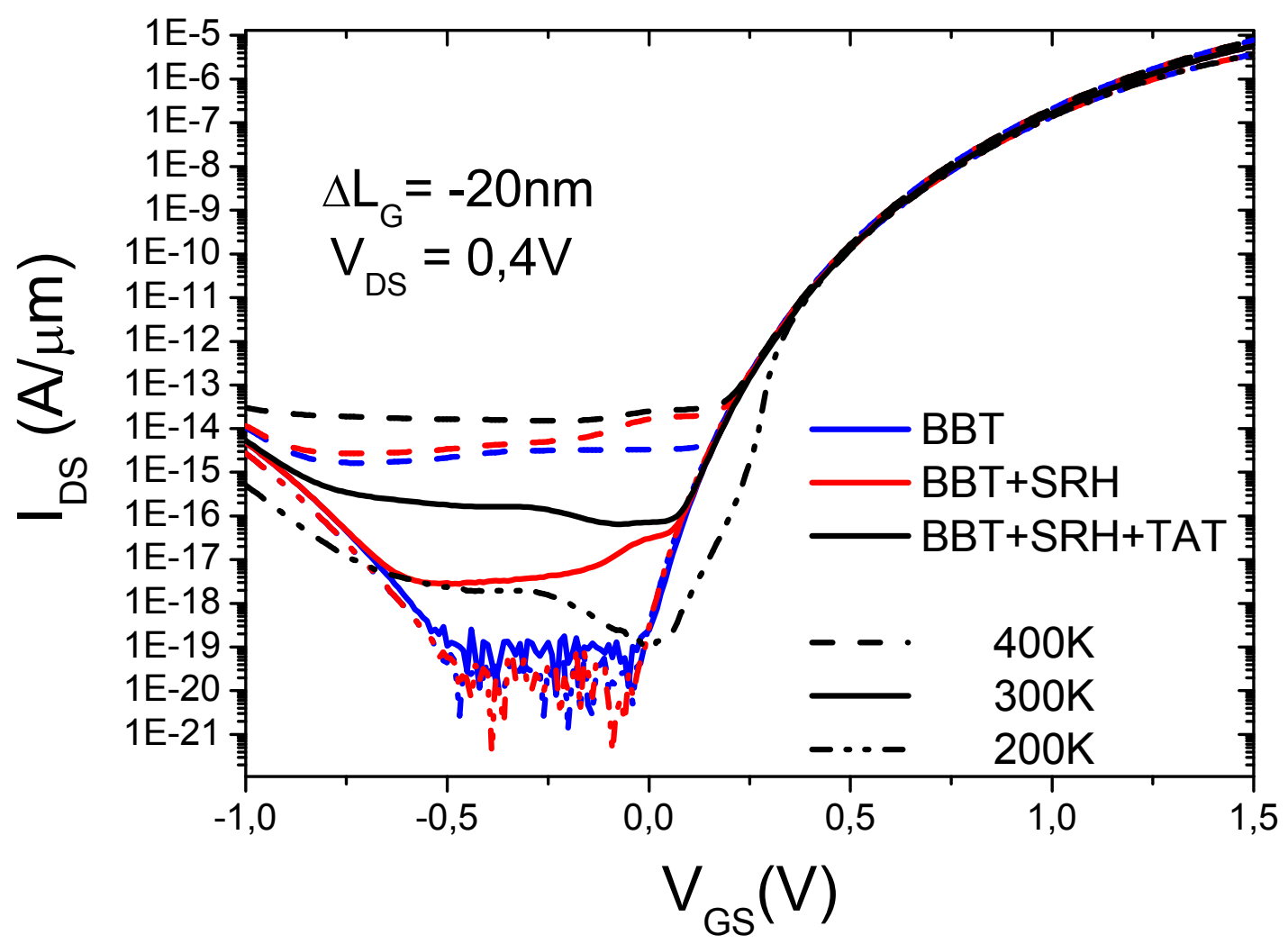

Figura 3.9 Corrente de dreno ( $\left.\mathrm{I}_{\mathrm{DS}}\right)$ em função da tensão de porta $\left(\mathrm{V}_{\mathrm{GS}}\right)$ para temperatura na faixa de $200 \mathrm{~K}$ a $400 \mathrm{~K}$ e $\Delta \mathrm{L}_{\mathrm{G}}=-20 \mathrm{~nm}$.

A etapa seguinte do trabalho consistiu na repetição da análise realizada sobre a Figura 3.9 para outras duas configurações de dispositivos não otimizados, uma com $\Delta \mathrm{L}_{\mathrm{G}}=-10 \mathrm{~nm}$ (Figura 3.10) e outra com $\Delta \mathrm{L}_{\mathrm{G}}=0 \mathrm{~nm}$ (Figura 3.11).

Com base no estudo já apresentado até este ponto, o trabalho propõe que essas estruturas alternativas induzam a corrente ambipolar a também ter uma significativa participação do tunelamento de banda para banda. Dessa maneira, espera-se que o impacto da temperatura no comportamento de cada um desses dispositivos também seja alterado quando comparado à estrutura otimizada. 


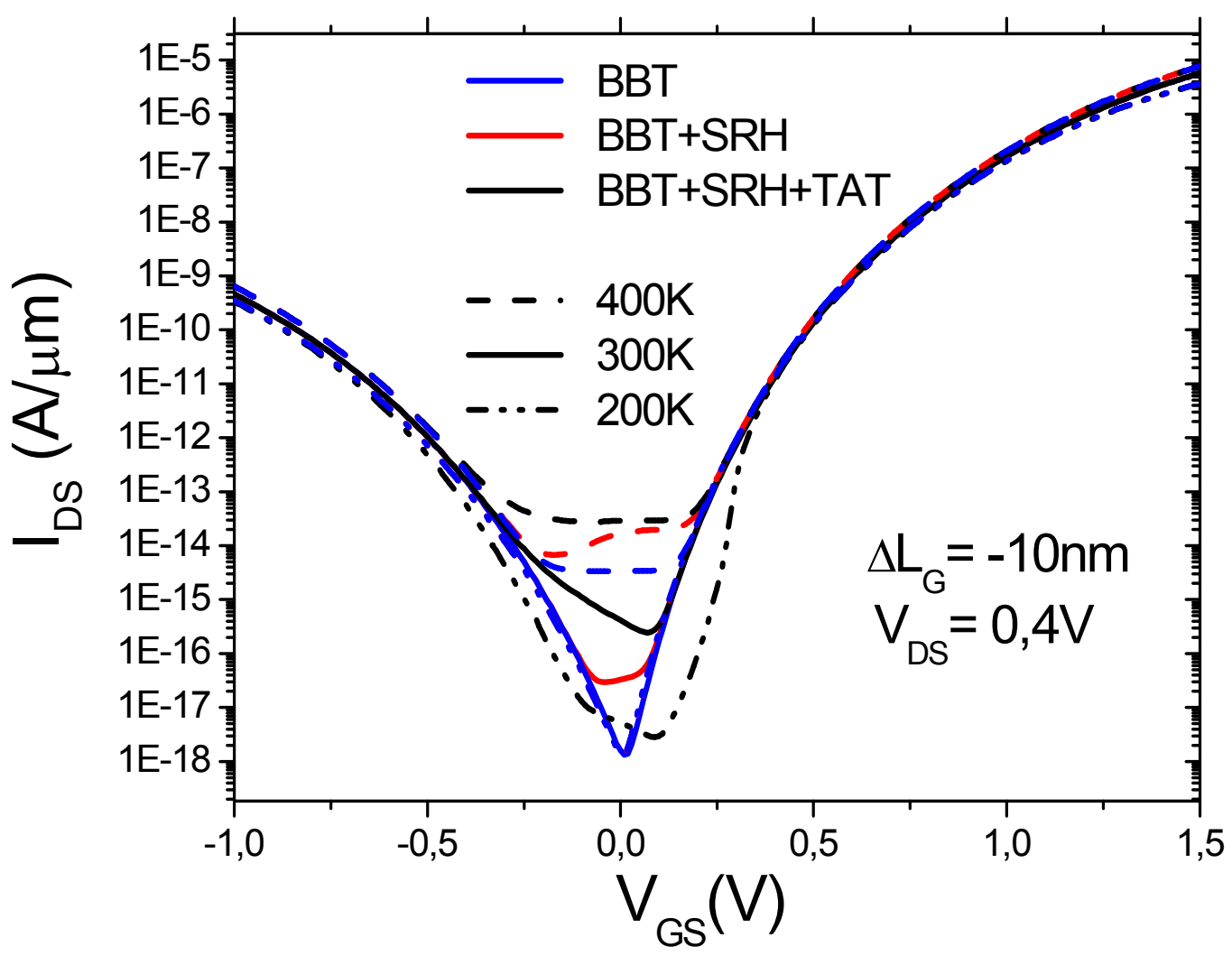

Figura 3.10 Corrente de dreno $\left(\mathrm{I}_{\mathrm{DS}}\right)$ em função da tensão de porta $\left(\mathrm{V}_{\mathrm{GS}}\right)$ para temperatura na faixa de $200 \mathrm{~K}$ a $400 \mathrm{~K}$ e $\Delta \mathrm{L}_{\mathrm{G}}=-10 \mathrm{~nm}$.

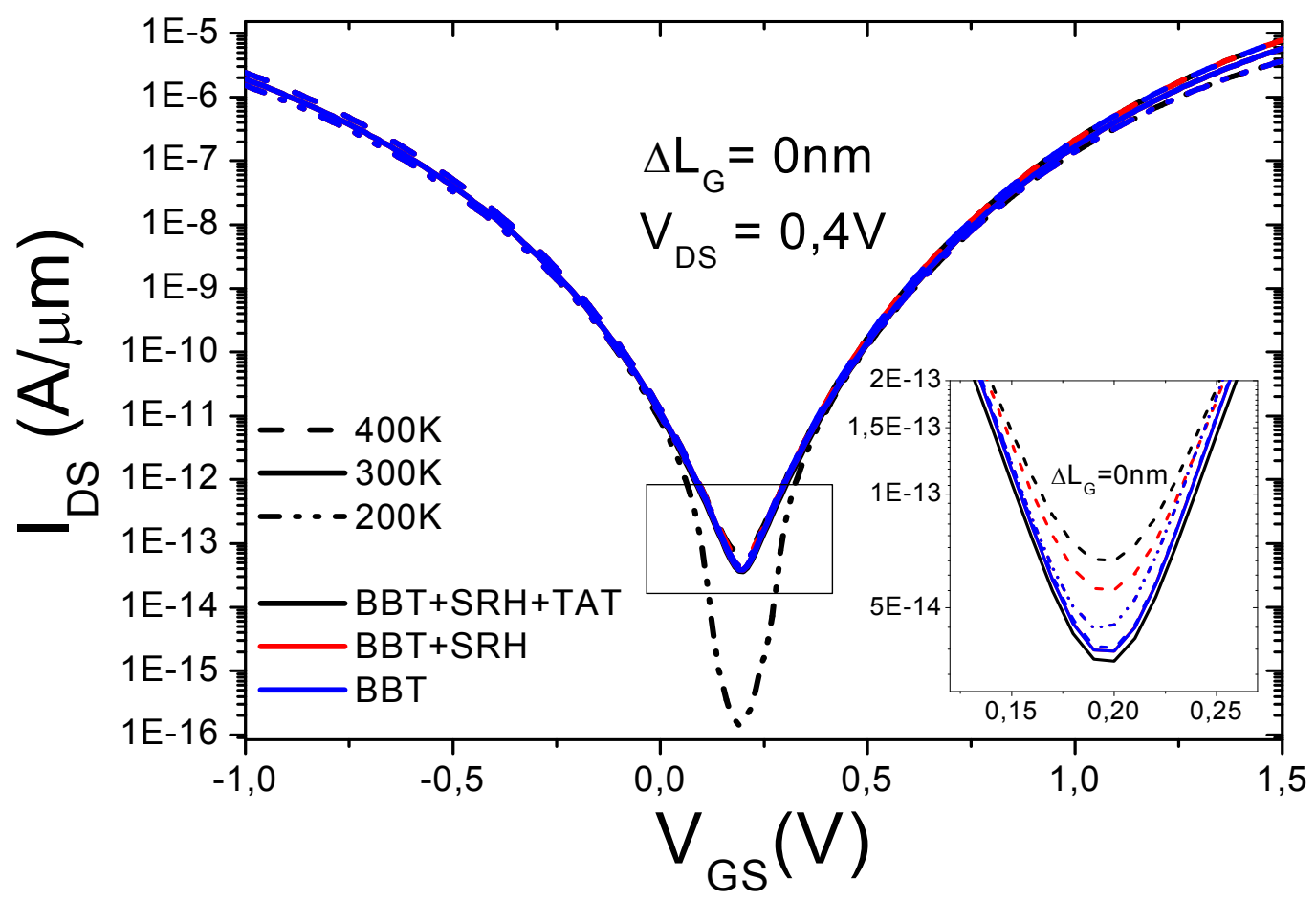

Figura 3.11 Corrente de dreno ( $\left.\mathrm{DSS}_{\mathrm{DS}}\right)$ em função da tensão de porta $\left(\mathrm{V}_{\mathrm{GS}}\right)$ para temperatura na faixa de $200 \mathrm{~K}$ a $400 \mathrm{Ke} \Delta \mathrm{L}_{\mathrm{G}}=0 \mathrm{~nm}$. 
Efetivamente, à medida que o efeito da subposição é suprimido, o efeito ambipolar é facilitado. Isto significa que valores negativos de tensão de porta deslocaram os diagramas de energia para a condição em que há tendência de tunelamento na junção canal/dreno. As consequências disso refletem na magnitude da corrente ambipolar, indesejavelmente ampliada, e na dependência em relação à variação da temperatura.

As curvas na Figura 3.10 mostram que para $V_{G S}$ na faixa de $-0,3 \mathrm{~V}$ a $0,2 \mathrm{~V}$ aproximadamente ainda há clara influência das correntes de SRH e TAT. Nessa condição, portanto, nota-se uma clara distinção entre as curvas referentes a cada temperatura.

Enquanto isso, na situação de porta auto-alinhada com a junção canal/dreno, a corrente BBT é predominante virtualmente ao longo de toda a faixa de $\mathrm{V}_{\mathrm{GS}}$. $\mathrm{O}$ impacto da temperatura torna-se pouco significativo, mantendo corrente ligeiramente maiores com o aumento da temperatura, com exceção de uma estreita faixa de tensão para o caso de $200 \mathrm{~K}$.

Para facilitar a análise da influência das dimensões, a Figura 3.12 mostra as curvas referentes aos três valores de $\Delta \mathrm{L}_{\mathrm{G}}$ e de temperatura analisados, sempre considerando a modelagem para BBT, SRH e TAT.

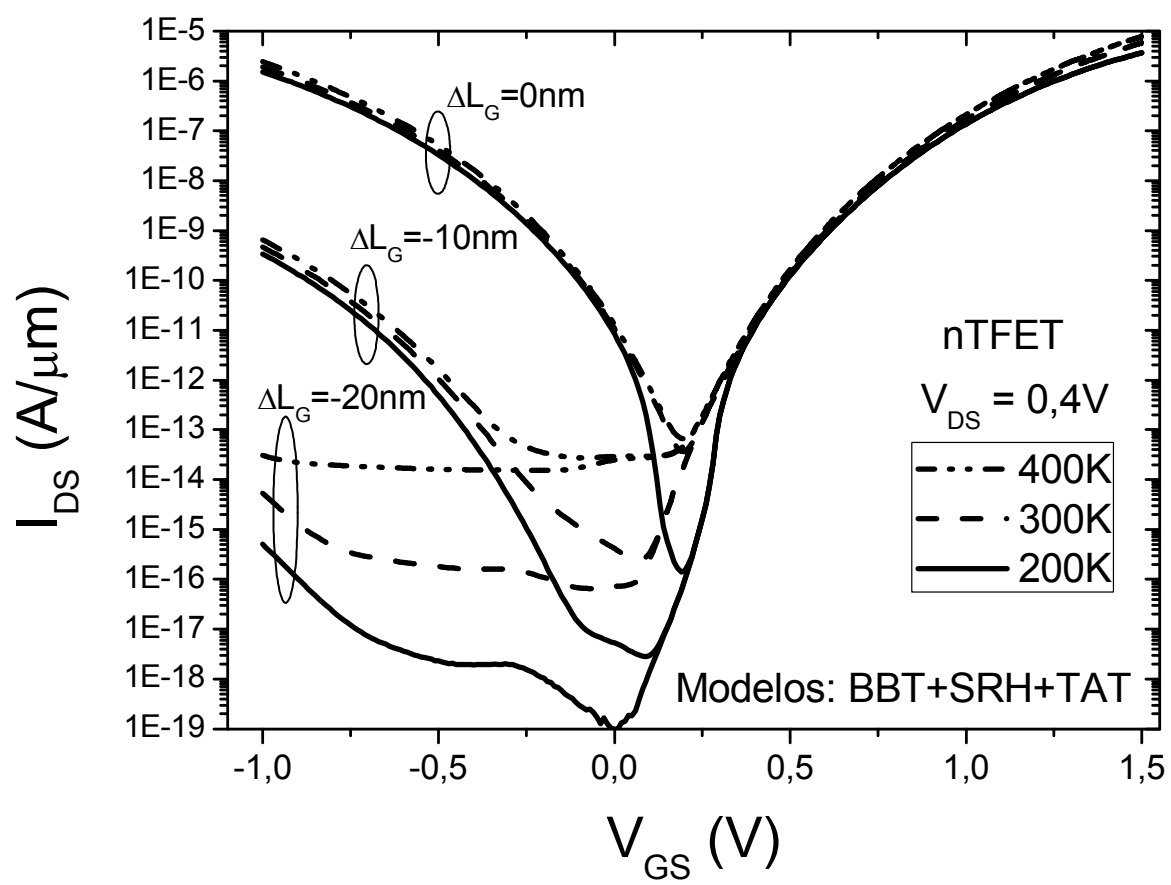

Figura 3.12 Corrente de dreno ( $\mathrm{IDS}_{\mathrm{DS}}$ em função da tensão de porta $\left(\mathrm{V}_{\mathrm{GS}}\right)$ para temperatura na faixa de $200 \mathrm{~K}$ a $400 \mathrm{~K}$ e $\Delta \mathrm{L}_{\mathrm{G}}$ variando de $-20 \mathrm{~nm}$ a $0 \mathrm{~nm}$. 
Pode-se resumir as análises realizadas, portanto, descrevendo que 0 aumento na subposição melhora o desempenhos dos dispositivos pela minimização da corrente ambipolar, a qual passa a ser composta predominantemente por efeitos como TAT e SRH, menos significativos que o BBT. A relação $\mathrm{I}_{\mathrm{ON}} / \mathrm{I}_{\mathrm{OFF}} \mathrm{e}$ a inclinação de sublimiar atuam como fatores quantitativos que permitiriam ainda uma conclusão numérica quanto à melhoria de desempenho dos TFETs em função destes parâmetros. 


\section{CARACTERIZAÇÃO ELÉTRICA E COMPARAÇÃO ENTRE RESULTADOS EXPERIMENTAIS E SIMULADOS DE DISPOSITIVOS PTFETS}

Neste capítulo são descritos os procedimentos práticos para a avaliação do desempenho de transistores de tunelamento controlados por efeito de campo já fabricados.

Dessa forma, além de validar as justificativas teóricas descritas nos capítulos anteriores, foi possível ajustar parâmetros das simulações e discutir a performance de pTFETs submetidos à variações de temperatura e de condições de polarização.

As medidas experimentais reportadas nesta etapa do trabalho foram realizadas no centro de pesquisas IMEC (Interuniversity Microelectronics Center) em Leuven, Bélgica. Foram utilizadas lâminas projetadas com estrutura similar à de transistores FinFETs, com ampla variedade de comprimento de canal, largura e quantidade de aletas (fins).

Todas as análises experimentais referem-se a estruturas com fonte, dreno e canal de silício, pois lâminas fabricadas mais recentemente com fonte de SiGe ainda apresentavam baixo rendimento, o que tornava análises mais específicas pouco conclusivas ${ }^{50}$. Além disso, assim como boa parte da literatura sobre o tema, foram privilegiados dispositivos do tipo $\mathrm{P}$, visto que o processo de dopagem com arsênio permite a obtenção de perfis mais abruptos do que com dopantes do tipo $\mathrm{N}^{23}$.

\subsection{Descrição detalhada dos dispositivos medidos}

As medições foram realizadas em cinco lâminas de dispositivos. Em todas elas, o óxido de porta tinha $1 \mathrm{~nm}$ de $\mathrm{SiO}_{2}$ e 2 ou $4 \mathrm{~nm}$ de $\mathrm{HfO}_{2}$. O óxido enterrado tinha $145 \mathrm{~nm}$ e cada aleta tinha altura de $65 \mathrm{~nm}$. O resumo das características estruturais dos dispositivos medidos é mostrado na Tabela 4.1. 
Tabela 4.1. Características dos dispositivos medidos.

\begin{tabular}{|c|c|c|c|}
\hline Parâmetros & Símbolos & Valores & Unidades \\
\hline Espessura do óxido enterrado & $t_{\text {box }}$ & 145 & $\mathrm{~nm}$ \\
\hline Altura da aleta & $\mathrm{H}_{\text {fin }}$ & 65 & $\mathrm{~nm}$ \\
\hline Largura da aleta & $W_{\text {fin }}$ & $10,20,40,250$ ou 500 & $\mathrm{~nm}$ \\
\hline Comprimento de canal & $\mathrm{L}_{\mathrm{ch}}$ & 150 ou 250 & $\mathrm{~nm}$ \\
\hline Dopagem natural da lâmina & $\mathrm{N}_{\mathrm{A}}$ & $10^{15}$ & $\mathrm{~cm}^{-3}$ \\
\hline Quantidade de aletas & $\mathrm{N}_{\text {fin }}$ & 5,15 ou 30 & - \\
\hline Eletrodo de porta & \multicolumn{3}{|c|}{$100 \mathrm{~nm}$ de Si-amorfo $+5 \mathrm{~nm}$ de TiN } \\
\hline Dielétrico de porta & \multicolumn{3}{|c|}{$1 \mathrm{~nm}$ de $\mathrm{SiO}_{2}+2$ ou $4 \mathrm{~nm}$ de $\mathrm{HfO}_{2}$} \\
\hline
\end{tabular}

Foram medidos dispositivos em cinco lâminas diferentes, com características variáveis de dopagem e de espessura de $\mathrm{HfO}_{2}$ na estrutura de porta. Sob o ponto de vista de processo de dopagem, foram previstas até duas etapas para formação das regiões de fonte e dreno.

A primeira, realizada apenas em algumas lâminas, consistia numa dopagem com menor dose (normalmente chamada de extensão ou LDD) e sem o prévio posicionamento de espaçadores ao lado da porta. Dessa forma, a realização desta etapa de extensão do lado $\mathrm{P}$ e/ou $\mathrm{N}$ garantia por difusão um caso de sobreposição (overlap) na respectiva junção.

A segunda etapa, realizada em todas as lâminas, consistia na dopagem principal, realizada apenas após o posicionamento de um espaçador de dimensão entre 15 e $45 \mathrm{~nm}$. Dependendo da dimensão deste espaçador, o processo resultava em um caso de subposição, auto-alinhamento ou sobreposição de porta. A Figura 4.1 ilustra as duas etapas de dopagem. O desenho está propositalmente fora de escala para facilitar a compreensão de cada etapa de dopagem. 


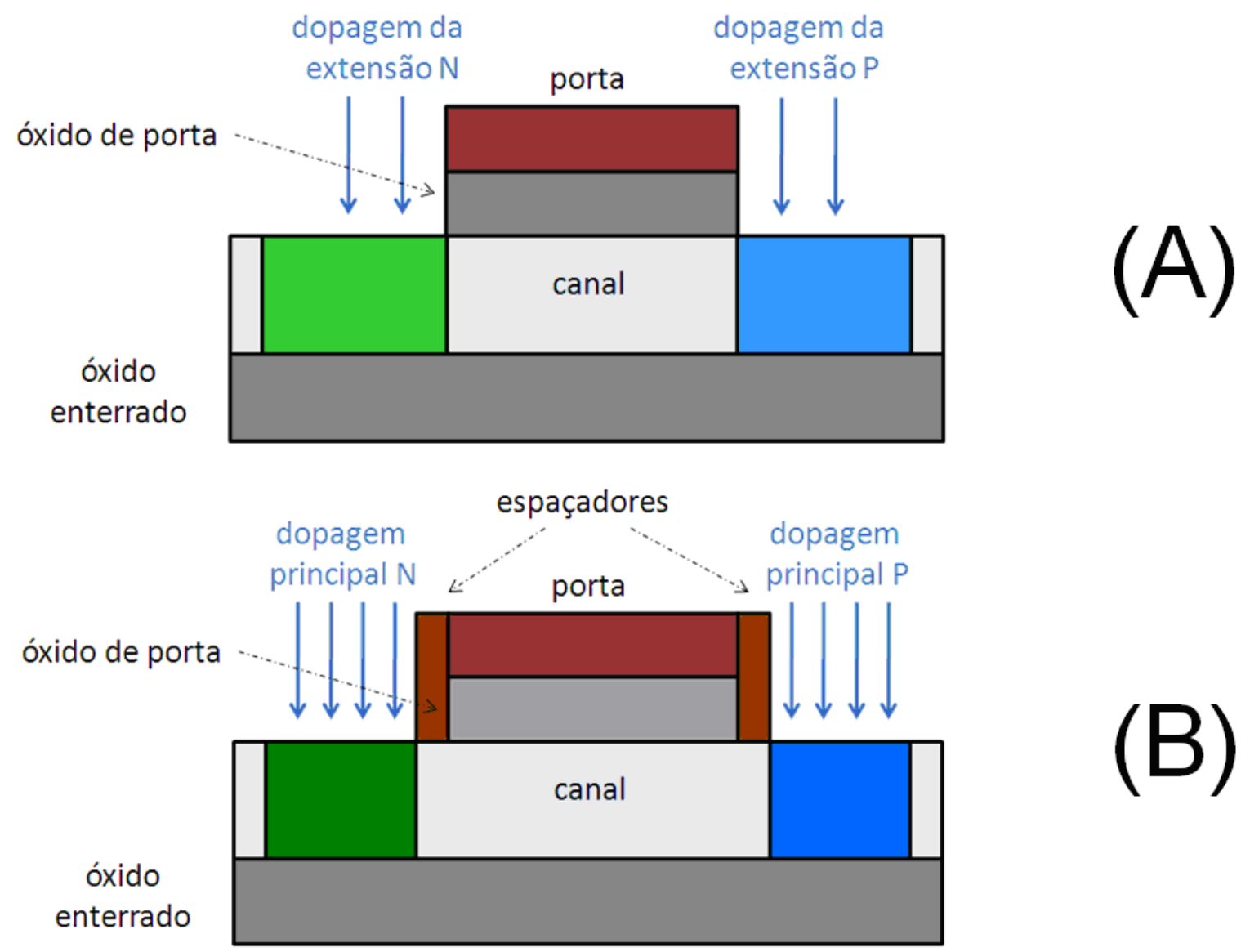

Figura 4.1 Representação das duas etapas de dopagem aplicadas durante a fabricação. A figura (A) refere-se á extensão de fonte e dreno e a figura $(B)$ refere-se à dopagem principal.

A Tabela 4.2 compara as cinco lâminas medidas e a ilustra o processo de dopagem realizado em cada caso. Vale notar que quando o espaçador utilizado tinha a dimensão de $30 \mathrm{~nm}$, o perfil resultante era próximo ao da condição de autoalinhamento de porta em relação à respectiva junção. Espaçadores menores resultavam em sobreposição e espaçadores maiores garantiam subposição.

Tabela 4.2. Características das lâminas medidas.

\begin{tabular}{|c|c|c|c|c|c|}
\hline & D23 - padrão & D07 & D08 & D21 & D22 \\
\hline Espessura de $\mathrm{HfO}_{2}$ (nm) & 2 & 2 & 2 & 4 & 4 \\
\hline Extensão do lado P & sim & não & não & não & sim \\
\hline Extensão do lado N & sim & não & não & sim & não \\
\hline Espaçador (nm) & 30 & 30 & 15 & 45 & 45 \\
\hline
\end{tabular}



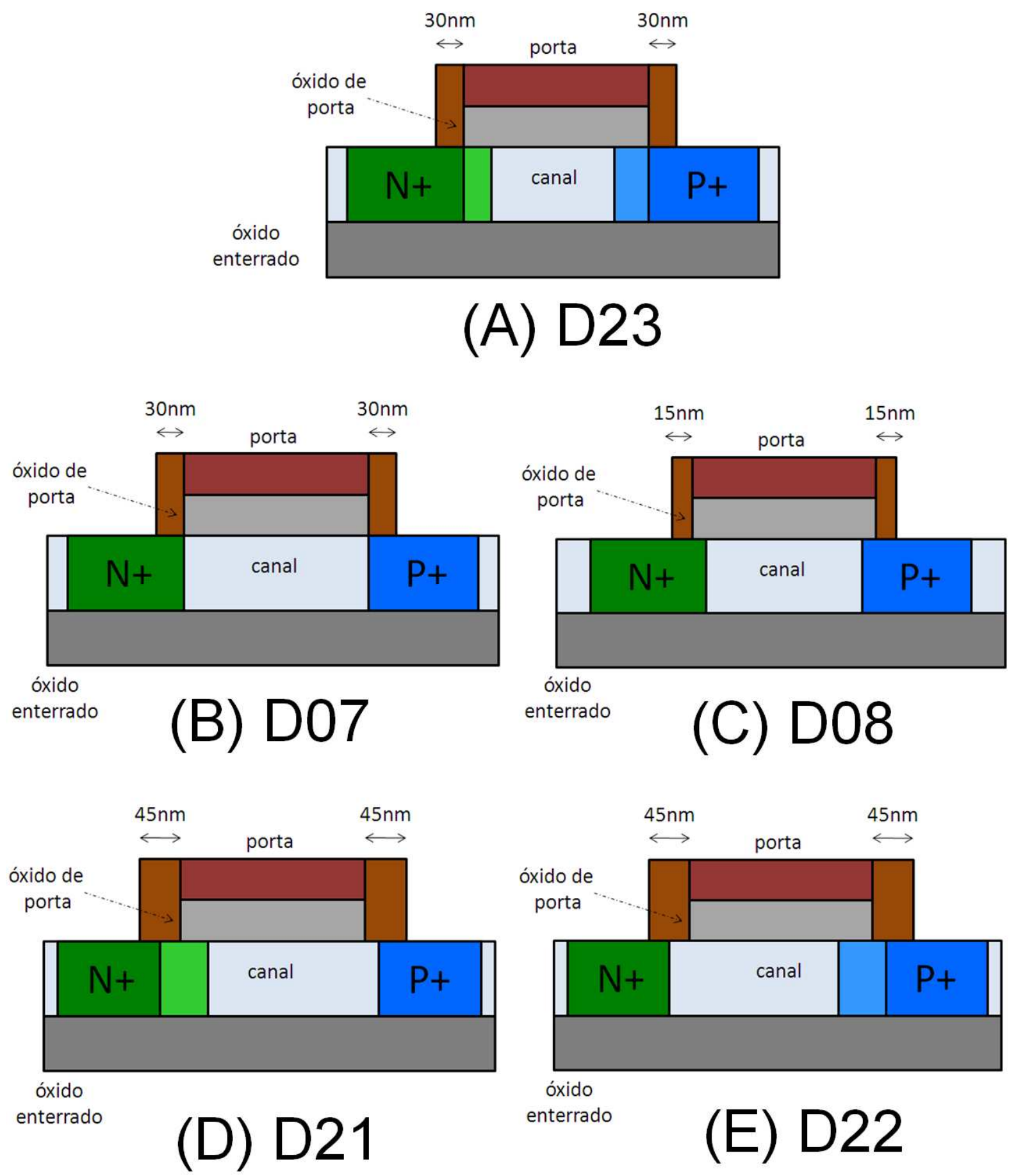

Figura 4.2 Representação da estrutura dos TFETs das lâminas D23 - padrão (A), D07 (B), D08 (C), D21(D) e D22 (E).

Nota-se que a lâmina padrão D23, cujos resultados serão destacados ao longo deste trabalho, apresentava dopagem preliminar em ambos os lados. Com isso, temos sobreposição de porta em relação à fonte e ao dreno, o que deve proporcionar um considerável efeito ambipolar. 
A lâmina D08, apesar de não contar com as dopagens preliminares, apresenta espaçadores muito pequenos. Dessa forma, observou-se na prática que há sobreposição também em ambas as extremidades de porta. Já no caso das lâminas D21 e D22, temos uma assimetria que causa sobreposição de um dos lados e subposição no outro. Na lâmina D07, temos uma condição na prática muito próxima à do auto-alinhamento de porta.

A Tabela 4.3 resume as condições nas junções de cada uma das lâminas. É importante salientar que para dispositivos do tipo $\mathrm{P}$, destacados neste capítulo, a região de dopagem $\mathrm{N}$ corresponde à fonte e a de dopagem $\mathrm{P}$ é denominada dreno.

Tabela 4.3. Condições de sobreposição/subposição nas junções com os lados $\mathrm{N}$ e P.

\begin{tabular}{|c|c|c|}
\hline & Condição do lado N & Condição do lado P \\
\hline D23 - padrão & sobreposição & sobreposição \\
\hline D07 & auto-alinhado & auto-alinhado \\
\hline D08 & sobreposição & sobreposição \\
\hline D21 & sobreposição & subposição \\
\hline D22 & subposição & sobreposição \\
\hline
\end{tabular}

\subsection{Metodologia da tomada de dados experimentais e de calibração das simulações}

A avaliação experimental dos dispositivos pTFETs foi realizada com base em tomadas de dados de curvas da corrente de dreno em função da tensão de porta $\left(\mathrm{l}_{\mathrm{DS}} \times \mathrm{V}_{\mathrm{GS}}\right)$ para diferentes tensões de dreno $\left(\mathrm{V}_{\mathrm{DS}}\right)$ e da corrente de dreno em função da tensão de dreno ( $\left.I_{D S} \times V_{D S}\right)$ para distintas tensões de porta $\left(V_{G S}\right)$. Estes dados experimentais foram obtidos com o analisador de parâmetros HP4156.

Após a comprovação prática dos princípios teóricos de operação dos TFETs, foi analisado o impacto da variação de temperatura e da sobreposição/subposição 
de porta e foi possível calibrar os parâmetros dos modelos utilizados nas simulações.

Desse modo, após a validação dos princípios teóricos e da confiabilidade das simulações, foram realizadas novas avaliações da influência de cada mecanismo de transporte de corrente e de cada configuração de comprimento de porta.

A Tabela 4.4 resume a faixa de valores utilizados para as medidas realizadas no IMEC e apresentadas ao longo deste capítulo. Nota-se que os valores de tensão utilizados para polarização dos pTFETs são opostos em relação aos adotados no capítulo anterior, com nTFETs. Foi utilizada como padrão a lâmina D23, com condição de auto-alinhamento de porta em ambos os lados. Na Figura 4.16 é realizada uma análise comparativa entre dispositivos de diferentes lâminas.

Tabela 4.4. Condições de polarização dos dispositivos.

\begin{tabular}{|c|c|}
\hline Tipo de caracterização & Condições de medidas \\
\hline Impacto da temperatura & $\mathrm{T}=300 \sim 420 \mathrm{~K}$ \\
\hline $\begin{array}{l}\text { Corrente de dreno em função da } \\
\text { tensão de porta }\left(I_{D S} \times V_{G S}\right)\end{array}$ & $\begin{array}{l}V_{G S}=-2,0 \sim+0,4 V \\
V_{D S}=-0,5 \text { e }-0,9 V\end{array}$ \\
\hline $\begin{array}{l}\text { Corrente de dreno em função da } \\
\left.\text { tensão de dreno ( } I_{D S} \times V_{D S}\right)\end{array}$ & $\begin{array}{c}V_{D S}=-1,5 \sim+0,4 V \\
V_{G S}=-0,9,-1,3 e-1,7 V\end{array}$ \\
\hline
\end{tabular}

\subsection{Identificação experimental do impacto das dimensões e das condições de polarização}

Primeiramente foi selecionado um dispositivo de $150 \mathrm{~nm}$ de comprimento de canal, $20 \mathrm{~nm}$ de largura de aleta e 15 aletas por transistor para avaliação das características de entrada e saída. Foi medida a corrente de dreno para tensão de dreno de $-1,5 \mathrm{~V}$ a $+0,4 \mathrm{~V}$, com três diferentes patamares de tensão de porta. A seguir, a corrente de dreno foi determinada para $V_{G S}$ variando de $-2 \mathrm{~V}$ a $+0,4 \mathrm{~V}$. Os resultados obtidos experimentalmente foram plotados na Figura 4.3 ( $\left.\mathrm{I}_{\mathrm{DS}} \times \mathrm{V}_{\mathrm{DS}}\right)$ e na Figura $4.4\left(\mathrm{I}_{\mathrm{DS}} \times \mathrm{V}_{\mathrm{GS}}\right)$, todos submetidos à temperatura de $300 \mathrm{~K}$. 


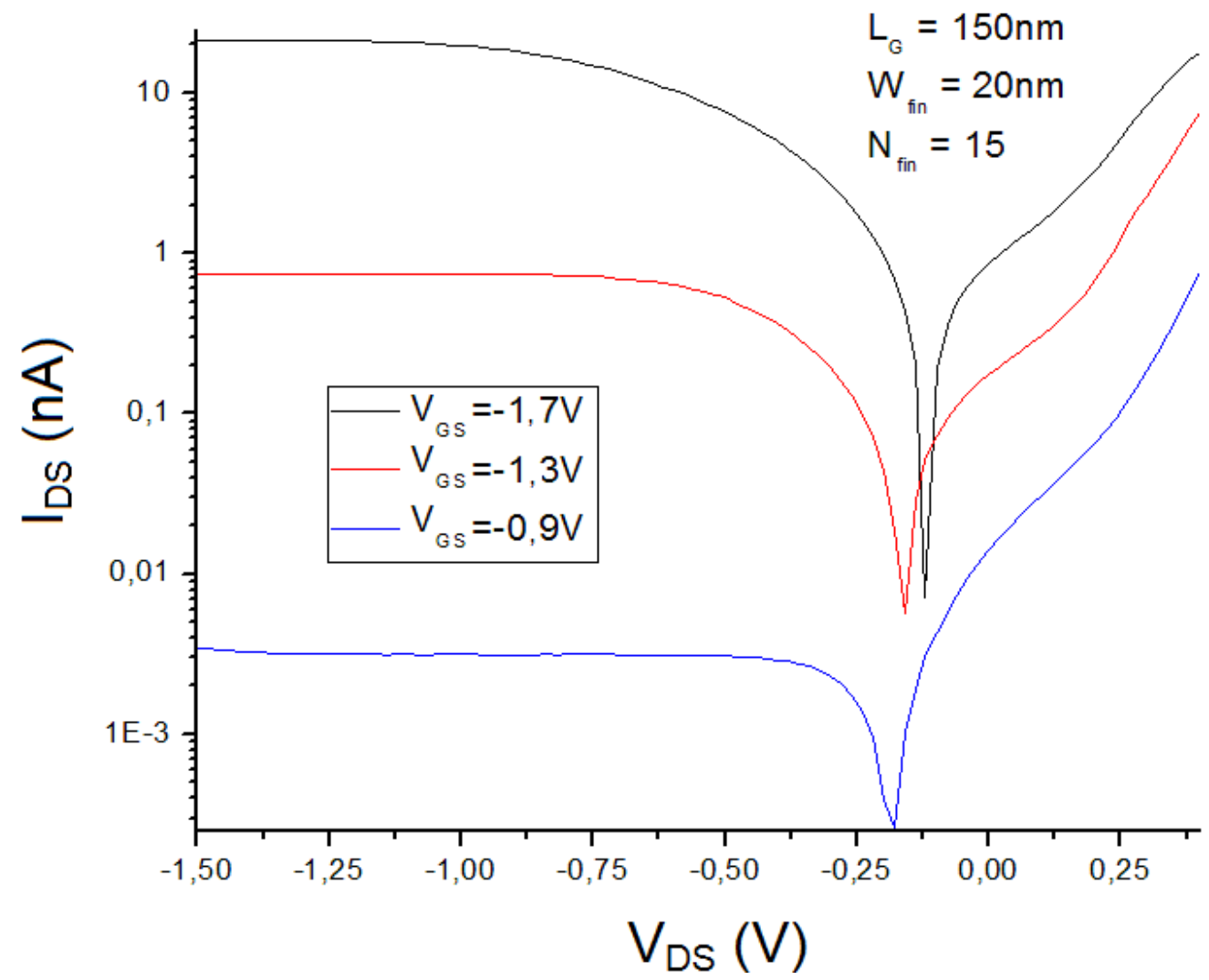

Figura 4.3 Corrente de dreno $\left(\mathrm{I}_{\mathrm{DS}}\right)$ de um pTFET em função da tensão de dreno $\left(\mathrm{V}_{\mathrm{DS}}\right)$ para $\mathrm{V}_{\mathrm{GS}}$ de $-1,7 \mathrm{~V},-1,3 \mathrm{~V}$ e $-0,9 \mathrm{~V}$.

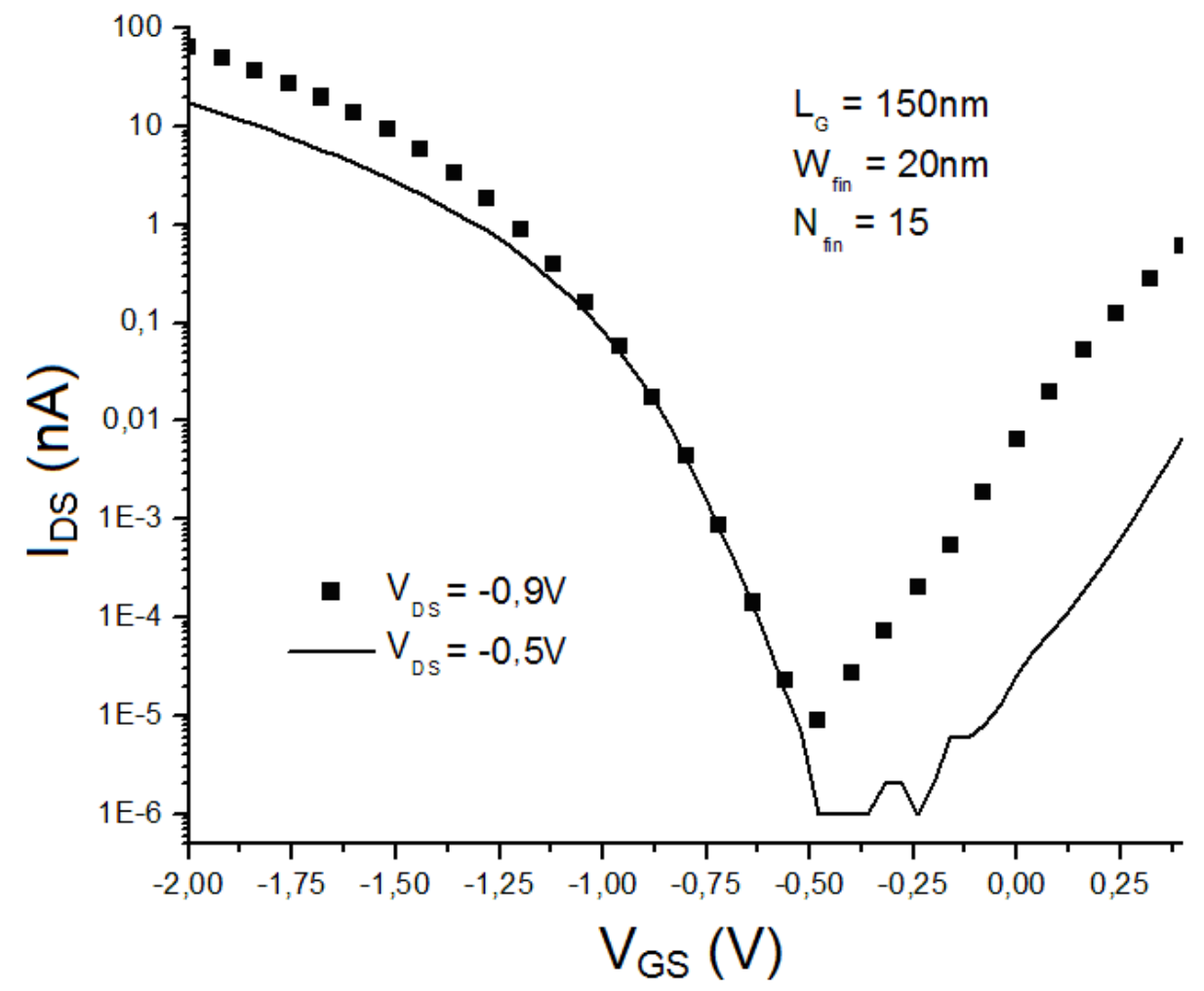

Figura 4.4 Corrente de dreno ( $\left.\mathrm{I}_{\mathrm{DS}}\right)$ de um pTFET em função da tensão de porta $\left(\mathrm{V}_{\mathrm{GS}}\right)$ para $\mathrm{V}_{\mathrm{DS}}$ de $-0,9 \mathrm{~V}$ e $-0,5 \mathrm{~V}$. 
Os resultados apresentados validam o funcionamento dos dispositivos TFETs conforme proposto ao longo do trabalho. Deve ser dado destaque ao flagrante efeito ambipolar, resultante da estrutura com sobreposição de porta em ambas as extremidades.

Vale ressaltar que na curva $I_{D S} \times V_{G S}$ são obtidos valores virtualmente iguais para ambas as polarizações de dreno na faixa de $V_{G S}$ entre $-1 \mathrm{~V}$ e $-0,6 \mathrm{~V}$, justamente região em que a inclinação de sublimiar é minimizada. Desse modo, pode-se intuir que a definição sobre a tensão de dreno ideal para operação recairia sobre os efeitos na redução da corrente ambipolar (melhor para $V_{D S}=-0.5 \mathrm{~V}$ ) e sobre 0 aumento do módulo de $\mathrm{I}_{\mathrm{ON}}$ (melhor para $\mathrm{V}_{\mathrm{DS}}=-0,9 \mathrm{~V}$ ).

A observação da separação das curvas de corrente de dreno para tensão de porta muito baixa na Figura 4.4 justifica a observação na Figura 4.3 , que indica a necessidade de baixar bastante a tensão de dreno até que a corrente de dreno se estabilize para $\mathrm{V}_{\mathrm{GS}}=-1,7 \mathrm{~V}$.

Para permitir a comparação entre dispositivos com dimensões distintas, a Figura 4.5 junta os dados medidos para transistores com largura e quantidade de aletas diferentes às mesmas curvas já exibidas na Figura 4.4.

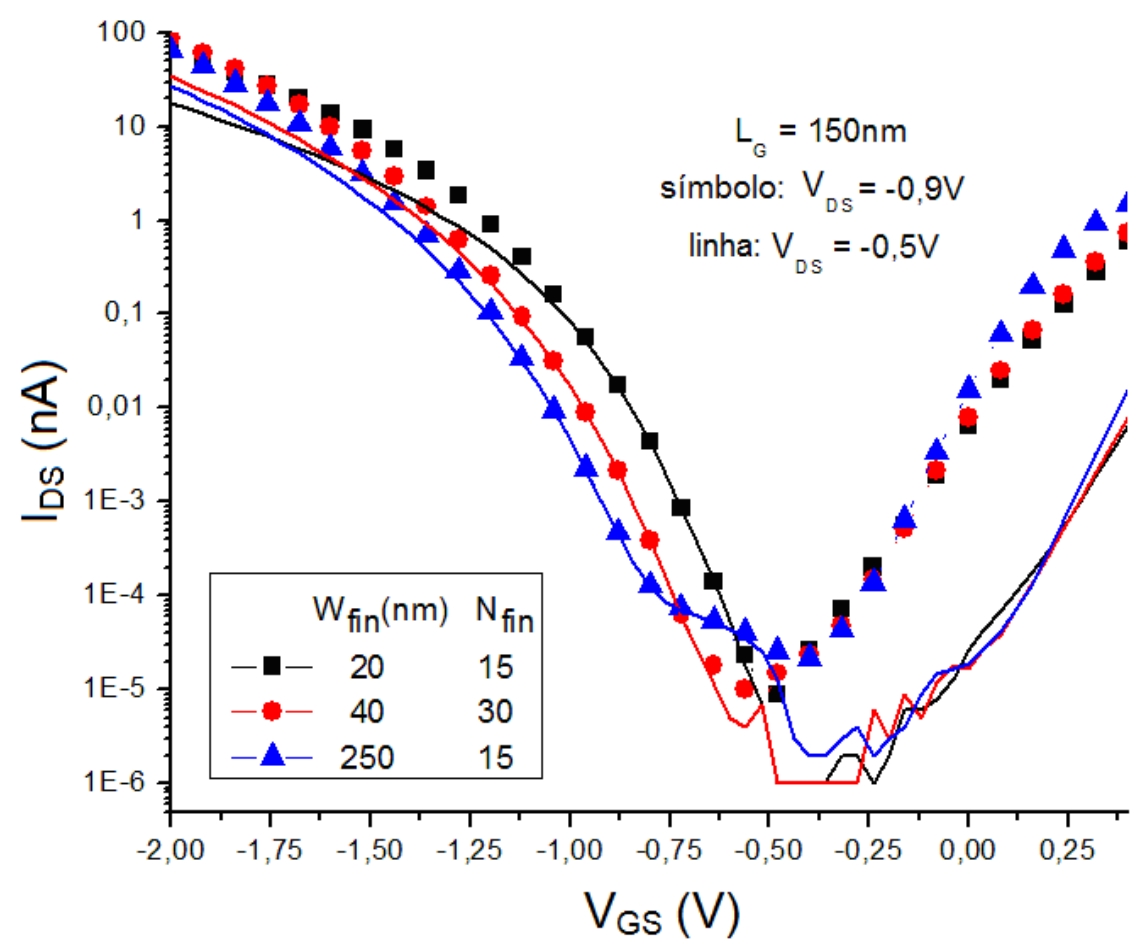

Figura 4.5 Corrente de dreno ( $\left.\mathrm{I}_{\mathrm{DS}}\right)$ de $\mathrm{pTFETs}$ em função da tensão de porta $\left(\mathrm{V}_{\mathrm{GS}}\right)$ para $\mathrm{V}_{\mathrm{DS}}$ variando de $-0,9 \mathrm{~V}$ a $-0,5 \mathrm{~V}, \mathrm{~W}_{\text {fin }}$ variando de $20 \mathrm{~nm}$ a $250 \mathrm{~nm}$ e $\mathrm{N}_{\text {fin }}$ alternando em 15 e 30 . 
É possível dividir a análise da figura em três regiões distintas. Inicialmente, pode-se destacar a região do efeito ambipolar, que se mostrou muito mais dependente da condição de polarização do dreno e da porta do que das dimensões propriamente ditas.

A segunda observação destes dados experimentais vem da região em que a tensão de porta é pouco menor do que $-0,5 \mathrm{~V}$, na qual coincidem os valores obtidos para $V_{D S}=-0,5 \mathrm{~V}$ e para $V_{D S}=-0,9 \mathrm{~V}$. Quanto maior a área efetiva da seção do dispositivo, maior a faixa de valores de $V_{G S}$ para a qual a corrente de dreno não variou com a tensão de dreno.

Finalmente, para tensão de porta muito baixa, temos o distanciamento das curvas de corrente de dreno em virtude de $V_{D S}$. Analogamente ao comentado no parágrafo anterior, a susceptibilidade da corrente de dreno em relação a $V_{D S}$ tende a ser majorada com o aumento da área efetiva do dispositivo.

\subsection{Identificação experimental do impacto da temperatura}

A Figura 4.6 mostra a corrente de dreno em função da tensão de porta para três patamares de temperatura, variando entre $300 \mathrm{~K}$ e $360 \mathrm{~K}$.

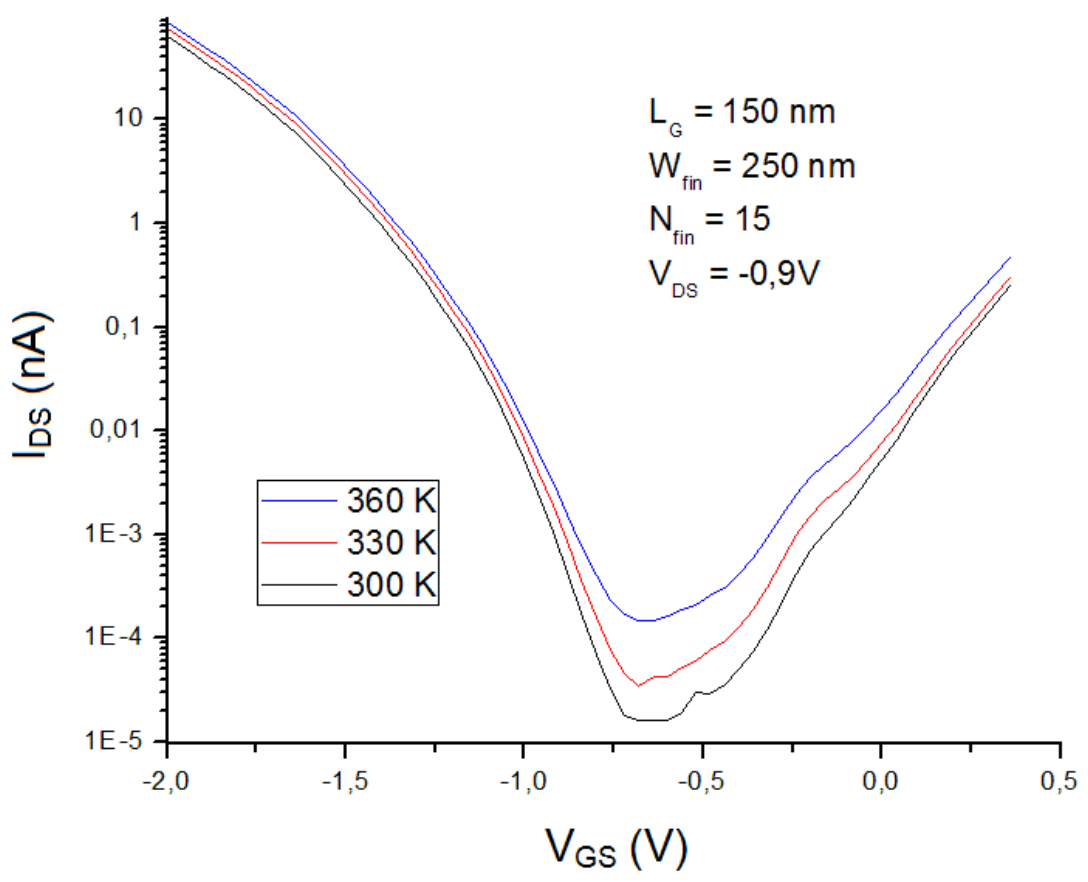

Figura 4.6 Corrente de dreno ( $\left.\mathrm{I}_{\mathrm{DS}}\right)$ de um pTFET em função da tensão de porta $\left(\mathrm{V}_{\mathrm{GS}}\right)$ para $\mathrm{V}_{\mathrm{DS}}$ de $-0,9 \mathrm{~V}, \mathrm{~W}_{\text {fin }}$ de $250 \mathrm{~nm}$ e $\mathrm{N}_{\text {fin }}$ de 15. 
Nesta análise foi observado que a dependência da temperatura está de acordo com o explicado no desenvolvimento teórico e nas avaliação das diversas simulações preparadas para diferentes condições de ambipolaridade.

Efetivamente, foram medidos valores crescentes de corrente com o aumento da temperatura, com distanciamento menor à medida que o módulo da tensão de porta aumentava, isto é, à medida que a componente de tunelamento de banda para banda tornava-se mais relevante.

O maior impacto da temperatura nas curvas de corrente de dreno ocorreu para $V_{G S}$ na faixa aproximada de $-0,8 \mathrm{~V}$ a $-0,2 \mathrm{~V}$, em que o BBT tinha uma participação menor na composição da corrente e passavam a se destacar correntes de TAT e SRH, exponencialmente dependentes da temperatura.

\subsection{Calibração das simulações com os dados experimentais para temperatura ambiente}

Após a validação do funcionamento básico dos dispositivos pTFET, foram confrontadas as partes de simulação e de dados experimentais deste projeto. Dessa maneira, foram revisados os parâmetros dos modelos implementados no Atlas, de modo a garantir confiabilidade do método de simulação aos transistores analisados na prática.

Para isso, foi preciso inicialmente configurar as simulações para as condições de polarização exigidas por pTFETs e ajustar as dimensões conforme os dados fornecidos pelo IMEC. Foi utilizado como padrão um dispositivo com dimensões intermediárias em relação às disponíveis nas lâminas testadas. A largura de aleta $\left(W_{\text {fin }}\right)$ foi de $40 \mathrm{~nm}$, o comprimento de canal $\left(L_{c h}\right)$ foi de $150 \mathrm{~nm}$ e a espessura de $\mathrm{HfO}_{2}$ foi de $2 \mathrm{~nm}$. Demais dimensões seguiram os dados da tabela 4.1, a não ser quando expressamente mencionado.

Reforçando que a lâmina padrão determinada foi a D23, justifica-se a comparação dos dados experimentais com as simulações referentes ao autoalinhamento de porta. 
A Figura 4.7 exibe três curvas simulando a corrente de dreno em função da tensão de porta com $V_{D S}$ constante de $0,9 \mathrm{~V}$ e a sobreposição da curva experimental comparada ao caso de $\Delta \mathrm{L}_{\mathrm{G}}=0 \mathrm{~nm}$.

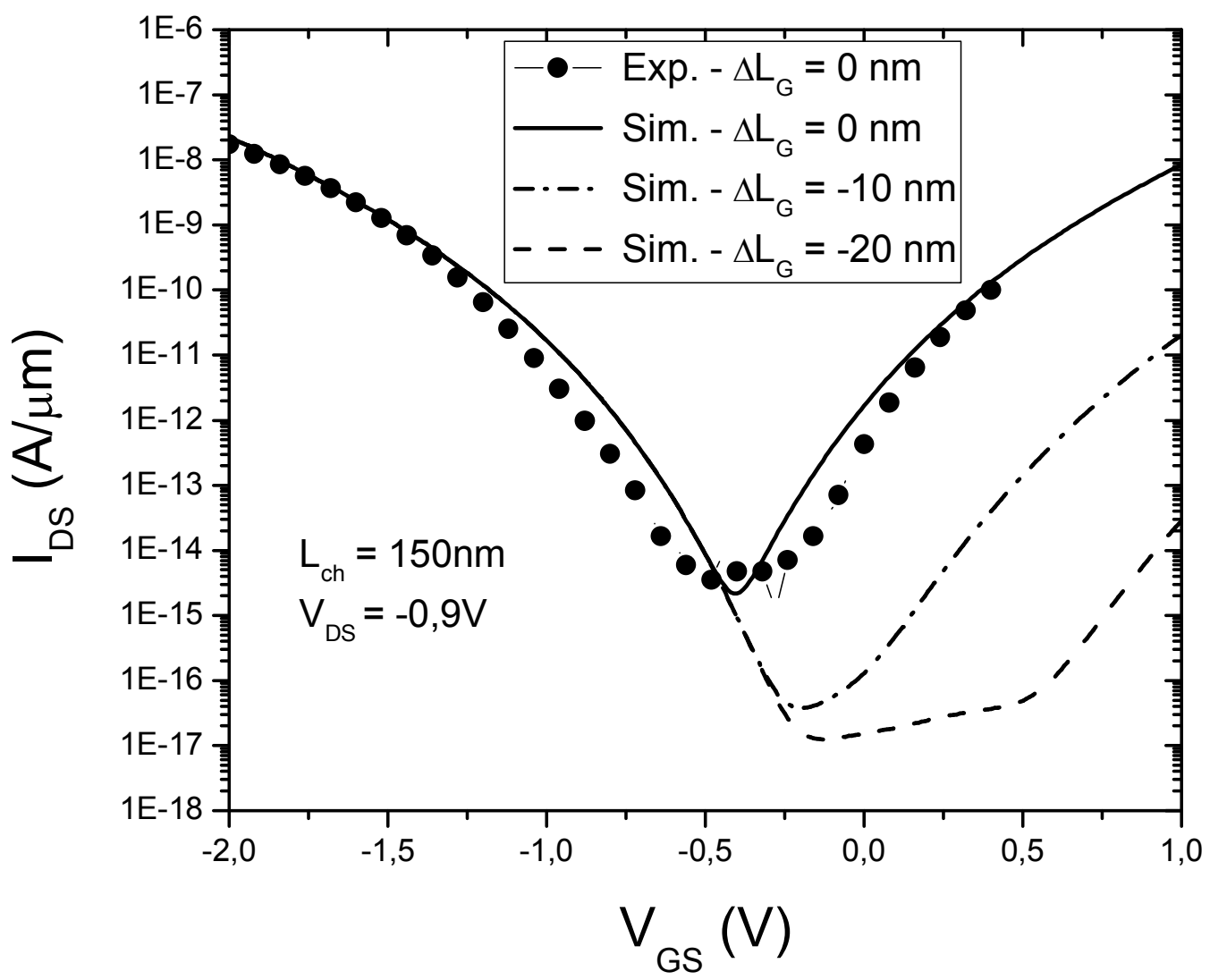

Figura 4.7 Curvas simuladas e experimental da corrente de dreno ( $\left.I_{D S}\right)$ de pTFETs em função da tensão de porta $\left(\mathrm{V}_{\mathrm{GS}}\right)$ para $\mathrm{V}_{\mathrm{DS}}$ de $-0,9 \mathrm{~V}$.

Para ajustar a simulação, bastou alterar um parâmetro de correção da taxa de geração incluído no modelo de Kane e os tempos de vida dos elétrons e das lacunas equacionados no cálculo do SRH.

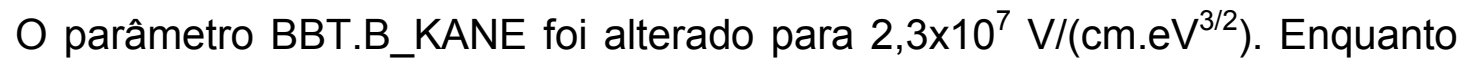
isso, os parâmetros BBT.A_KANE e BBT.GAMMA continuaram com os valores iniciais definidos na equação (3-5).

Para a equação que modela os efeitos do tunelamento induzido por armadilhas e do $\mathrm{SRH}$, o tempo de vida dos elétrons e das lacunas foi ajustado para $10^{-6} \mathrm{~s}$. Não foi necessário alterar a escolha de nenhum dos modelos explicados no capítulo anterior. 
Analisando maiores detalhes das curvas da Figura 4.7, nota-se que a simetria da estrutura experimental faz com que a corrente direta $\left(\mathrm{V}_{\mathrm{GS}}<-0,5 \mathrm{~V}\right)$ apresente 0 mesmo comportamento da corrente resultante do efeito da ambipolaridade ( $\mathrm{V}_{\mathrm{GS}}>$ $-0,5 \mathrm{~V})$, com predomínio da corrente de tunelamento de banda para banda (BBT) em ambos os casos.

Também para dispositivos pTFETs nota-se que a redução do comprimento de porta, ocasionando uma subposição em relação à junção canal/dreno, atenua o efeito ambipolar. Com isso, para maiores valores de $V_{G S}$, a corrente passa a ser mais dependente da recombinação pelos efeitos de TAT e de SRH.

\subsection{Simulações para análise do impacto dos mecanismos de transporte}

A partir de então, será utilizado o mesmo dispositivo e o mesmo arquivo base da simulação calibrada para análise dos demais efeitos destacados neste projeto, como o impacto dos mecanismos de transporte e a variação da temperatura.

Nesta seção será discutido como os mecanismos de transporte predominantes são influenciados pela variação da temperatura e pela estrutura de porta do dispositivo. Este tipo de análise é importante para determinar as condições otimizadas para aplicações que requeiram menor susceptibilidade à variação de temperatura ou maior relação $\mathrm{I}_{\mathrm{ON}} / \mathrm{l}_{\mathrm{OFF}}$.

As Figuras 4.8, 4.9 e 4.10 mostram a corrente de dreno em função da tensão de porta para temperatura variando de 240 a 420K. Para cada situação, são exibidas curvas considerando três combinações de efeitos de mecanismo de transporte. A diferença das três figuras entre si é o valor de $\Delta \mathrm{L}_{\mathrm{G}}$, equivalente a -20 $\mathrm{nm}$ na Figura 4.8, a -10 nm na Figura 4.9 e a 0 nm na Figura 4.10.

A avaliação é análoga ao estudo dos transistores nTFETs realizado no capítulo anterior, particularmente quanto aos comentários das Figuras 3.9, 3.10 e 3.11. 


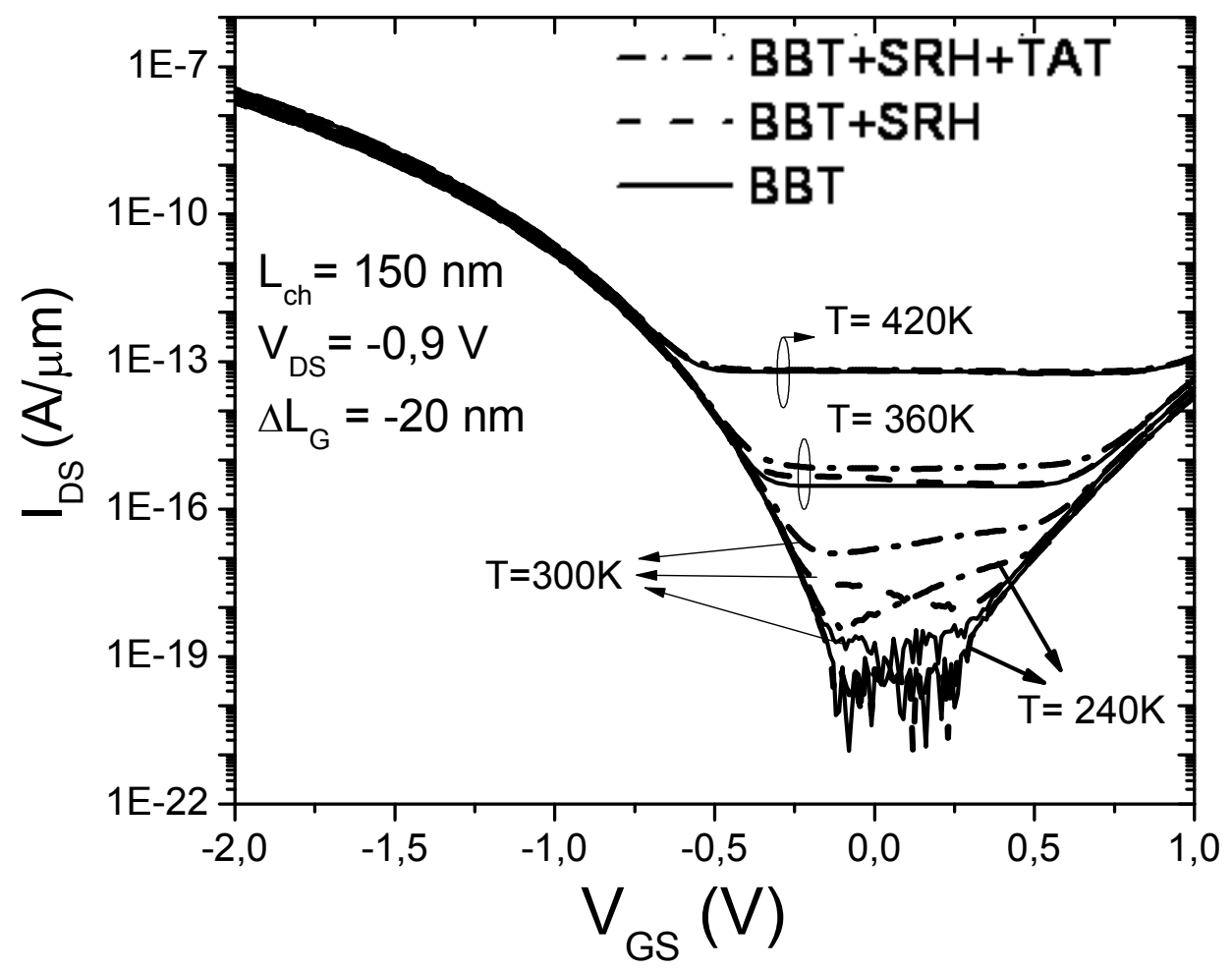

Figura 4.8 Corrente de dreno ( $\left.\mathrm{l}_{\mathrm{DS}}\right)$ em função da tensão de porta $\left(\mathrm{V}_{\mathrm{GS}}\right)$ para $\mathrm{V}_{\mathrm{DS}}$ de $-0,9 \mathrm{~V}$, $\Delta \mathrm{L}_{\mathrm{G}}$ de $-20 \mathrm{~nm}$, temperatura de 240 a $420 \mathrm{~K}$ e três combinações de mecanismos de transporte.

Para inferir o impacto da temperatura, é necessário identificar o mecanismo de transporte predominante em cada caso. Nas situações em que a componente do tunelamento de banda para banda é mais relevante, a influência da temperatura é menos significativa. Por outro lado, os equacionamentos dos modelos de tunelamento induzido por armadilhas e da corrente de Schockley-Read-Hall sugerem uma variação notória quando a temperatura é modificada.

Nas três figuras em questão, a corrente é majoritariamente devida ao BBT para tensão de porta menor que $-0,75 \mathrm{~V}$. Nesse caso, nota-se mínima alteração com a variação da temperatura de simulação.

No caso de $\Delta L_{G}=-20 \mathrm{~nm}$, quando a tensão de porta aumenta a partir de $-0,75 \mathrm{~V}$, os fenômenos de TAT e SRH tornam-se dominantes. Nessa parte da curva, nota-se que a variação de temperatura claramente modifica a magnitude da corrente total de dreno. Comparando com a situação em que é considerado apenas o modelo BBT, a inclusão do SRH leva a um aumento na corrente de dreno em virtude do fator de geração/recombinação. Contabilizando ainda a correção para o cálculo do TAT, a corrente aumenta ainda mais, graças à influência das armadilhas. 
É interessante observar que sob temperatura de 420K, uma aparentemente inesperada alta corrente predomina para $\mathrm{V}_{\mathrm{GS}}>-0,5 \mathrm{~V}$. Este comportamento pode ser justificado diretamente pela corrente reversa na junção dreno/canal por difusão térmica. Esta corrente também é altamente dependente da temperatura, visto que é proporcional a $\mathrm{n}_{\mathrm{i}}^{2}$.

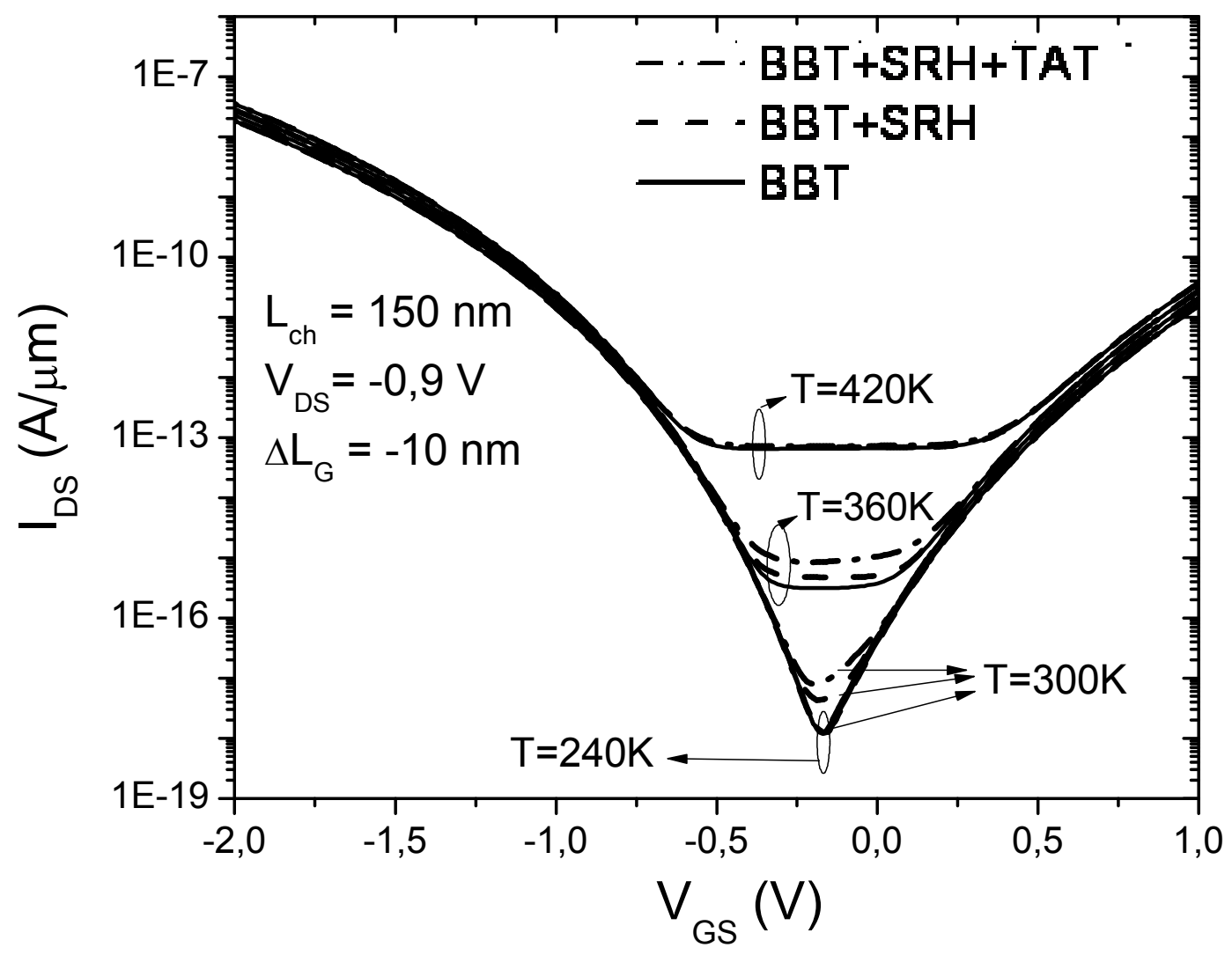

Figura 4.9 Corrente de dreno (lDS) em função da tensão de porta $\left(\mathrm{V}_{\mathrm{GS}}\right)$ para $\mathrm{V}_{\mathrm{DS}}$ de $-0,9 \mathrm{~V}$, $\Delta L_{G}$ de $-10 \mathrm{~nm}$, temperatura de 240 a $420 \mathrm{~K}$ e três combinações de mecanismos de transporte.

Conforme a Figura 4.9, reduzindo a subposição para a condição com $\Delta \mathrm{L}_{\mathrm{G}}$ de -10 nm, a influência do tunelamento de banda para banda na corrente ambipolar torna-se mais significativa. Para o caso de temperatura de $420 \mathrm{~K}$, por exemplo, a corrente de dreno tem comportamento similar ao do caso de $\Delta \mathrm{L}_{\mathrm{G}}$ quando a tensão de porta está entre $-0,4 \mathrm{~V}$ e $+0,4 \mathrm{~V}$. Para $\mathrm{V}_{\mathrm{GS}}$ fora dessa faixa, o predomínio é do $\mathrm{BBT}$, tornando a corrente ambipolar pior do que no caso anterior.

Para temperaturas menores, a faixa de predomínio do SRH e do TAT tornase ainda mais reduzida e passa a não ser mais observável um patamar na corrente de dreno entre o crescimento da corrente direta e da ambipolar. 


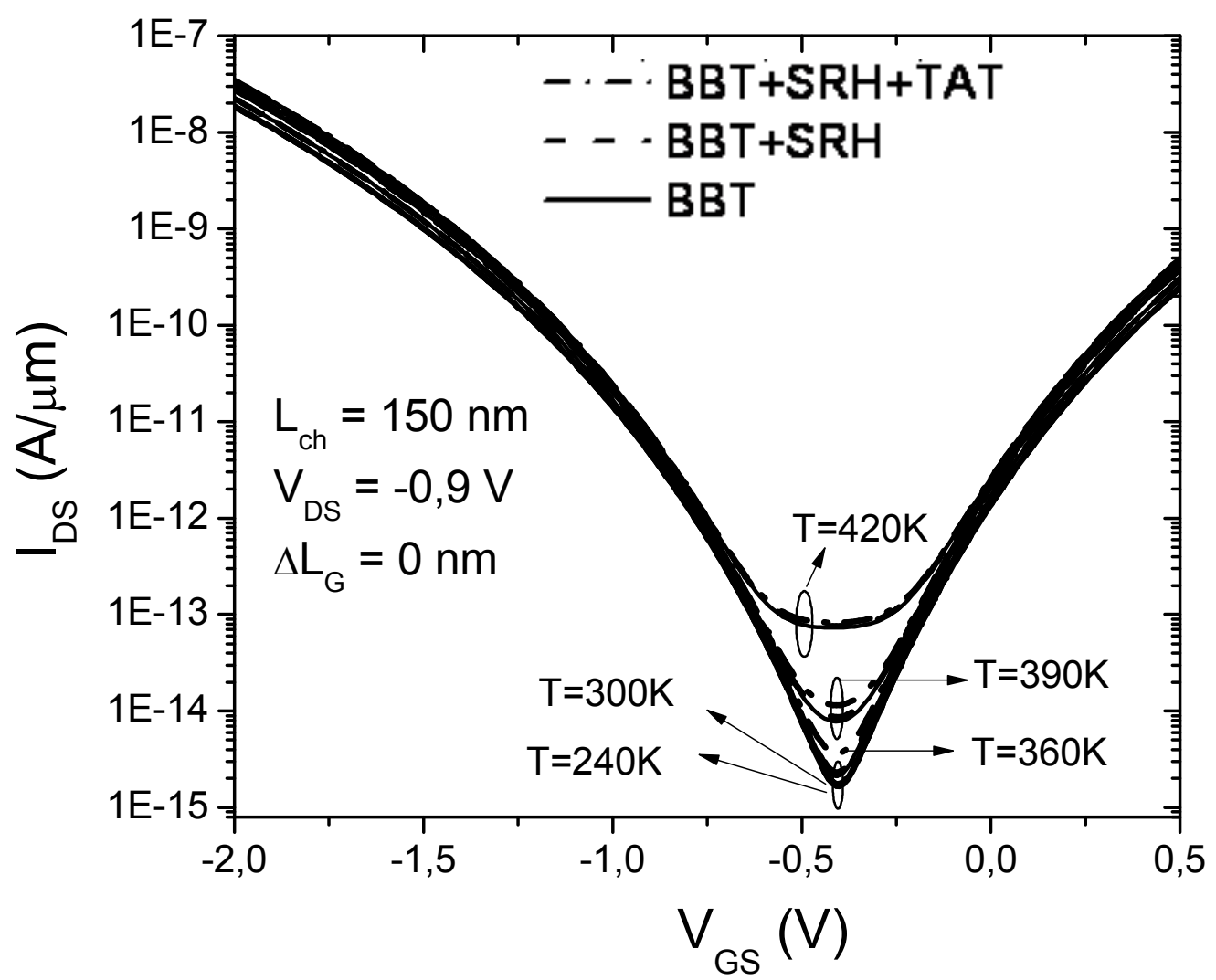

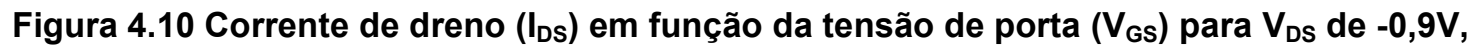
$\Delta \mathrm{L}_{\mathrm{G}}$ de $0 \mathrm{~nm}$, temperatura de 240 a $420 \mathrm{~K}$ e três combinações de mecanismos de transporte.

Enquanto isso, a Figura 4.10 mostra que no caso de auto-alinhamento o efeito ambipolar é ainda mais acentuado, com amplo predomínio da componente de tunelamento de banda para banda. Em termos de impacto da temperatura, nota-se que a variação é bastante reduzida em comparação aos casos anteriores.

Para sintetizar os efeitos da temperatura e da dimensão da porta, a Figura 4.11 condensa os resultados obtidos com a inclusão de todos os modelos (BBT, SRH e TAT) para a faixa de temperatura completa.

É bastante claro que o aumento da subposição contribuiu para melhorar a performance dos dispositivos, na medida em que a corrente ambipolar foi reduzida. Quanto ao impacto da temperatura, é possível notar que menores valores de inclinação de sublimiar são obtidos quando os transistores são submetidos a temperaturas inferiores. Além disso, a melhora no desempenho ocorreu sem prejuízo à corrente de lon na faixa de polarização estudada. 


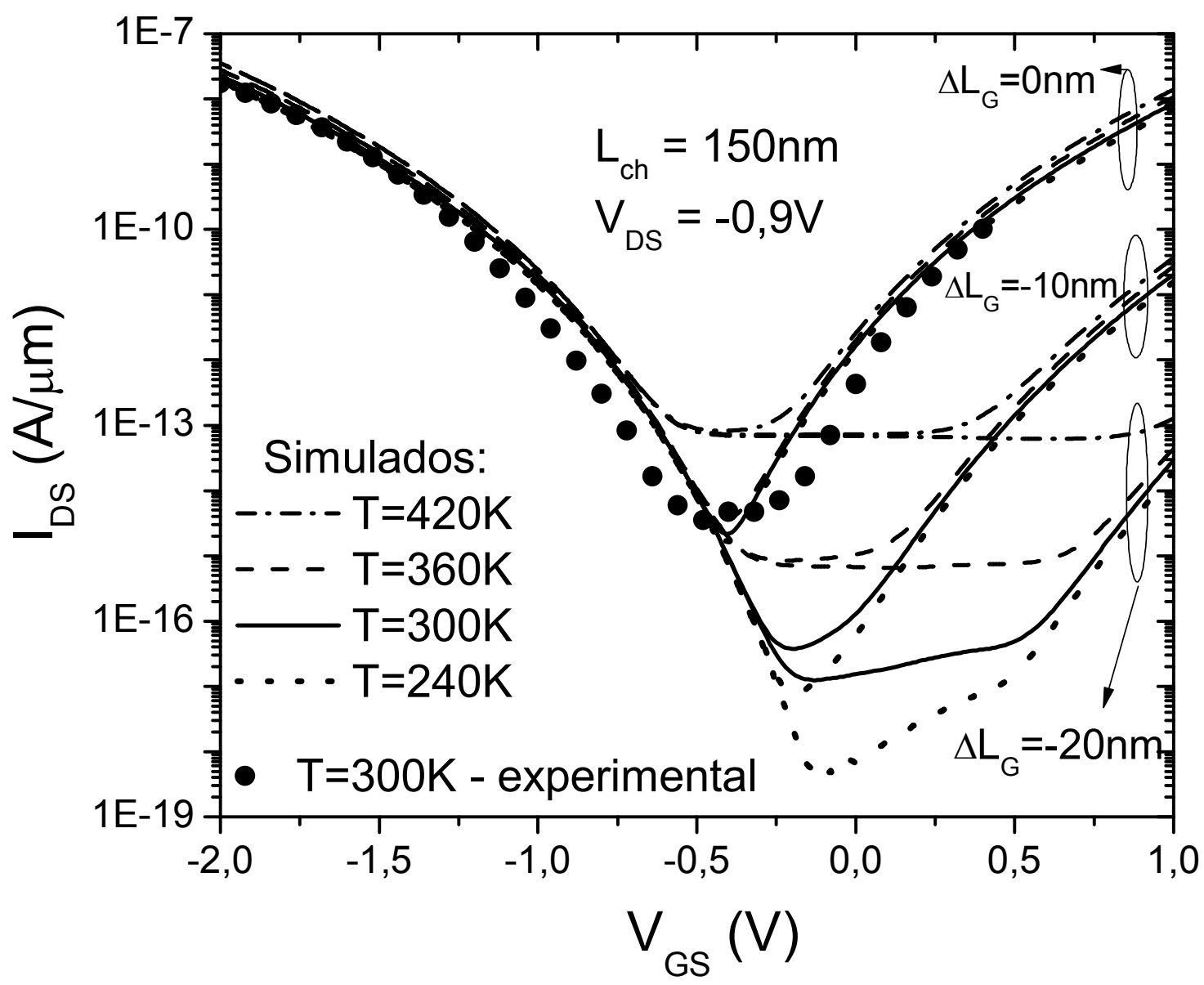

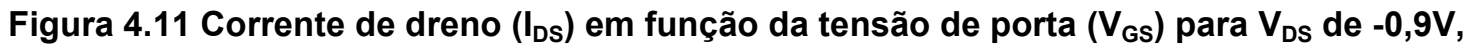
$\Delta L_{G}$ de $-20 \mathrm{~nm},-10 \mathrm{~nm}$ e $0 \mathrm{~nm}$ e temperatura de 240 a $420 \mathrm{~K}$.

4.7 Análise experimental do impacto da temperatura e das condições de polarização nos dispositivos pTFETs padrões

Após a realização e a análise das novas simulações, voltadas para dispositivos pTFETs, a Figura 4.12 exibe os resultados experimentais para o mesmo dispositivo utilizado como padrão durante a etapa de calibração das simulações.

É possivel observar que o impacto da temperatura efetivamente tem comportamento condizente com o verificado por simulação. Nota-se um aumento da corrente de dreno com o aumento da temperatura, sendo que a diferença é muito mais significativa para tensão de porta na faixa de $-0,7 \mathrm{~V}$ a $-0,2 \mathrm{~V}$, para a qual os mecanismo de tunelamento induzido por armadilhas e o efeito $\mathrm{SRH}$ prevalecem sobre o tunelamento de banda para banda. 


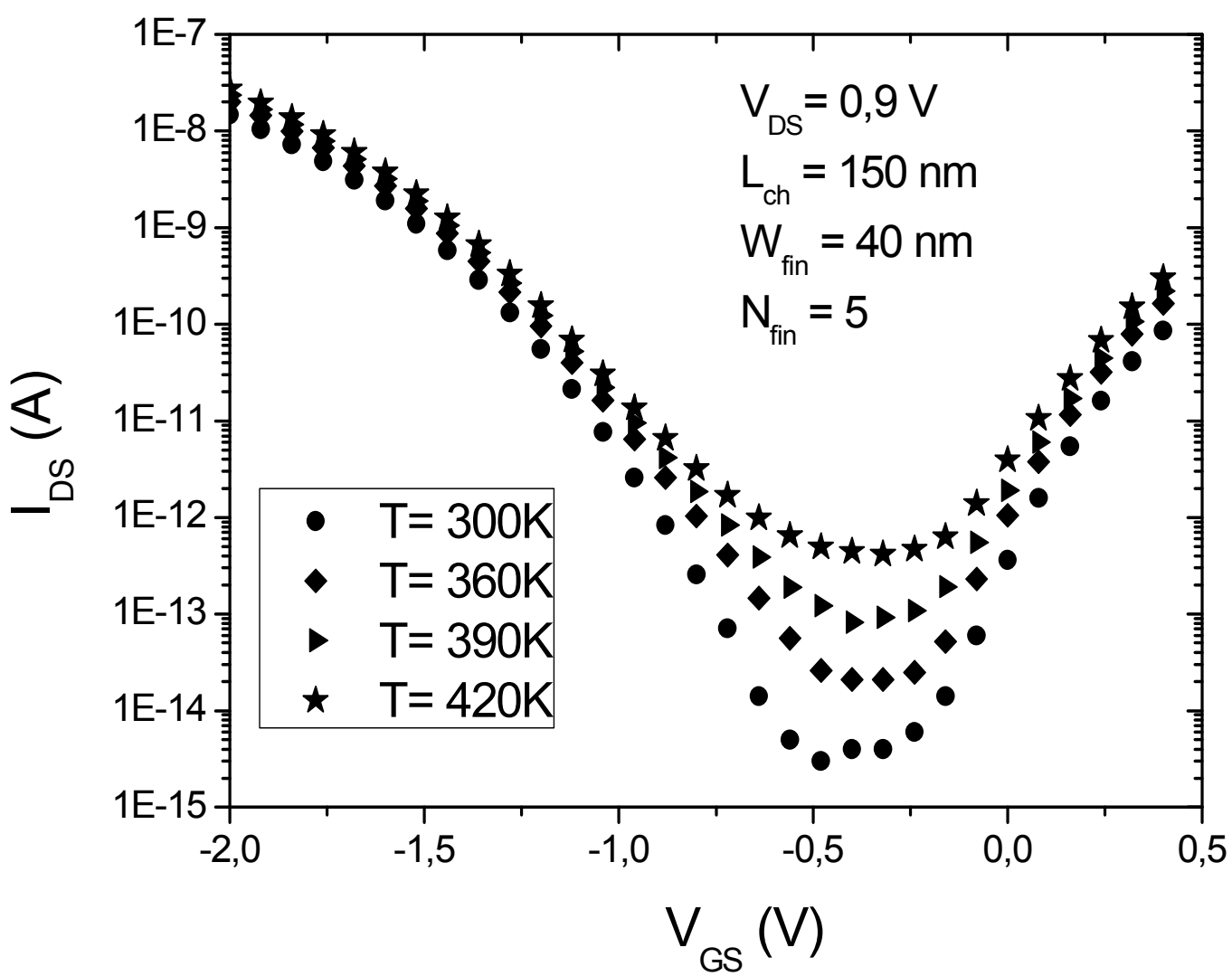

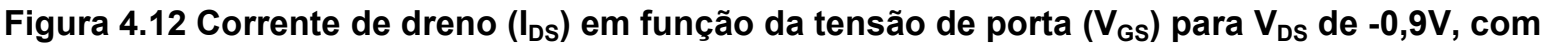
$\mathrm{W}_{\text {fin }}$ de $40 \mathrm{~nm}$ e $\mathrm{N}_{\text {fin }}$ de 5 e temperatura de 300 a $420 \mathrm{~K}$.

Também é notório que a simetria da estrutura proporciona uma corrente ambipolar também simétrica quando comparada à corrente de acionamento dos transistores. Os menores valores de inclinação de sublimiar aparecem para temperatura de $300 \mathrm{~K}$, mas o efeito ambipolar deixa estreita a faixa de tensão de porta para a qual a corrente de dreno permanece num nível bem mais baixo que a corrente de acionamento.

Quantitativamente, o menor valor de S obtido com temperatura de $420 \mathrm{~K}$ foi de $220 \mathrm{mV} /$ década $\left(\mathrm{V}_{\mathrm{GS}}=-1,0 \mathrm{~V}\right)$. Diminuindo a temperatura para $300 \mathrm{~K}$, a mínima inclinação de sublimiar caiu para $130 \mathrm{mV} /$ década $\left(V_{G S}=-0,7 \mathrm{~V}\right)$, o que corresponde a uma queda de mais de $40 \%$. A título de comparação, o mínimo valor de $S$ previsto teoricamente para $300 \mathrm{~K}$ com a tecnologia CMOS tradicional seria $29 \%$ menor que o para $420 \mathrm{~K}$.

Vale a pena reforçar que, conforme explicado em 2.3, estes valores práticos acima dos limites teóricos são esperados para este tipo de transistor fabricado com 
estrutura apenas com silício como semicondutor ${ }^{26}$ e efeito ambipolar pronunciado. Para o tipo de estrutura analisada, os valores estão de acordo com o esperado ${ }^{51}$.

Em termos de razão $\mathrm{I}_{\mathrm{ON}} / \mathrm{l}_{\mathrm{OFF}}$, os melhores resultados também são medidos sob temperatura ambiente. Quando $T=300 \mathrm{~K}$, a relação é de aproximadamente 7

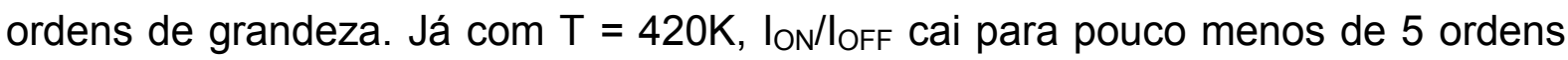
de grandeza.

Para explorar mais a fundo o comportamento deste dispositivo, foram plotados nas Figuras 4.13 e 4.14 os gráficos da corrente de dreno em função da tensão de dreno para diferentes condições de polarização de porta. Novamente, foi utilizada a faixa de temperatura experimental de 300 a $420 \mathrm{~K}$.

A diferença entre os dois gráficos é que enquanto a Figura 4.13 apresenta a corrente de dreno em escala logarítmica, a Figura 4.14 representa esta grandeza em escala linear.

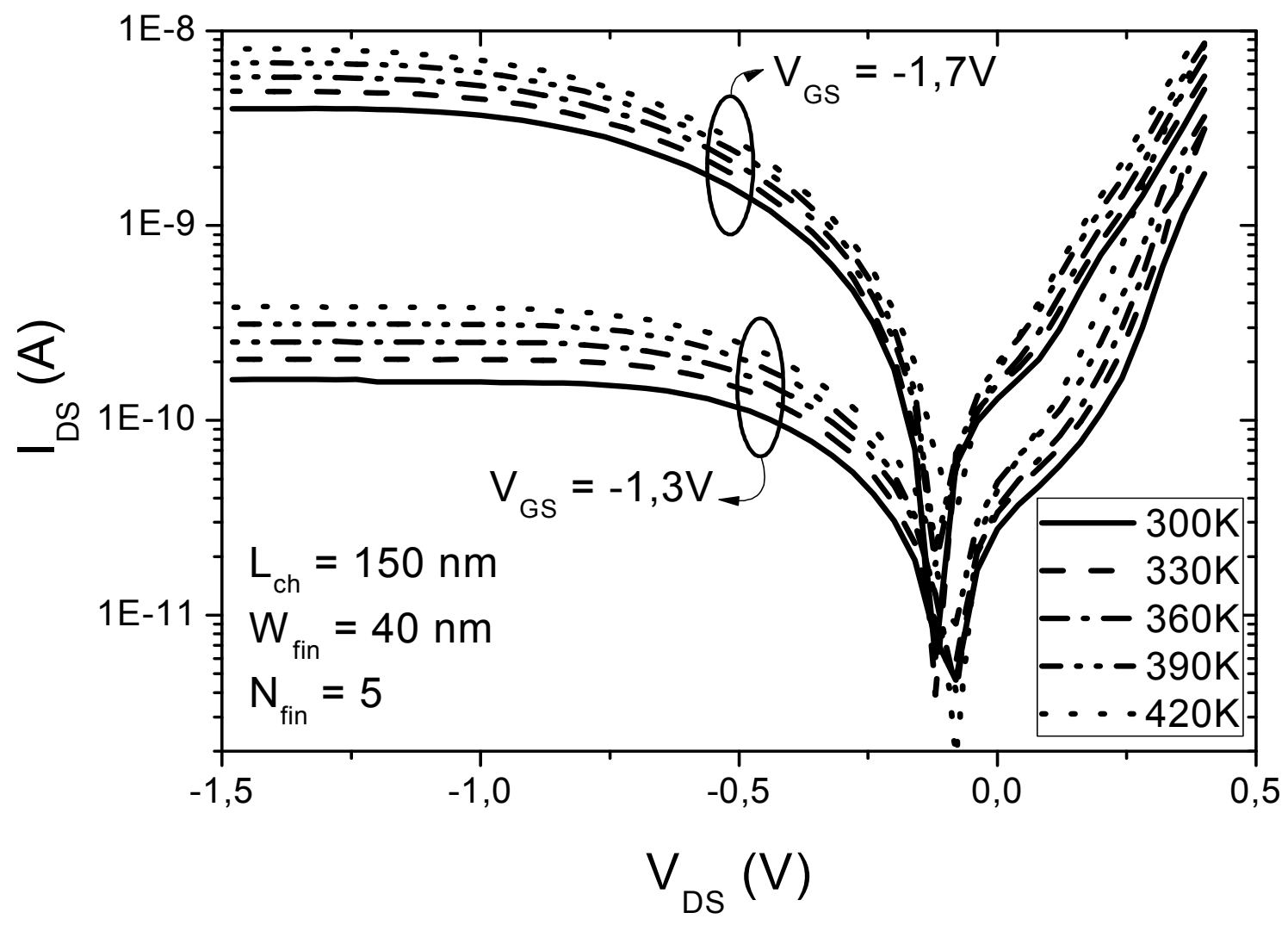

Figura 4.13 Corrente de dreno ( $\left.\mathrm{IDS}_{\mathrm{DS}}\right)$ em função da tensão de dreno $\left(\mathrm{V}_{\mathrm{DS}}\right)$ para $\mathrm{V}_{\mathrm{GS}}$ de $-1,3 \mathrm{~V} e$ $-1,7 \mathrm{~V}$, com $\mathrm{W}_{\text {fin }}$ de $40 \mathrm{~nm}$ e $\mathrm{N}_{\text {fin }}$ de 5 . 
Observa-se que para tensão de dreno positiva o dispositivo atua como um diodo convencional e para tensão de dreno negativa o transistor se comporta efetivamente como um pTFET.

Em ambas as situações, a corrente tende a aumentar na medida em que a temperatura também é incrementada. Para os valores de tensão de porta considerados, a corrente já é devida basicamente ao BBT, de maneira que a variação observada na corrente é relacionada ao já comentado estreitamente da faixa proibida.

A mais interessante observação referente ao comportamento como pTFET consiste no patamar observado em ambas as figuras das curvas $I_{D S} \times V_{D S}$. Afinal, esta característica indica uma baixa condutância de saída, o que sugere que este dispositivo seja uma boa opção também para aplicações analógicas.

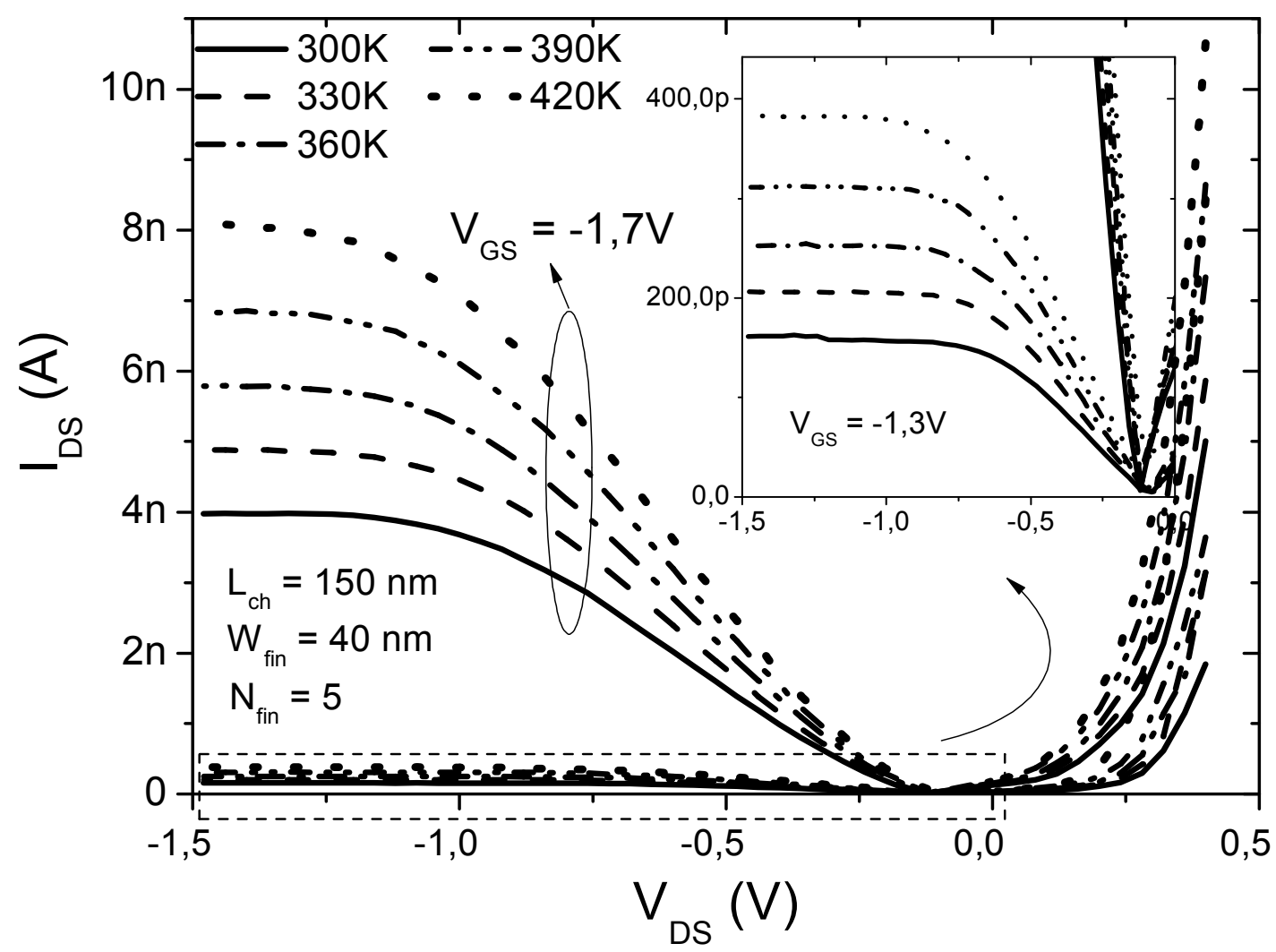

Figura 4.14 Corrente de dreno ( $\left.\mathrm{I}_{\mathrm{DS}}\right)$ em função da tensão de dreno $\left(\mathrm{V}_{\mathrm{DS}}\right)$ para $\mathrm{V}_{\mathrm{GS}}$ de $-1,3 \mathrm{~V}$ e $-1,7 \mathrm{~V}$, com $\mathrm{W}_{\text {fin }}$ de $40 \mathrm{~nm}$ e $\mathrm{N}_{\text {fin }}$ de 5 .

Nota-se uma vez mais que o aumento do módulo da tensão de porta contribui para o aumento da corrente, na medida em que fica mais estreita a faixa proibida na direção do tunelamento entre fonte e canal. 
Enquanto isso, para que seja atingida a condição de polarização que resulte no patamar da corrente de dreno, deve-se aplicar uma tensão de dreno também com módulo maior. Para temperatura ambiente, considerando o gráfico com escala de corrente linear, o patamar é atingido para $V_{D S}<-0,8 \mathrm{~V}$ com $V_{G S}=-1,3 \mathrm{~V}$ e para $V_{D S}<1,2 \mathrm{~V}$ para $\mathrm{V}_{G S}=-1,7 \mathrm{~V}$

Para finalizar esta análise, a Figura 4.15 exibe o comportamento da tensão de dreno em função da tensão de porta para demonstrar que as condições de polarização das Figuras 4.13 e 4.14, com tensão de porta de $-1,3 \mathrm{~V}$ e $-1,7 \mathrm{~V}$, correspondem efetivamente à região da curva com comportamento ditado pelo crescimento do tunelamento de banda para banda.

Nota-se que valores de tensão de dreno nessa faixa de $-0,9 \vee$ a $-0,5 \bigvee$ não interferem na inclinação de sublimiar para $\mathrm{V}_{\mathrm{GS}}$ de $-1,2 \mathrm{~V}$ a $-0,6 \mathrm{~V}$. Nesse conjunto de medidas, o valor de $S$ flutua de cerca de 130 até quase $200 \mathrm{mV} /$ década. Por causa desse valor, apesar de a relação loN/lofF ser relativamente alta (sete ordens de grandeza), a variação de tensão de porta de 1,5V necessária para varrer toda essa faixa de corrente é maior do que a aceitável na prática.

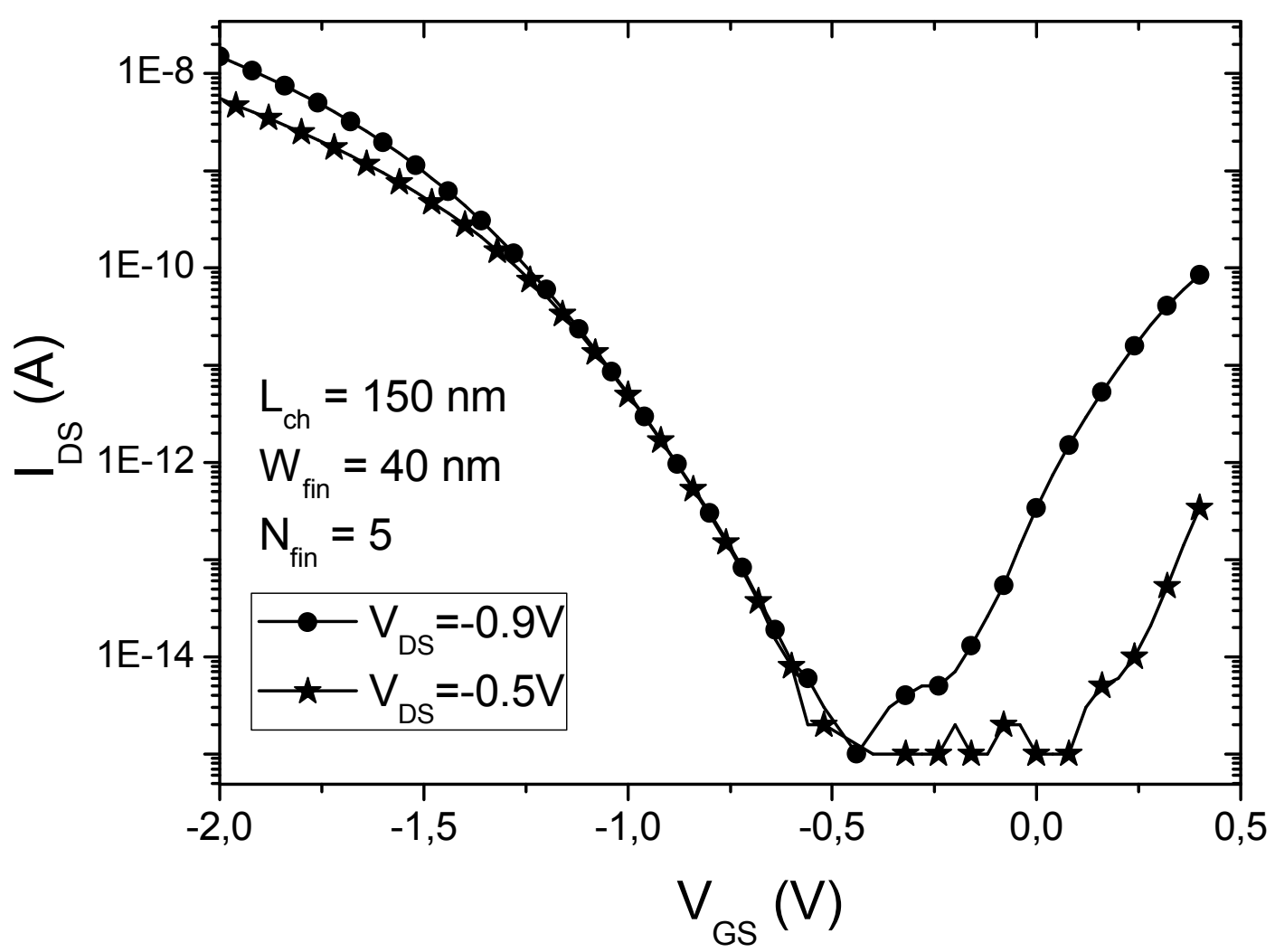

Figura 4.15 Corrente de dreno ( $\left.\mathrm{I}_{D S}\right)$ em função da tensão de porta $\left(V_{G S}\right)$ para $V_{D S}$ de $-0,9 V$ e $-0,5 \mathrm{~V}$, com $\mathrm{W}_{\text {fin }}$ de $40 \mathrm{~nm}$ e $\mathrm{N}_{\text {fin }}$ de 5 . 


\subsection{Comparação entre dispositivos de lâminas diferentes}

Finalmente, após extensa avaliação dos dispositivos da lâmina D23, considerada como padrão, será comparado o impacto experimental da configuração de sobreposição/subposição de porta. Com este intuito, foram comparadas as curvas referentes aos dispositivos análogos de cada uma das cinco lâminas e os dados foram compilados na Figura 4.16.

Desta forma, foram comparados os dados da corrente de dreno em função da tensão de porta e a avaliação destacou parâmetros como a magnitude da corrente ambipolar e a relação das correntes $\mathrm{I}_{\text {ON }} /_{\text {OFF. }}$. Vale lembrar que a comparação estrutural entre as cinco lâminas em questão foi detalhada na Figura 4.2 e na Tabela 4.3.

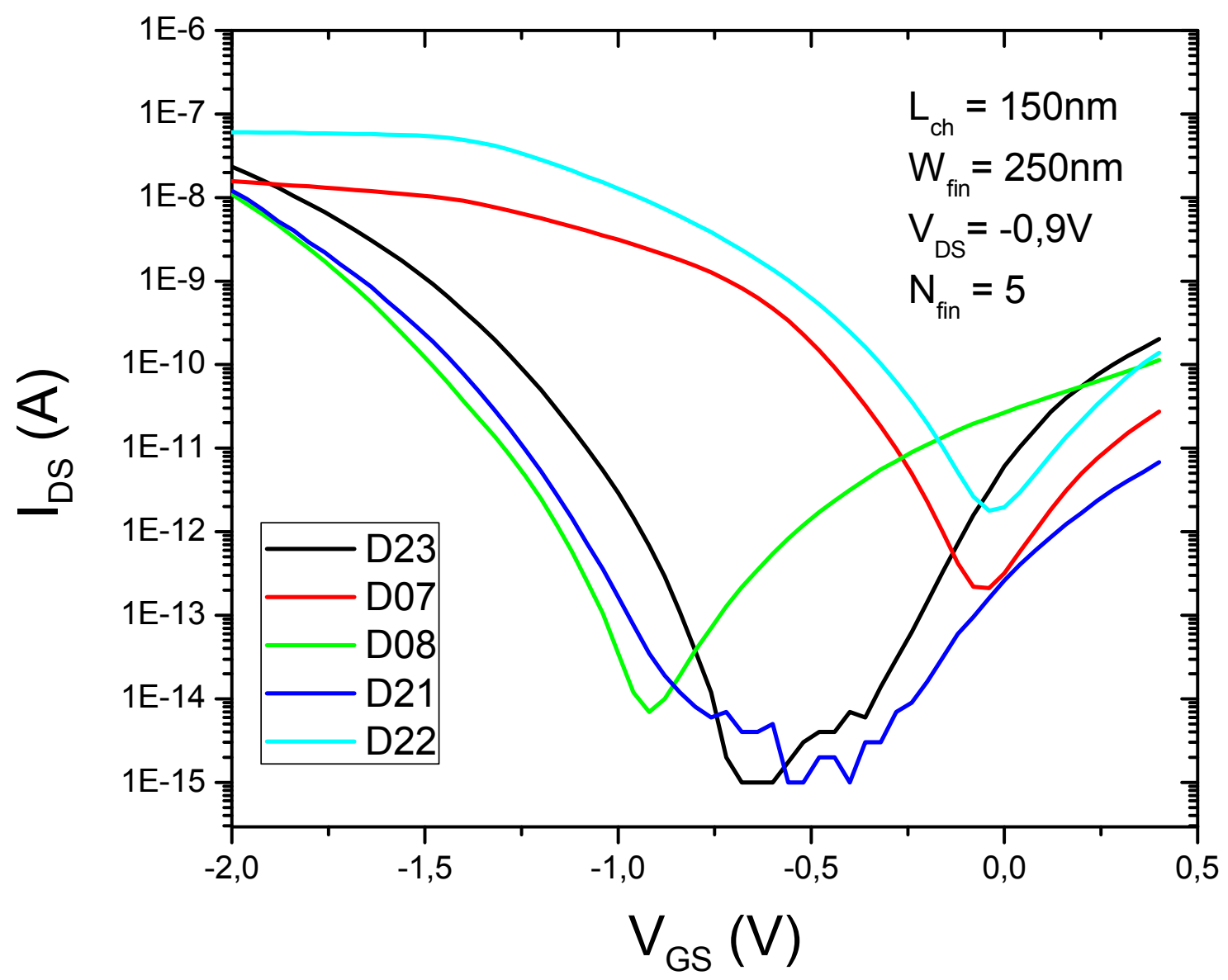

Figura 4.16 Corrente de dreno ( $\left.\mathrm{l}_{D S}\right)$ em função da tensão de porta $\left(\mathrm{V}_{\mathrm{GS}}\right)$ para $\mathrm{V}_{\mathrm{DS}}$ de $-0,9 \mathrm{~V}$ em dispositivos de 5 lâminas diferentes. 
Inicialmente, é localizada a curva referente a lâmina D23, com formato bastante semelhante ao das demais figuras analisadas neste capítulo. A mais importante comparação deve ser feita em relação à lâmina D21, para a qual há uma subposição de porta em relação à junção canal/dreno.

Nota-se claramente a assimetria da curva de D21 como uma conseqüência direta da assimetria imposta na sua estrutura de porta. A subposição gerou de fato uma menor corrente ambipolar cerca de 30 vezes menor do que a lâmina padrão para $\mathrm{V}_{\mathrm{GS}}$ de $+0,4 \mathrm{~V}$. A título de comparação, para $\mathrm{V}_{\mathrm{GS}}=-2,0 \mathrm{~V}$ a razão entre as correntes é de menos de 3 vezes, com inclinação de sublimiar bastante parecida em todo o trecho de tensão de porta inferior a $-0,8 \mathrm{~V}$.

Enquanto isso, é interessante verificar o forte efeito ambipolar no dispositivo da lâmina D08. Esta característica também é amplamente respaldada pela sua sequência de fabricação com espaçadores de apenas $15 \mathrm{~nm}$ antes da dopagem principal (o menor entre todas as lâminas), com sobreposição de porta em ambos os lados.

Em termos de razão $\mathrm{I}_{\mathrm{ON}} / \mathrm{I}_{\mathrm{OFF}}$, as lâminas D07 e D22 apresentam claramente os piores desempenhos, com razão de cinco ordens de grandeza contra até oito da lâmina padrão. Estas são justamente as lâminas que não garantiram sobreposição de porta em relação à junção de tunelamento principal (fonte/canal) nem por espaçadores pequenos, nem por aplicação da dopagem de extensão de porta. Desta forma, a inclinação de sublimiar relativamente alta também aparece como uma desvantagem desta técnica de fabricação de componentes visando aplicações digitais.

Em outras palavras, a comparação entre diferentes lâminas permitiu a visualização experimental do impacto da dimensão da porta e das características de dopagem em parâmetros como efeito ambipolar, inclinação de sublimiar e razão ION/lOFF. 


\section{CONCLUSÕES DO TRABALHO}

Este trabalho apresentou um estudo de transistores de tunelamento controlados por efeito de campo, com análises de simulações e de resultados experimentais que enfatizaram o impacto do dimensionamento e da temperatura no desempenho dos dispositivos.

Foram apresentados os princípios básicos de funcionamento desta tecnologia e as principais dificuldades encontradas na prática, com ênfase à intrínseca ambipolaridade da estrutura p-i-n e à baixa corrente loN. Neste trabalho, foram estudadas estruturas com atenuação destes efeitos indesejáveis através da especificação de dispositivos com porta dupla e com assimetria no alinhamento de porta em relação às junções do canal com a fonte e com o dreno. Diagramas de banda ilustraram como a estrutura proposta para um TFET, do tipo p-i-n com canal controlado por uma porta, poderia ter a corrente de tunelamento de banda para banda como predominante na medida em que eram aplicados maiores valores de tensão de porta.

O foco inicial voltou-se à determinação das metodologias mais adequadas para simular os efeitos dessa estrutura, de maneira a permitir uma avaliação preliminar da sua viabilidade e de possibilidades de otimização. Utilizando o simulador Atlas da Silvaco, foram determinados os modelos mais adequados para representar os fenômenos sob impacto de variação de temperatura e de comprimento de porta. Foi determinado que os modelos BBT.KANE, SRH e TRAP.TUNNEL apresentavam o equacionamento mais adequado para os fenômenos de tunelamento de banda para banda (BBT), de geração/recombinação $\mathrm{SRH}$ e de tunelamento induzido por armadilhas (TAT), respectivamente. Os valores numéricos padronizados do simulador foram adotados para as primeiras simulações de dispositivos nTFETs.

Variando as condições de sobreposição e subposição de porta em relação à junção canal/dreno nas simulações, foi possível minimizar significativamente a magnitude do efeito ambipolar. Além disso, com subposição a partir de $20 \mathrm{~nm}$, os 
transistores apresentaram inclinação de sublimiar de apenas $47 \mathrm{mV} /$ década, ao invés dos cerca de $78 \mathrm{mV} /$ década do caso de auto-alinhamento de porta.

Na sequência, foi avaliado como o desempenho era afetado por mudanças de temperatura de 150 a 400K. Dessa forma, foi possível constatar como cada região da curva de corrente de dreno em função da tensão de porta tinha uma dependência diferente em relação à temperatura. Conforme o mecanismo de transporte predominante, a susceptibilidade com a temperatura era maior (SRH e TAT) ou menor (BBT).

Ainda por simulação, foi possível avaliar separadamente o efeito de cada uma das principais componentes da corrente em função da estrutura e da temperatura. Concluiu-se que quando a subposição aumenta, a corrente ambipolar diminui, ficando menos dependente do BBT e mais sujeita ao impacto da temperatura.

No caso da estrutura simulada neste trabalho, para o caso otimizado de subposição de porta de $20 \mathrm{~nm}$, a corrente de tunelamento de banda para banda era predominante apenas para $\mathrm{V}_{\mathrm{GS}}>0$, visto que o efeito ambipolar havia sido suficientemente atenuado. Com subposição de $10 \mathrm{~nm}$, havia apenas uma estreita faixa de tensão de porta de cerca de $0,5 \mathrm{~V}$ para a qual as correntes de SRH e TAT predominavam sobre BBT. Finalmente, com auto-alinhamento de porta em relação à junção canal/dreno, o tunelamento de banda para banda era a componente mais importante para virtualmente toda a faixa de valores de $V_{G S}$.

Posteriormente, foi realizada a etapa prática do trabalho, com a caracterização elétrica de dispositivos fabricados pelo centro de pesquisas do IMEC em Leuven, na Bélgica. Cinco lâminas diferentes foram disponibilizadas, com variação mais significativa quanto aos procedimentos de dopagem, que levavam a diferenças na configuração de sobreposição ou subposição de porta. Nesta etapa foram destacados dispositivos do tipo pTFET com estrutura apenas de silício. A escolha de transistores do tipo $P$ foi justificada pela possibilidade de obtenção de um perfil de dopagem mais abrupto e a utilização de estruturas apenas de silício foi explicada pela melhor repetibilidade e confiabilidade na tomada de dados em virtude do estágio atual do processo de fabricação. 
Após a identificação experimental do funcionamento conforme previsto pelos capítulos anteriores do trabalho, as simulações foram calibradas e devidamente adaptadas para os pTFETs estudados. Com este ajuste de parâmetro, foi possível extrair informações numéricas mais fidedignas em relação à inclinação de sublimiar e à razão $\mathrm{I}_{\mathrm{ON}} / \mathrm{l}_{\mathrm{OFF}}$. Também foram realizadas medidas experimentais com variação de temperatura, evidenciando como a inclinação de sublimiar decresce fortemente com a diminuição da temperatura, uma vez que os efeitos do SRH e do TAT tornamse muito menos acentuados.

Quantitativamente, foram extraídos dados que indicavam uma queda de mais de $40 \%$ na inclinação de sublimiar mínima entre os casos de temperatura de $420 \mathrm{~K}$ e de $300 \mathrm{~K}$ para os dispositivos com a tecnologia TFET. Comparando-se com a tecnologia CMOS convencional, tal redução ficaria na casa de $29 \%$. Por outro lado, a escolha dos dispositivos de fonte, dreno e canal de silício ainda não permitiu a obtenção prática da almejada inclinação de sublimiar inferior a $60 \mathrm{mV} /$ década a temperatura ambiente, o que está em conformidade com outras referências levantadas sobre o assunto.

Quanto ao efeito ambipolar, a comparação entre diferentes lâminas mostrou como é mais adequado utilizar dispositivos com subposição de porta, porém com condições de polarização adequadas para não prejudicar a amplitude da corrente quando o dispositivo está acionado.

Com isso, conclui-se o trabalho de estudo dos transistores de tunelamento controlados por efeito de campo. De modo geral, as análises apresentadas justificam a continuidade dos estudos com os TFETs, considerados como uma alternativa promissora para as próximas gerações tecnológicas

Como sequência de trabalho, propõe-se a análise de lâminas mais recentes de TFETs com material de fonte de SiGe tanto em estruturas planares, foco deste trabalho, como em estrutura de nanofios. A verificação prática da baixa condutância de saída também pode ser explorada para avaliação da viabilidade destes dispositivos em aplicações analógicas. 


\section{PUBLICAÇÕES GERADAS}

M. D. V. Martino, P. G. D. Agopian, J. A. Martino, Cross-Section Features Influence on Surrounding MuGFETs, In: 23rd Symposium on Integrated Circuits and Systems Design - SBMicro 2010, São Paulo/SP, 2010.

M. D. V. Martino, P. G. D. Agopian, S. G. Santos Filho, J. A. Martino, Temperature Influence on Tunnel Field Effect Transistors (TFETs) with Low Ambipolar Currents, In: 24th Symposium on Integrated Circuits and Systems Design - SBMicro 2011, João Pessoa/PB, 2011.

M. D. V. Martino, P. G. D. Agopian, S. G. Santos Filho, J. A. Martino, Temperature Impact on Double Gate nTFET Ambipolar Behavior, In: VI Workshop on Semiconductors and Micro \& Nano Technology - ISDRS 2011, College Park/MD, EUA, 2011.

P. G. D. Agopian, M. D. V. Martino, S. G. Santos Filho, J. A. Martino, R. Rooyackers, D. Leonelli, C. Claeys, Temperature Impact on Tunnel FET OffState Current, submetido a Solid-State Electronics Special Issue - ISDRS 2011. 


\section{REFERÊNCIAS BIBLIOGRÁFICAS}

${ }^{1}$ CHANG, L.; CHOI, Y. K.; KEDZIERSKI, J.; LINDERT, N.; XUAN, P.; BOKOR, J.; HU, C.; KING, T. J. K.; Moores's law lives on [CMOS transistor], Circuits and Devices Magazine, IEEE, v. 19, n. 1, 2003.

${ }^{2}$ MOORE, G. E.; Cramming more components onto integrated circuits, Electronics Magazine, n. 4, 1965.

${ }^{3}$ ANDO, V. F.; Genetic algorithm for preliminary design of high-performance axial-flow compressors, Dissertação de Mestrado, Instituto Tecnológico de Aeronáutica, 2011.

${ }^{4}$ HISAMOTO, D.; KAGA, T.; TAKEDA, E.; Impact of the vertical SOI DELTA structure on planar device technology, IEEE Transaction on Electron Devices, v. 38, n.1, p.1419, 1991.

${ }^{5}$ HISAMOTO, D.; et al.; A folded-channel MOSFET for deep-sub-tenth micron era, Technical Digest International Electron Devices Meeting, IEDM., p. 1032, 1998.

${ }^{6}$ CLAEYS, C.; LEONELLI, D.; ROOYACKERS, R.; VANDOOREN, A.; VERHULST, A.; HEYNS, M.; GROESENEKEN, G.; DE GENDT, S.; Fabrication and characterization of $\mathrm{Si}$ and hetero-junction tunnel field effect transistors, G-COE PICE International Symposium, Tóquio, 2009.

${ }^{7}$ NILSSON, P.; Arithmetic reduction of the static power consumption in nanoscale CMOS, IEEE International Conference on Electronics, Circuits and Systems, p. 656-659, 2006.

${ }^{8}$ PACKAN, P.; Short Course, IEDM, 2007.

${ }^{9}$ COX, D.; Trends and challenges in device scaling and circuit design, IRPS Tutorials, 2004.

${ }^{10}$ CHEN, H. H.; LIN, J. T.; LU, K. Y.; ENG, Y. C.; LIN, P. H.; A new type of CMOS inverter with Lubistor load and TFET driver for sub-20 nm technology generation, Solid-State and Integrated Circuit Technology, ICSICT, p. 93, 2010.

${ }^{11}$ SEABAUGH, A.; ZHANG, Q.; Low-voltage tunnel transistors for beyond CMOS logic, Proceedings of the IEEE, v. 28, n. 12, p. 2095-2110, 2010.

12 LEONELLI, D.; VANDOOREN, A.; ROOYACKERS, R.; VERHULST, A. S.; GENDT, S.; HEYNS,M. M.; GROESENEKEN, G.; Performance enhancement in multi gate tunneling field effect transistors by scaling the fin-width, Japanese Journal of Applied Physics, 04DC10, 2010.

${ }^{13}$ GUO, P. F.; YANG, L. T.; YANG, Y.; FAN, L.; HAN, G. Q.; SAMUDRA, G. S.; YEO, Y. C.; Tunneling field-effect transistor: Effect of strain and temperature on tunneling current, IEEE Electron Device Letters, v. 30, p. 981, 2009.

${ }^{14}$ KRISHNAMOHAN, T.; KIM, D.; RAGHUNATHAN, S.; SARASWAT, K.; Double-gate strained-Ge heterostructure tunneling FET (TFET) with record high drive currents and $<60 \mathrm{mV} / \mathrm{dec}$ subthreshold slope, IEDM Technical Digest, p. 947, 2008.

15 COLINGE, J. P.; Silicon-on-insulator technology: Materials to VLSI, Kluwer Academics Publishers, 2003.

${ }^{16}$ ANGHEL, C.; VLADIMIRESCU, A.; AMARA, A.; Design of silicon double gate tunnel FETs with ultra low ambipolar currents, EUROSOI 2011 Conference Proceedings, v. 1, p. 73-74, 2011. 
${ }^{17}$ WANG., P.-F.; HILSENBECK, K.; NIRSCHL, T.; OSWALD, M.; STEPPER, C.; WEISS, M.; SCHMITT-LANDSIEDEL, D.; HANSCH, W.; Complementary tunneling transistor for low power application, Solid-State Electronics, v. 48, n. 12, p. 2281, 2004.

${ }^{18}$ LEONELLI, D.; VANDOOREN, A.; ROOYACKERS, R.; VERHULST, A. S.; GENDT, S.; HEYNS, M. M.; GROESENEKEN, G.; Drive current improvement in Si tunnel field effect transistors by means of silicide engineering, Proceedings of the International Conference on SSDM, p. 693-694, 2010.

${ }^{19}$ SCHENK, A.; Rigorous theory and simplified model of the band-to-band tunneling in silicon, SolidState Electronics, v. 36, p. 19-34, 1993.

${ }^{20}$ ANGHEL, C.; CHILAGANI, P.; AMARA, A.; VLADIMIRESCU, A.; Tunnel field effect transistor with increased ON current, low-k spacer and high-k dielectric, Applied Physics Letters, v. 96, 122104, 2010.

${ }^{21}$ WAN, J.; LE ROYER, C.; ZASLAVSKY, A.; CRISTOLOVEANU, S.; Tunneling FETs on SOI: Supressing of ambipolar leakage, low-frequency noise behavior and modeling, Solid-State Electronics, v. 65-66, p. 226, 2011.

22 BOUCART, K.; Simulation of double-gate silicon tunnel FETs with a high-k gate dielectric, Dissertação de Doutorado, École Polytechnique Fédérale de Lausanne, 2010.

23 LEONELLI, D.; VANDOOREN, A.; ROOYACKERS, R.; GENDT, S.; HEYNS, M. M.; GROESENEKEN, G.; Drive current enhancement in p-tunnel FETs by optimization of the process conditions, Solid-State Electronics, v. 65-66, p. 28, 2011.

${ }^{24}$ PATEL, N.; RAMESHA, A.; MAHAPATRA, S.; Drive current boosting of $n$-type tunnel FET with strained SiGe layer at source, Microelectronics Journal, v. 39, n. 12, p. 1671-1677, 2008.

${ }^{25}$ CLAEYS, C.; LEONELLI, D.; ROOYACKERS, R.; VANDOOREN, A.; VERHULST, A. S.; HEYNS, M. M.; GROESENEKEN, G.; DE GEND, S.; Trends and challenges in $\mathrm{Si}$ and hetero-junction tunnel field effect transistors, ECS Transactions, v. 35, n. 5, p. 15-26, 2011.

${ }^{26}$ VERHULST, A. S.; VANDENBERGHE, W. G.; MAEX, K.; GROESENEKEN, G.; Boosting the oncurrent of a n-channel nanowire tunnel field-effect transistor by source material optimization, Journal of Applied Physics, v. 104, n. 6, 4514, 2008.

${ }^{27}$ VeRHULST, A. S.; VANDENBERGHE, W. G.; MAEX, K.; DE GENDT, S.; HEYNS, M.; GROESENEKEN, G.; Complementary silicon-based heterostructure tunnel-FETs with high tunnel rates, Electron Device Letters, v. 29, n. 12, p. 1398, 2008.

${ }^{28}$ QUINN, J.; KAWAMOTO, G.; McCOMBE, B.; Subband spectroscopy by surface channel tunneling, Surface Science, v. 73, p. 190-196, 1978.

${ }^{29}$ KOGA, J.; TORIUMI, A.; Negative differential conductance in three-terminal silicon tunneling device, Applied Physics Letters, v. 69, n. 10, p. 1435-1437, 1996.

${ }^{30}$ AYDIN, C.; ZASLAVSKY, A.; LURYI, S.; CRISTOLOVEANU, S.; MARIOLLE, D.; FRABOULET, D.; DELEONIBUS, S.; Lateral interband tunneling transistor in silicon-on-insulator, Applied Physics Letters, v. 84, n. 10, p. 1780-1782, 2004.

${ }^{31}$ TAKEDA, E.; MATSUOKA, H.; IGURA, Y.; ASAI, S.; A band to band tunneling MOS device $\left(\mathrm{B}^{2} \mathrm{~T}\right.$ MOSFET), IEDM Technical Digest, p. 402-405, 1988. 
32 BABA, T.; Proposal for surface tunnel transistors, Japanese Journal of Applied Physics, v. 31, p. L455-L457, 1992.

${ }^{33}$ APPENZELLER, J.; LIN, Y.; KNOCH, J.; AVOURIS, P.; Band-to-band tunneling in carbon nanotube field-effect transistors, Physical Review Letters, v. 93, n. 19, p. 196805-1-4, 2004.

${ }^{34}$ BHUWALKA, K.; SCHULZE, J.; EISELE, I.; Performance enhancement of vertical tunnel field-effect transistor with SiGe in the p+ layer, Japanese Journal of Applied Physics, v. 43, n. 7A, p. 40734078, 2004.

${ }^{35}$ BHUWALKA, K.; BORN, M.; SCHINDLER, M.; SCHMIDT, M.; SULIMA, T.; EISELE, I.; P-channel tunnel field-effect transistors down to sub-50 $\mathrm{nm}$ channel lengths, Japanese Journal of Applied Physics, v. 45, n. 4B, p. 3106-3109, 2006.

${ }^{36}$ VERHULST, A. S.; VANDENBERGHE, W.; MAEX, K.; GROESENEKEN, G.; Tunnel field-effect transistor without gate-drain overlap, Applied Physics Letters, v. 91, p. 053102-1-3, 2007.

${ }^{37}$ FULDE, M.; HEIGL, A.; WEIS, M.; WIRNSHOFER, M.; ARNIM, K.; NIRSCHL, T.; STERKEL, M.; KNOBLINGER, G.; HANSCH, W.; WACHUTKA, G.; SCHMITT-LANDSIEDEL, D.; Fabrication, optimization and application of complementary multiple-gate tunneling FETs, Proccedings INEC, $p$. 579-584, 2008.

${ }^{38}$ KAM, H.; KING-LIU, T.; ALON, E.; HOROWITZ, M.; Circuit-level requirements for MOSFET replacement devices, IEDM Technical Digest, 2008.

${ }^{39}$ Atlas Device Simulation, User's Manual, version 5.16.3.R, Silvaco International, 2011.

40 HURKX, G. A. M.; GRAAF, H. C.; KLOSTERMAN, W. J. et. al.; A novel compact model description of reverse biase diode characteristics including tunneling, ESSDERC Proceedings, p. 49-52, 1990.

41 HURKX, G. A. M.; KLAASSEN, D. B. M.; KNUVERS, M. P. G.; A new recombination model for device simulation including tunneling, IEEE Trans. Electron Devices, v. 39, p. 331-338, 1992.

42 KLAASSEN, D. B. M.; Physical modeling bipolar device simulation, Simulation of Semiconductor Devices and Processes, v. 4, p. 23-43, 1991.

43 KANE, E. O.; Zener tunneling in semiconductors, Journal Phys. Chem. Solids, v. 12, p. 181-188, 1959.

44 HURKX, G. A. M.; KLAASSEN, D. B. M.; KNUVERS, M. P. G.; O'HARA, F. G.; A new recombination model describing heavy-doping effects and low temperature behaviour, IEDM Technical Digest, p. 307-310, 1989.

${ }^{45}$ SELBERHERR, S.; Analysis and simulation of semiconductor devices, Springer-Verlag, 1984.

${ }^{46}$ YU, Z.; DUTTON, R. W.; SEDAN III-A generalized electronic material device analysis program, Stanford Electronics Laboratory Technical Report, Stanford University, 1985.

${ }^{47}$ KLAASSEN, D. B. M.; SLOTBOOM, J. W.; DE GRAAFF, H. C.; Unified apparent bandgap narrowing in n- and p-type silicon", Solid-State Electronics, v. 35, n. 2, p. 125-129, 1992.

${ }^{48}$ JAEGER, R. C.; GAENSSLER, F. H.; Simulation of impurity freezeout through numerical solution of Poisson's equations and applications to MOS device behavior, IEEE Transaction on Electron Devices, v. 27, p. 914-920, 1980. 
${ }^{49}$ VERHULST, A. S.; VANDENBERGHE, W. G.; MAEX, K.; GROESENEKEN, G.; Tunnel field-effect transistor without gate-drain overlap, Applied Physics Letters, v. 91, 053102, 2007.

50 SCHULZE, A.; HANTSCHEL, T.; EYBEN, P.; VERHULST, A. S.; ROOYACKERS, R.; VANDOOREN, A.; MODY, J.; NAZIR, A.; LEONELLI, D.; VANDERVORST, W.; Observation of diameter dependent carrier distribution in nanowire-based transistors, Nanotechnology, v. 22, n. 18, 185701, 2011.

${ }^{51}$ MAYER, F.; ROYER, C. L.; DAMLENCOURT, J.-F.; ROMANJEK, K.; ANDRIEU, F.; TABONE, C.; PREVITALI, B.; DELEONIBUS, S.; Impact of SOI, Si1-xGexOI and GeOI substrates on CMOS compatible tunnel FET performance, Proceedings of International Electron Devices Meeting, $p$. 163, 2008. 


\section{ANEXO 1: ARQUIVO DE SIMULAÇÃO DE UM NTFET}

Arquivo de simulação de um dispositivo nTFET para caracterização $I_{D S} X$ $\mathrm{V}_{\mathrm{GS}}$, com $\mathrm{V}_{\mathrm{GS}}$ variando de $-1 \mathrm{~V}$ a $2,5 \mathrm{~V}, \mathrm{~V}_{\mathrm{DS}}$ de $0,4 \mathrm{~V}$ e $\Delta \mathrm{L}_{\mathrm{G}}$ de $-20 \mathrm{~nm}$.

\# Arquivo Tunnel FETs

\# Caracterizacao IDS X VGS

go atlas

\#

$\#^{* * * * * * * * * * *}$ Definicao da grade

\#

mesh space . mult $=1.0$

$x$. mesh loc $=-0.1425$ spac $=0.01$

x.mesh loc $=-0.1325$ spac $=0.005$

$x$. mesh loc $=-0.0925$ spac $=0.0005$

x.mesh loc $=-0.0825$ spac $=0.001$

x.mesh loc $=-0.07$ spac $=0.001$

x.mesh loc $=0 \quad$ spac $=0.002$

$\mathrm{x}$. mesh loc $=0.07$ spac $=0.001$

$\mathrm{x}$. mesh loc $=0.0825$ spac $=0.001$

x.mesh loc $=0.0925$ spac $=0.0005$

$\mathrm{x}$. mesh loc $=0.1325$ spac $=0.005$

$\mathrm{x} \cdot \mathrm{mesh} \mathrm{loc}=0.1425 \mathrm{spac}=0.01$

y.mesh loc $=-0.0165$ spac $=0.0005$

y.mesh loc $=-0.0145$ spac $=0.0005$ 
y. mesh loc $=-0.0125 \quad \mathrm{spac}=0.0005$

y. mesh loc $=-0.01 \quad$ spac $=0.001$

y.mesh loc $=0 \quad$ spac $=0.001$

y.mesh loc $=0.01 \quad$ spac $=0.001$

y.mesh loc $=0.0125 \quad$ spac $=0.0005$

y.mesh loc $=0.0145 \mathrm{spac}=0.0005$

y.mesh loc $=0.0165$ spac $=0.0005$

\#

\# Regioes da estrutura

\#

region num=1 y.min=-0.0165 y.max $=-0.0125$ oxide

\# x.min=-0.0925 x.max $=0.0925$

region $n u m=2 x \cdot \min =-0.1325 x \cdot \max =0.1325$ y.min $=-0.0125$ y.max $=0.0125$ silicon region num $=3$ y.min $=0.0125$ y.max $=0.0165$ oxide

\# x.min=-0.0925 x.max $=0.0925$

\#

$\#^{\star \star * \star * \star * \star * \star *}$ Definicao dos eletrodos

\#

\#1-GATE \#2-SOURCE \#3-DRAIN \#4-SUBSTRATE(below oxide)

\#

electrode name $=$ gate $x \cdot \min =-0.0925 x \cdot \max =0.0625 y \cdot \min =-0.0165 \mathrm{y} \cdot \max =-$ 0.0145

electrode name $=$ source $x \cdot \min =-0.1425 x \cdot \max =-0.1325 \mathrm{y} \cdot \min =-0.0125$

y. $\max =0.0125$

electrode name $=$ drain $x \cdot \min =0.1325 x \cdot \max =0.1425 \mathrm{y} \cdot \min =-0.0125$

y. $\max =0.0125$

electrode name $=$ gate $2 \times \cdot \min =-0.0925 x \cdot \max =0.0625 \mathrm{y} \cdot \min =0.0145$

y. $\max =0.0165$ 


\section{$\#$}

$\#^{* * * * * * * * * * *}$ Definicao das concentracoes de dopagens ${ }^{* * * * *}$

\#

\#canal

doping uniform conc $=5 \mathrm{e} 15$ p.type region $=2 \mathrm{x} \cdot \min =-0.0825 \mathrm{x} \cdot \max =0.0825$

$y \cdot \min =-0.0425$ y.max $=0.0425$

\# fonte e dreno

doping gauss $p . t y p e$ conc $=1 \mathrm{e} 20$ char $=0.2$ lat.char $=0.00304$ region $=2$ x.min=$0.1325 x \cdot \max =-0.0825 y \cdot \min =-0.0125 y \cdot \max =0.0125$

doping gauss n.type conc $=1 \mathrm{e} 20$ char $=0.2$ lat.char $=0.00304$ region $=2$

$x \cdot \min =0.0825 x \cdot \max =0.1325 y \cdot \min =-0.0125$ y.max $=0.0125$

structure outf=tsi25_doped.str

\# Definicao das cargas nas duas interfaces do oxido

interf $q f=5 e 10$ y.min $=-0.0125$ y. $\max =-0.0025$

interf $\quad \mathrm{qf}=1 \mathrm{e} 11 \mathrm{y} \cdot \mathrm{min}=0.0025 \mathrm{y} \cdot \max =0.0125$

\# Funcao trabalho da porta

contact name $=$ gate n.poly workfunc $=4.7$

contact name $=$ gate 2 n.poly common $=$ gate workfunc $=4.7$

\# Definicao de modelos

models kla shi bgn klaaug fldmob fermi drift.diff print temp=300 bbt.kane srh trap.tunnel

solve init

\#

\# caracterizacao IDSxVGS

\# 
method newton autonr trap maxtrap $=10$

solve prev

solve vdrain $=0.05$

solve vdrain $=0.1$

solve vdrain $=0.4$

\#solve vdrain=0.6

\#

\# ramp gate voltage

\#

log outf=nTFET_vd400m_20nm.log

solve $\quad$ gate $=-1$ vstep $=0.01$ name $=$ gate vfinal $=2.5$

structure outf=nTFET_vd400m_20nm.str

quit 


\section{ANEXO 2: ARQUIVO DE SIMULAÇÃO DE UM PTFET}

Arquivo de simulação de um dispositivo pTFET para caracterização $I_{D S} X$ $\mathrm{V}_{\mathrm{GS}}$, com $\mathrm{V}_{\mathrm{GS}}$ variando de $-2,5 \mathrm{~V}$ a $1 \mathrm{~V}, \mathrm{~V}_{\mathrm{DS}}$ de $-0,4 \mathrm{~V}$ e $\Delta \mathrm{L}_{\mathrm{G}}$ de $-20 \mathrm{~nm}$.

\# Arquivo Tunnel FETs

\# Caracterizacao IDS X VGS

go atlas

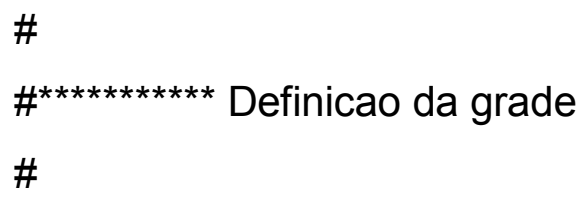

mesh space. mult=1.0

x.mesh loc $=-0.1425$ spac $=0.01$

x.mesh loc $=-0.1325$ spac $=0.005$

$\mathrm{x}$. mesh loc $=-0.0925 \mathrm{spac}=0.0005$

x.mesh loc $=-0.0825$ spac $=0.001$

x.mesh loc $=-0.07$ spac $=0.001$

$\mathrm{x} . \mathrm{mesh}$ loc $=0 \quad \mathrm{spac}=0.002$

$\mathrm{x}$. mesh loc $=0.07 \mathrm{spac}=0.001$

x.mesh loc $=0.0825$ spac $=0.001$

X.mesh loc $=0.0925$ spac $=0.0005$

$\mathrm{x}$. mesh loc $=0.1325$ spac $=0.005$

$\mathrm{x} \cdot \mathrm{mesh} \mathrm{loc}=0.1425 \mathrm{spac}=0.01$ 
y.mesh loc $=-0.0165$ spac $=0.0005$

y. mesh loc $=-0.0145$ spac $=0.0005$

y.mesh loc $=-0.0125$ spac $=0.0005$

y. mesh loc $=-0.01 \quad$ spac $=0.001$

y.mesh loc $=0 \quad$ spac $=0.001$

y.mesh loc $=0.01 \quad$ spac $=0.001$

y.mesh loc $=0.0125$ spac $=0.0005$

y.mesh loc $=0.0145$ spac $=0.0005$

y.mesh loc $=0.0165$ spac $=0.0005$

\#

\# Regioes da estrutura

\#

region num=1 y.min=-0.0165 y.max $=-0.0125$ oxide

\# x.min=-0.0925 x.max $=0.0925$

region num $=2 x \cdot \min =-0.1325 x \cdot \max =0.1325 \mathrm{y} \cdot \min =-0.0125 \mathrm{y} \cdot \max =0.0125$ silicon region num $=3$ y.min $=0.0125$ y.max $=0.0165$ oxide

$\# x \cdot \min =-0.0925 x \cdot \max =0.0925$

\#

$\#^{* * * * * * * * * * *}$ Definicao dos eletrodos

\#

\#1-GATE \#2-SOURCE \#3-DRAIN \#4-SUBSTRATE(below oxide)

\#

electrode name $=$ gate $x \cdot \min =-0.0925 x \cdot \max =0.0625 \mathrm{y} \cdot \min =-0.0165 \mathrm{y} \cdot \max =-$ 0.0145

electrode name $=$ source $x \cdot \min =-0.1425 x \cdot \max =-0.1325$ y.min $=-0.0125$ y. $\max =0.0125$

electrode name $=$ drain $x \cdot \min =0.1325 \quad x \cdot \max =0.1425 \quad y \cdot \min =-0.0125$ y. $\max =0.0125$

electrode name $=$ gate $2 x \cdot \min =-0.0925 x \cdot \max =0.0625 y \cdot \min =0.0145$ y. $\max =0.0165$ 
\#

$\#^{* * * * * * * * * * *}$ Definicao das concentracoes de dopagens ${ }^{* * * * *}$

\#

\#canal

doping uniform conc $=5 \mathrm{e} 15$ p.type region $=2 \mathrm{x} \cdot \min =-0.0825 \mathrm{x} \cdot \max =0.0825$

$y \cdot \min =-0.0425$ y.max $=0.0425$

\# fonte e dreno

doping gauss n.type conc=1e20 char=0.2 lat.char=0.00304 region=2 $x . \mathrm{min}=-$ $0.1325 x \cdot \max =-0.0825$ y. $\min =-0.0125 y \cdot \max =0.0125$

doping gauss p.type conc $=1 \mathrm{e} 20$ char $=0.2$ lat.char $=0.00304$ region $=2$

$x \cdot \min =0.0825 x \cdot \max =0.1325 y \cdot \min =-0.0125 y \cdot \max =0.0125$

structure outf=tsi25_doped.str

\# Definicao das cargas nas duas interfaces do oxido

interf $\quad \mathrm{qf}=5 \mathrm{e} 10 \mathrm{y} \cdot \min =-0.0125 \mathrm{y} \cdot \max =-0.0025$

interf $\quad \mathrm{qf}=1 \mathrm{e} 11 \mathrm{y} \cdot \min =0.0025 \mathrm{y} \cdot \max =0.0125$

\# Funcao trabalho da porta

contact name $=$ gate n.poly workfunc $=4.7$

contact name=gate 2 n.poly common $=$ gate workfunc $=4.7$

\# Definicao de modelos

models kla shi bgn klaaug fldmob fermi drift.diff print temp $=300$ bbt.kane srh trap.tunnel

solve init

\#

\# caracterizacao IDSxVGS

\# 
method newton autonr trap maxtrap $=10$

solve prev

solve vdrain $=-0.05$

solve vdrain $=-0.1$

solve vdrain $=-0.4$

\#solve vdrain=-0.6

\#

\# ramp gate voltage

\#

log outf=pTFET_vd400m_20nm.log

solve vgate $=+1$ vstep $=-0.01$ name $=$ gate vinal $=-2.5$

structure outf=pTFET_vd400m_20nm.str

quit 